\title{
DISPLACEMENT-BASED SEISMIC DESIGN OF REINFORCED CONCRETE SHEAR WALL BUILDINGS
}

By

\author{
AMR AHMED SALAH ELDIN ELRODESLY \\ B. Eng.(Civil Engineering) \\ Ain Shams University, Cairo, Egypt , 2003 \\ A thesis submitted to \\ The Faculty of Graduate Studies and Research \\ in partial fulfillment of the requirements \\ for the degree of \\ Master of Applied Science \\ in \\ Engineering*
}

\section{Department of Civil and Environmental Engineering Carleton University, Ottawa, Canada \\ November, 2007}

*The Master of Applied Science in Civil Engineering is a joint program with the University of Ottawa, administrated by Ottawa-Carleton Institute for Civil Engineering 


$\begin{array}{ll}\begin{array}{l}\text { Library and } \\ \text { Archives Canada }\end{array} & \begin{array}{l}\text { Bibliothèque et } \\ \text { Archives Canada }\end{array} \\ \begin{array}{l}\text { Published Heritage } \\ \text { Branch }\end{array} & \begin{array}{l}\text { Direction du } \\ \text { Patrimoine de l'édition }\end{array} \\ \begin{array}{l}\text { 395 Wellington Street } \\ \text { Ottawa ON K1A 0N4 }\end{array} & \begin{array}{l}\text { 395, rue Wellington } \\ \text { Ottawa ON K1A ON4 }\end{array} \\ \text { Canada } & \begin{array}{l}\text { Canada } \\ \end{array}\end{array}$

Yourfile Votre référence

ISBN: 978-0-494-36823-7

Our file Notre référence

ISBN: 978-0-494-36823-7

NOTICE:

The author has granted a nonexclusive license allowing Library and Archives Canada to reproduce, publish, archive, preserve, conserve, communicate to the public by telecommunication or on the Internet, loan, distribute and sell theses worldwide, for commercial or noncommercial purposes, in microform, paper, electronic and/or any other formats.

The author retains copyright ownership and moral rights in this thesis. Neither the thesis nor substantial extracts from it may be printed or otherwise reproduced without the author's permission.
AVIS:

L'auteur a accordé une licence non exclusive permettant à la Bibliothèque et Archives Canada de reproduire, publier, archiver, sauvegarder, conserver, transmettre au public par télécommunication ou par l'Internet, prêter, distribuer et vendre des thèses partout dans le monde, à des fins commerciales ou autres, sur support microforme, papier, électronique et/ou autres formats.

L'auteur conserve la propriété du droit d'auteur et des droits moraux qui protège cette thèse. $\mathrm{Ni}$ la thèse ni des extraits substantiels de celle-ci ne doivent être imprimés ou autrement reproduits sans son autorisation.
In compliance with the Canadian

Privacy Act some supporting forms may have been removed from this thesis.

While these forms may be included in the document page count, their removal does not represent any loss of content from the thesis.
Conformément à la loi canadienne sur la protection de la vie privée, quelques formulaires secondaires ont été enlevés de cette thèse.

Bien que ces formulaires aient inclus dans la pagination, il n'y aura aucun contenu manquant.

\section{Canadä}




\begin{abstract}
A displacement-based design method for the seismic design of symmetric and unsymmetric but torsionally stiff buildings with reinforced concrete shear walls is presented. For the preliminary design of such buildings approximate estimates of the yield displacements of individual walls are required; they are calculated from simple empirical relations that depend only on the geometry of the walls. The relative strengths of the walls are then selected, and based on these the global yield displacement is obtained. The ultimate displacement is determined so as to ensure stability under P-Delta effects, keep the ductility demand within ductility capacity, and limit the maximum storey drift to that specified by the codes in order to achieve the near collapse performance level under specified seismic hazard represented by a uniform hazard spectrum. For a multi storey building the structure is converted to an equivalent singledegree-of-freedom system using an assumed deformation shape to represent the first mode shape. The required base shear strength and the corresponding base moment of the system are determined from the inelastic demand spectrum corresponding to the ductility demand, or the ratio of ultimate to yield displacement. In subsequent iterations a pushover analysis for the force distribution based on the first mode is used to obtain better estimates of the yield and ultimate displacements. When the process has converged, a multi-mode pushover analysis is carried out to find more accurate estimates of the shear demands. For a torsionally stiff unsymmetric building the multi-mode pushover analysis is carried out using only the lateral displacement dominant mode shapes. The contribution of the rotational or torsion dominant mode shapes to the
\end{abstract}


different response parameters is negligible. The evaluation of the two design methods is performed using rigorous nonlinear response history analyses for 20 ground motion records scaled to match the seismic demand represented by the UHS of the city of Vancouver. The results of the nonlinear response history analysis show that: (1) the near collapse performance level is achieved for the symmetric buildings and for each edge of the unsymmetric buildings, (2) the roof displacements that the symmetric building and each edge of the unsymmetric building have been designed to experience are not exceeded except for very few records, (3) the square root of the sum of squares (SRSS) rule for combining the modal contributions somewhat underestimates the base shear, while the absolute sum (ABSSUM) combination rule provides a conservative estimate of the base shear. Thus the design methods developed in this work provide a safe and conservative design for the two types of buildings. 


\section{Acknowledgments}

I feel deeply indebted to my supervisor, Professor Dr. Jagmohan Humar, for his patience, guidance, constant supervision, creative advising and availability throughout the progress of this work. He has been, for me, not only a source of inspiration and encouragement but also a model of ideal academic relationship between a professor and his students. What I have learned during the progress of this thesis I owe, in fact, to him. Working under the supervision of a distinguished professor and an investigator of the highest international academic and human caliber like Professor Humar has been for me and will continue to be an unforgettable and a unique experience of my life.

I would like to express my great appreciation and gratitude to Professor A. O. Halim, Chairperson of the Department of Civil Engineering, Carleton University as well as to all the Professors of the Department for offering all the facilities and the academic environment that made this work possible.

I would like to express my deepest appreciation to my parents and my brother for the moral support, encouragement, patience and unconditional love they offered me during the progress of this work. 


\section{Table of Contents}

Abstract $\quad$ ii

Acknowledgements iv

Table of Contents $\quad v$

List of Tables $\quad$ x

List of Figures $\quad$ xii

List of symbols $\quad$ xvi

Acronyms and Abbreviations $\quad$ xviii

\section{Introduction}

1.1 Background 1

1.2 Performance based seismic design 4

$\begin{array}{lll}\text { 1.3 Symmetric and unsymmetric buildings } & 6\end{array}$

1.4 Modal pushover analysis for symmetric and unsymmetric buildings $\quad 8$

1.5 Review of displacement based design methods $\quad 10$

$\begin{array}{lll}\text { 1.6 Software used in the analysis } & 12\end{array}$

$\begin{array}{lll}1.7 & \text { Objective and scope } & 14\end{array}$

$\begin{array}{lll}1.8 & \text { Thesis layout } & 15\end{array}$

\section{Displacement-based seismic design}

$\begin{array}{lll}2.1 & \text { Introduction } & 20\end{array}$

2.2 Displacement-based design $\quad 21$

2.3 Estimates of yield and ultimate displacement 22 
2.3.1 Drift limit specified in guidelines and codes

2.3.2 Local ductility capacity limit

2.3.3 Limit to preclude instability caused by P- $\Delta$ effect 26

$\begin{array}{lll}2.4 & \text { Equivalent SDOF system } & 27\end{array}$

2.4.1 Equivalent SDOF system for symmetric building 28

2.4.2 Equivalent SDOF system for unsymmetric building 28

$\begin{array}{lll}2.5 & \text { Inelastic demand spectrum } & 30\end{array}$

$\begin{array}{lll}2.6 & \text { Preliminary design } & 32\end{array}$

2.7 Moment curvature relationship 33

2.8 Modal pushover analysis 35

2.8.1 Modal pushover analysis for elastic symmetric buildings 37

2.8.2 Modal pushover analysis for inelastic symmetric buildings $\quad 41$

2.9 Subsequent iterations of design 43

2.10 Multi-mode pushover analysis $\quad 45$

$\begin{array}{lll}2.11 & \text { Summary } & 46\end{array}$

2.11.1 DBSD for symmetric buildings with different wall sizes 47

2.11.2 DBSD for unsymmetrical torsionaly stiff building 49

3 Application for the Displacement-based seismic design methods developed in this thesis

$\begin{array}{lll}3.1 & \text { Introduction } & 58\end{array}$

3.2 Displacement based design for a 12-storey symmetric building $\quad 59$

$\begin{array}{ll}3.2 .1 & \text { Building description }\end{array}$ 
3.2.2 Load definition $\quad 59$

$\begin{array}{lll}\text { 3.2.3 Material properties } & 60\end{array}$

3.2.4 Load calculations 61

$\begin{array}{lll}\text { 3.2.4.1 Floor dead load } & 61\end{array}$

3.2.4.2 Load due to self weight 61

3.2.4.3 Total dead load and mass for each floor 62

3.2.4.4 Gravity load calculation for each wall 63

3.2.4.5 Axial load for P-delta effect 64

3.2.5 Preliminary design $\quad 64$

$\begin{array}{lll}\text { 3.2.5.1 Yield displacement and curvature } & 64\end{array}$

3.2.5.2 Ultimate displacement 65

3.2.5.2.1 Limit on storey drift 65

3.2.5.2.2 Limit on ductility capacity 66

$\begin{array}{lll}\text { 3.2.5.3 Ductility demand } & 67\end{array}$

$\begin{array}{lll}\text { 3.2.5.4 Equivalent SDOF system } & 67\end{array}$

$\begin{array}{lll}\text { 3.2.5.5 Seismic demand } & 68\end{array}$

$\begin{array}{lll}\text { 3.2.5.6 Design of shear wall sections } & 68\end{array}$

$\begin{array}{lll}3.2 .6 & \text { First iteration } & 70\end{array}$

$\begin{array}{lll}\text { 3.2.7 } & \text { Multi-modal pushover analysis } & 73\end{array}$

3.3 Displacement based design for a 12-storey unsymmetric building $\quad 74$

$\begin{array}{lll}\text { 3.3.1 Building description } & 74\end{array}$

$\begin{array}{lll}\text { 3.3.2 Load definition } & 74\end{array}$

$\begin{array}{lll}\text { 3.3.3 Material properties } & 75\end{array}$ 
$\begin{array}{lll}\text { 3.3.4 Load calculations } & 76\end{array}$

$\begin{array}{lll}\text { 3.3.4.1 Floor dead load } & 76\end{array}$

3.3.4.2 Load due to self weight 76

3.3.4.3 Total dead load and mass for each floor 77

3.3.4.4 Gravity load calculation for each wall 77

$\begin{array}{lll}\text { 3.3.5 Preliminary design } & 79\end{array}$

$\begin{array}{lll}\text { 3.3.5.1 Yield displacement and curvature } & 79\end{array}$

$\begin{array}{lll}\text { 3.3.5.2 Ultimate displacement } & 79\end{array}$

3.3.5.2.1 Limit on storey drift 79

3.3.5.2.2 Limit on ductility capacity 80

$\begin{array}{lll}\text { 3.3.5.3 Equivalent SDOF system } & 81\end{array}$

3.3.5.4 Seismic demand 83

3.3.5.5 Design of shear wall sections 84

$\begin{array}{ll}\text { 3.3.6 Further iterations } & 86\end{array}$

3.3.6.1 Second iteration $\quad 88$

$\begin{array}{lll}\text { 3.3.6.2 Third iteration } & 92\end{array}$

3.3.7 Multimodal pushover analysis 95

3.3.7.1 Rotational dominant modes 96

3.3.7.2 Translational dominant modes 96

\section{Evaluation of displacement based seismic design methods}

$\begin{array}{lll}4.1 & \text { Introduction } & 116\end{array}$

4.2 Finite element model used in the Nonlinear RHA 117

$\begin{array}{lll}4.3 & \text { Ground motion for the city of Vancouver } & 119\end{array}$

4.4 The methodology of the statistical evaluation of the response 120 
4.5 Evaluation of the results of the 12-storey symmetric building

4.5.1 Roof displacement

122

4.5.2 Maximum inter-storey drift ratio

4.5.3 Base shear

124

4.6 Evaluation of the results of the 12-storey unsymmetric building

4.6.1 Roof displacement

4.6.1.1 Stiff edge roof displacement

4.6.1.2 Middle wall roof displacement

4.6.1.3 Flexible edge roof displacement

4.6.2 Maximum inter-storey drift ratio

4.6.2.1 Stiff edge maximum inter-storey drift ratio

126

4.6.2.2 Middle wall maximum inter-storey drift ratio

4.6.2.3 Flexible edge maximum inter-storey drift ratio

4.7 Summary and conclusion

5 Summary, Conclusion and recommendations

5.1 Summary

5.2 Conclusions

5.3 Recommendation for future work 


\section{List of Tables}

Table 3.1: Dead loads and masses for each floor level for 12-storey symmetric building

Table 3.2: Gravity load calculations 6-meter wall of the 12-storey symmetric building

Table 3.3: Gravity load combinations 6-meter wall of 12-storey symmetric building

Table 3.4: Gravity load combinations 4-meter wall of 12-storey symmetric building

Table 3.5: Calculation of live load to be included in a pushover analysis with $\mathrm{P}-\Delta$ effect included for 12-storey symmetric building

Table 3.6: Total response for roof displacement, maximum inter-storey drift ratio and base shear for 12-storey symmetric building

Table 3.7: Dead loads, masses and mass moment of inertias for each floor level for 12-storey unsymmetric building

Table 3.8: Gravity load calculations 7-meter edge wall of 12-storey unsymmetric building

Table 3.9: Gravity load combinations 7-meter edge wall of 12 -storey unsymmetric building

Table 3.10: Gravity load calculations 5-meter edge wall of 12 -storey unsymmetric building 
Table 3.11: Gravity load combinations 5-meter edge wall of 12-storey unsymmetric building

Table 3.12: Gravity load calculations 5-meter central wall of 12-storey unsymmetric building

Table 3.13: Gravity load combinations 5-meter central wall of 12-storey unsymmetric building

Table 3.14: Periods, effective modal masses and modal participation factors for the rotational dominant mode shapes

Table 3.15: Periods, effective modal masses, modal participation factors and base shear for the translational dominant mode shapes

Table 3.16: Roof displacement for each mode shape at each edge and total roof displacement at each edge

Table 3.17: Maximum inter-storey drift ratio for each mode shape at each edge and total maximum inter-storey drift ratio at each edge obtained using two combination rule 104 Table 4.1: Rayleigh damping coefficient for 12-storey symmetric and 12-storey usymmetric buildings

Table 4.2: Final selections for 20 ground motions for the city of Vancouver 


\section{List of Figures}

Figure 1.1: Seismic Performance Design Objective Matrix SEAOC Vision 2000 [1995]

Figure 1.2: Plan view of shear wall symmetric building

Figure 1.3: Plan view of shear wall unsymmetric building

Figure 1.4: Mode shapes for different unsymmetric buildings adopted by Chopra (2004)

(a) Torsionally stiff system (b) Torsionally similarly stiff system (c) Torsionally flexible system

Figure 2.1: Yield, plastic and ultimate displacement and rotations for a cantilever shear wall

Figure 2.2: Shear wall section

Figure 2.3: Demand and capacity diagram for equivalent SDOF system

Figure 2.4: Mode shapes of unsymmetric torsionaly stiff building: (a) lateral displacement component, (b) rotation angle $\mathrm{x} b / 254$

Figure 2.5: Plan view of the shear wall unsymmetric building 55

Figure 2.6: Moment curvature relationship adopted from (Yavari 2001) 55

Figure 2.7: Idealized stress-strain curve for concrete in uniaxial compression

Figure 2.8: Realistic tri-linear stress-strain relationship for reinforcing steel

Figure 2.9: Static response of the $\mathrm{n}^{\text {th }}$ mode

Figure 3.1: Plan and elevation of 12 -storey symmetric building

Figure 3.2: Preliminary design; demand and capacity diagrams for 12-storey symmetric building 
Figure 3.3: Preliminary design; moment-curvature relationship for 6-meter wall of the 12-storey symmetric building

Figure 3.4: Preliminary design; moment-curvature relationship for 4-meter wall of the 12-storey symmetric building

Figure 3.5: Push over curves showing the relationships between base shear and roof displacement with and without P-Delta effect included for 12-storey symmetric building 107

Figure 3.6: First design iteration; capacity and demand curves for 12 -storey symmetric building

Figure 3.7: Plan view of unsymmetric 12-storey shear wall building

Figure 3.8: Mode shapes of 12-storey unsymmetric building: (a) lateral displacement component, (b) rotation angle $\mathrm{x} b / 2$

Figure 3.9: Preliminarily design; demand and capacity diagrams for 12 -storey unsymmetric building

Figure 3.10: Preliminarily design; moment-curvature relationship for the 7-meter stiff edge wall of the 12-storey unsymmetric building

Figure 3.11: Preliminarily design; moment-curvature relationship for the 5-meter flexible edge wall of the 12-storey unsymmetric building

Figure 3.12: Preliminarily design; moment curvature diagram for the central 5-meter wall of the 12-storey unsymmetric building

Figure 3.13: Push over curve in the first iteration for 12-storey unsymmetric building 
Figure 3.14: Revised demand capacity diagram for 12-storey unsymmetric shear wall building

Figure 3.15: Second iteration; moment-curvature relationship for the 7-meter stiff edge wall of the 12-storey unsymmetric building

Figure 3.16: Second iteration; moment-curvature relationship for the 5-meter flexible edge wall of the 12-storey unsymmetric building

Figure 3.17: Second iteration; moment curvature diagram for the central 5-meter wall of the 12-storey unsymmetric building

Figure 3.18: Revised demand capacity diagram for 12-storey unsymmetric shear wall building

Figure 3.19: Third iteration; moment-curvature relationship for the 7-meter stiff edge wall of the 12-storey unsymmetric building

Figure 3.20: Third iteration; moment-curvature relationship for the 5-meter flexible edge wall of the 12-storey unsymmetric building

Figure 3.21: Revised demand capacity diagram for 12-storey unsymmetric shear wall building

Figure 4.1: Histogram of the roof displacement, maximum inter-storey drift ratio and base shear obtained from the nonlinear RHA for the 12- storey symmetric building 132 Figure 4.2: Histogram of the ratio between the roof displacement, maximum drift and base shear obtained from DBSD and nonlinear RHA for the 12- storey symmetric building

Figure 4.3: Histograms of the roof displacements at each edge of the 12-storey unsymmetric torsionaly stiff building obtained from nonlinear RHA 
Figure 4.4: Histogram of the ratio between the roof displacements obtained from DBSD and nonlinear RHA at each edge of the 12- storey unsymmetric torsionaly stiff building

Figure 4.5: Histograms of the maximum inter-storey drift ratios obtained from nonlinear RHA at each edge of unsymmetric torsionaly stiff building 136 Figure 4.6: Histogram of the ratio between the drift obtained from DBSD and nonlinear RHA at each edge of the 12- storey unsymmetric torsionaly stiff building

Figure 4.7: Histogram of the base shear of 12-storey unsymmetric torsionaly stiff building obtained from nonlinear RHA

Figure 4.8: Histogram of the ratio between the base shear obtained from DBSD and nonlinear RHA for 12- storey unsymmetric torsionaly stiff building

Figure 4.9: Beam with hinges element developed by Michael H. Scott (2006) 


\section{Symbols}

\begin{tabular}{|c|c|}
\hline $\mathrm{A}_{\mathrm{y}}$ & spectral acceleration of inelastic spectrum \\
\hline $\mathrm{CA}_{\text {trib }}$ & cumulative tributary area \\
\hline $\mathrm{D}$ & displacement of SDOF \\
\hline $\mathrm{E}_{\mathrm{c}}$ & concrete modulus of elasticity \\
\hline$f_{c}$ & concrete compressive strength \\
\hline$f_{y}$ & yield strength of reinforcement steel \\
\hline $\mathrm{H}$ & wall height \\
\hline $\mathrm{I}_{\text {eff }}$ & effective moment of inertia \\
\hline $\mathrm{I}_{\mathrm{o}}$ & polar moment of inertia matrix \\
\hline $\mathbf{K}$ & stiffeness matrix \\
\hline $\mathrm{L}_{\mathrm{P}}$ & plastic hinge length \\
\hline $\mathrm{L}_{\mathrm{w}}$ & wall length \\
\hline $\mathbf{M}$ & mass matrix \\
\hline$M^{*}$ & effective modal mass \\
\hline $\mathrm{n}$ & number of columns \\
\hline $\mathrm{p}$ & axial load \\
\hline $\mathrm{q}$ & modal coordinate \\
\hline $\mathrm{R}_{\mathrm{y}}$ & reduction factor \\
\hline $\mathbf{S}_{1}$ & lateral force pattern for pushover analysis using first mode \\
\hline $\mathrm{T}_{\mathrm{n}}$ & natural period \\
\hline $\mathrm{th}_{\mathrm{w}}$ & thickness of wall \\
\hline $\mathrm{V}$ & base shear \\
\hline
\end{tabular}




\begin{tabular}{|c|c|}
\hline$\mu$ & ductility capacity \\
\hline$\varphi_{y}$ & curvature at yield \\
\hline$\varphi_{\mathrm{u}}$ & ultimate curvature \\
\hline$\varepsilon_{\mathrm{y}}$ & yield strain of reinforcement steel \\
\hline$\varphi_{\mathrm{u}}$ & ultimate curvature \\
\hline$\Delta_{\mathrm{y}}$ & yield roof displacement \\
\hline$\Delta_{\mathrm{u}}$ & ultimate roof displacement \\
\hline$\theta_{\mathrm{y}}$ & yield roof rotation \\
\hline$\theta_{\mathrm{u}}$ & ultimate rotation \\
\hline$\theta_{\mathrm{p}}$ & plastic rotation \\
\hline$\Gamma$ & modal participation factor \\
\hline$\varphi_{1}$ & first mode shape \\
\hline 1 & unite vector \\
\hline$\varphi_{\mathrm{yr}}$ & roof translational component of the mode shape \\
\hline$\varphi_{\theta \mathrm{r}}$ & roof rotational component of the mode shape \\
\hline$\delta_{\mathrm{y}}$ & yield displacement of the equivalent SDOF \\
\hline$\delta_{\mathrm{u}}$ & ultimate displacement of the equivalent SDOF \\
\hline$\delta$ & dispersion \\
\hline$\omega_{\mathrm{n}}$ & $\mathrm{n}^{\text {th }}$ mode natural frequency \\
\hline$\varphi_{\mathrm{c}}$ & concrete performance factor \\
\hline$\varphi_{\mathrm{s}}$ & steel performance factor \\
\hline$\varphi$ & modal matrix \\
\hline$\gamma_{\mathrm{rc}}$ & self weight of reinforcement concrete \\
\hline
\end{tabular}




\section{Acronyms and Abbreviations}

ABSSUM Absolute Sum

CSA Canadian Standard Association

DBSD Displacement based seismic design

DOF Degree of Freedom

DL Dead Load

E Earthquake

FEMA Federal Emergency Agency

FBSD Force based seismic design

GM ground motion

LL Live Load

LLRF Live Load Reduction Factor

MDOF Multi Degree of Freedom

MPA Modal Pushover Analysis

NBCC National Building Code of Canada

PBSD Performance Based seismic design

PO Performance Objective

PSHA Probabilistic seismic hazard analysis

Opensees Open System for Earthquake Engineering Simulation

RHA Response History Analysis 
SDOF $\quad$ Single Degree of Freedom

SEAOC Structural Engineering Association of California

SRSS Square Root of the sum of the squares

UBC Uniform building code

UHS Uniform Hazard Spectra

UMRHA Uncoupled Modal Response History Analysis 


\section{Chapter 1}

\section{Introduction}

\subsection{Background}

Traditionally, the primary aim of earthquake resistant design of buildings has been to prevent loss of life during a rare earthquake. Experience in recent earthquakes has shown that while improvements in design and construction may have reduced the loss of life, economic loss due to property damage, business interruption and downtime could be very large, often causing a serious set back for the owners of the property and the society as a whole. The losses may be unacceptable to the owners, who would therefore want that their building be life safe during a rare earthquake, and at the same time not suffer damage beyond a specified level. They may in addition require that in the event of a more frequent earthquake the downtime not exceed a specified period of time. Performance objectives such as these are best expressed in terms of probabilities or mean annual frequency of exceedance of one or more specified limit states. The process of seismic design that aims to meet one or more performance objectives (POs) is referred to as performance based seismic design (PBSD). A probabilistic methodology of PBSD has recently been developed by Cornell and Krawinkler (2000). A simplified version of such methodology is proposed in the SEAOC Vision 2000 report (1995). In either case, the client selects the POs in consultation with the design professional, who then designs the structure to meet such objectives. 
Performance-based design provides a framework to control structural performance over a range of contemplated ground shaking intensities. Under this framework, a performance level is described in terms of the degree of damage or functionality of the structure for a specific intensity or likelihood of ground shaking (Edgar F. 2000). Performance of structures can be defined in terms of the level of damage expected for a future seismic hazard. The research community agrees that the level of damage is better defined by displacements or strains than forces or strengths. Consequently, force based design can not predict the level of damage that a structure will experience under different seismic hazards. This has motivated researchers and engineers to develop new seismic design methods that will enable the design professionals to design structures so as to achieve specified performance objectives and to avoid the shortcoming inherent in the force based design. These new design methods are displacement based, in which structures are designed to experience specified levels of displacements under different seismic hazards. The roof displacement is often selected as a measure of the targeted performance objectives corresponding to a given seismic demand.

In order to apply the displacement based design in the seismic design of symmetric and unsymmetric buildings, performance levels should be defined first in a quantitative manner. The quantitative performance levels may be defined in terms of maximum interstorey drift ratio. Consequently, the performance level will be achieved by limiting the maximum inter-storey drift ratio for each level of seismic hazard. For example the performance level adopted in this study is the near collapse performance level. According to the NBCC 2005, in order for the near collapse performance level to be achieved the 
maximum inter-storey drift ratio in any structure should not exceed $2.5 \%$ for a seismic hazard with a $2 \%$ probability of exceedance in 50 years, or a recurrence interval of 2500 years. Constraints on the maximum inter-story drift ratios can be related to limits on peak roof displacement response through empirical relationships presented in this thesis. This allows a performance level to be expressed as a constraint on peak roof displacement response and on the system ductility demand which will help researchers in developing displacement based design methods for performance based design of buildings.

Many researchers have worked on the development of different displacement based design methods for shear wall buildings having a symmetric configuration in plan. The need to extend the research effort to develop displacement based design methods for unsymmetric buildings is obvious. Unsymmetric buildings are buildings whose centers of rigidity do not coincide with their centers of mass. Consequently, when they are subjected to any kind of ground motion they will experience both lateral displacement motion and rotational torsion motion. Force based design methods available in the current building codes for design against earthquake induced torsion use an equivalent static load procedure in which the design inertia forces are applied through points that are eccentric with respect to the center of mass. Researchers have suggested different design eccentricities for the seismic design of stiff and flexible edges of an unsymmetric building. Those design eccentricities were developed from empirical formulas that provide approximate representation of the torsional behavior. Therefore considerable uncertainty is inherent in force based design methods for unsymmetric buildings, especially if they are designed to experience inelastic deformation. Also, given the 
shortcomings mentioned earlier in the force based design methods, development of a displacement based design method for unsymmetric buildings represents an important topic of research.

This study presents a new approach to the displacement based design of unsymmetric torsionaly stiff systems and symmetric buildings with multiple shear walls that is based on the application of a form of capacity-spectrum method, in which the demand is expressed by an inelastic spectrum and the capacity by a realistic force displacement relationship. The objective of the study is to develop a method of DBSD, which while based on the essential concepts reported earlier in the literature, attempts to make the method simple and transparent and suitable for design office use. The study is part of a wider study on the application of DBSD to structures of various kinds. A special consideration in the seismic design of shear wall structures is that certain response parameters in such a structure are dominated by the contribution of higher modes (Krawinkler and Seneviratna 1998, Gupta and Kunnath 2000). The DBSD method presented here is combined with multi-mode pushover analyses to account for the higher mode effects.

\subsection{Performance based seismic design}

The seismic performance of buildings is generally associated with structural and nonstructural damage caused by ground motions. A performance objective is defined as a performance levels associated with a certain seismic hazard. For example, in the FEMA- 
273 and the Vision 2000 (SEAOC-1995) documents, performance is expressed in terms of an anticipated limiting level of damage, termed a performance level, for a given intensity of ground motion (Hamburger, 1997).

The Vision 2000 report specifies a set of discrete performance levels which the structure may be required to meet under specified levels of earthquake hazard. These performance levels are shown in Figure 1.1 and range from fully operational to near collapse. The earthquake hazard is determined from a probabilistic seismic hazard analysis (PSHA) and expressed in terms of the annual frequency of exceedance or the return period. A PO is a combination of the seismic hazard and the expected performance level under such hazard.

For the purpose of design the desired performance levels must be expressed in quantitative terms. The quantitative performance levels are defined through limiting values of measurable response parameters, such as storey drifts, floor velocities and accelerations, element deformation and ductility demands, and damage indices. Performance levels can mainly be associated with numeric values of roof drift and qualitative description of damage to components of the gravity and lateral force resisting systems. Storey drifts control damage to structural and nonstructural elements as well as instability induced by P- $\Delta$ effects, floor velocities and accelerations control damage to supported elements and equipment, and appendages, while damage indices, deformations, and ductility demands provide measures of structural damage. For the present study we will focus on structural and nonstructural damage. Because element deformations and ductility demands can be related to storey displacements and drifts, it is evident that both 
the structural and nonstructural damage could be controlled by limiting the storey drifts and displacements.

While the forced-based method of the present codes is a valid method of design, the structures designed by this method will not have a uniform risk of failure. This is mainly because of the lack of a consistent relationship between strength and damage. Damage is strain or deformation related (for structural components), or drift related (for both structural and nonstructural components) and therefore damage control may not be achieved simply by providing a certain amount of strength. For the foregoing reasons force design methods are not suitable for performance based design. The displacement-based method of design (DBSD) combined with PSHA offers a method of seismic design that is better able to offer a uniform level of safety and meet the requirements of a performance-based design.

\subsection{Symmetric and unsymmetric buildings}

Symmetric buildings are buildings whose centers of mass coincide with the centers of rigidity. Such buildings experience only translational motion (lateral displacement motion) in the direction of the ground motion as shown in Figure 1.2. Unsymmetric buildings are buildings whose centers of mass do not coincide with the centers of rigidity. Such buildings experience translational motion in the direction of the ground motion as well as rotational motion around their center of mass as shown in Figure 1.3. Consequently the edges in an unsymmetric building experience different displacements. 
Chopra (2004) has classified the unsymmetric buildings into three different types. His classification was based upon their torsional stiffness and mode shapes as shown in Figure 1.4.

(a) Torsionally stiff system: For such a system, as illustrated in Figure 1.4(a), lateral displacements dominate motion in the first, third and all the odd modes while torsional rotations dominate motion in the second, fourth and all the even modes. There is weak coupling between each pair of modes. The periods of the dominantly torsion modes are much shorter than the periods of the dominantly lateral modes.

(b) Torsionally similarly stiff system: As illustrated in Figure 1.4(b), for this type of systems the periods of the first pair of modes and all other pair of modes are very close, which indicates that there is strong coupling between the modes in a pair.

(c) Torsionally flexible system: As illustrated in Figure 1.4(c), for such systems torsional rotations dominate motion in the first mode and all the other odd modes while lateral displacements dominate motion in the second mode and all the other even modes. The periods of the dominantly lateral modes are much shorter than the periods of the dominantly torsion modes.

The displacement based design method developed in this thesis is applicable only to torsionally stiff systems. Displacement based design of the two other types of unsymmetric buildings is beyond the scope of this thesis and research effort should be 
extended to develop displacement based design methods applicable for the other two systems.

\subsection{Modal pushover analysis for symmetric and unsymmetric buildings}

The only known analysis methodology for obtaining the exact response of structures for different ground motion records is the nonlinear time history analysis. Such an analysis is time consuming and involves considerable difficulty and uncertainty in modeling and the selection of ground motions. The method is therefore not yet suitable for use in the seismic design of buildings. The nonlinear modal pushover analysis represents an approximate but a more practical alternative for displacement based seismic design especially when we consider the fact that a great portion of the roof displacement response is contributed by the fundamental mode shape. Thus in this work the

displacement based seismic design for both symmetric and unsymmetric torsionally stiff buildings will be performed on the basis of a modal pushover analysis using the first mode shape.

In the modal pushover analysis, the seismic capacity is obtained by subjecting the structure to monotonically increasing lateral forces for symmetric buildings, and lateral forces and torsional torques for unsymmetric buildings, until a predetermined roof displacement is reached.

Chopra and others (2004) have developed the Uncoupled Modal Response History Analysis (UMRHA) procedure in order to serve as a theoretical basis for the 
development of the nonlinear modal pushover analysis for both symmetric and unsymmetric buildings. The main assumptions and approximations inherent in the UMRHA procedure are:

1- Modal transformation using the mode shapes of the equivalent linear elastic system (the system that will not experience any inelastic deformation) is possible. This assumption allows one to neglect the fact that the mode shapes change through out the analysis for inelastic systems.

2- The system of differential equations that describe the dynamic behavior of inelastic systems in the modal coordinates remain uncoupled for inelastic systems. This assumption allows one to determine the structural response for any mode shape due to any ground motion record using the corresponding inelastic response spectrum for a predetermined ductility.

3- The modal responses determined in 2 above can be combined by standard procedures applicable to elastic systems, such as for example the square root of the sum of squares (SRSS) of the modal responses

The assumptions and approximations inherent in the UMRHA procedure are discussed in detail and the equations of motion for elastic and inelastic systems are developed from first principles of dynamics of structures in Chapter 2. 
Modal pushover analysis was evaluated by Chopra (2004) for different unsymmetric buildings mentioned earlier. The MPA was accurate for torsionally stiff and torsionally flexible systems. However due to strong coupling between the modes the accuracy of the MPA was reduced for torsionally similarly stiff systems.

\subsection{Review of displacement based design methods}

Several different methods of seismic design based on displacements have been developed during the last two decades. The design methods presented in this work are based on the capacity demand method which was first developed by (Freeman et al. 1975). In this method the seismic demand is represented by the acceleration displacement format of the response spectrum rather than the standard pseudo-acceleration versus natural period design spectra. The acceleration displacement format of the response spectrum allows one to obtain the strength demand for a predetermined displacement from the intersection between the capacity curve of the structure and the demand diagram which are plotted together. The capacity curve is obtained by transforming the force displacement relationship obtained from the modal pushover analysis based on the first mode shape to represent an equivalent SDOF. The demand diagram is obtained by transforming the design spectrum from the standard pseudo-acceleration versus natural period format to the acceleration displacement format.

The method is also included in FEMA274 (Federal Emergency Management Agency 1997), FEMA 440 (2005) and ATC-40(Applied technology council 1996) as a nonlinear 
static procedure. Improvements to this method have been made by Chopra (1999) and Fajfar (2000).

In order to implement the capacity-demand method for inelastic systems a relationship between the elastic and inelastic seismic demand diagrams in acceleration displacement format should be developed. The inelastic design spectrum is obtained by dividing the elastic design spectrum by a reduction factor $R_{y}$ which depends on the elastic period $T_{n}$ and the ductility factor $\mu$. Three $R_{y}-\mu-T_{n}$ relationships were studied by Chopra (2001). These relationships were originally developed by (a) Newmark and Hall (1982); (b) Krawinkler and Nassar (1992); and (c) Fajfar and Fischinger (1994). The relationship developed by Krawinkler and Nassar (1992) provided average results among the three relationships and is adopted in this work.

Fajfar (1996) presented the $\mathrm{N}_{2}$ method for DBSD in which the roof displacement demand was obtained from a simplified pushover curve and an elastic demand spectrum. The inelastic displacement was obtained from $R_{y}-\mu-T_{n}$ developed by Newmark and Hall. The $\mathrm{N}_{2}$ method was implemented for a 7-storey $\mathrm{RC}$ frame. The method provided good estimates for global demand.

Priestly and Calvi (1997) developed a direct displacement based design for SDOF systems using the equivalent damping concept. Like most DBSD the yield displacement for preliminary design is a function of the building height and the design displacement is obtained from the rotation of the plastic hinge which depends on the serviceability limit state or damage control. The same procedure could be applied to MDOF. 
A direct displacement based design was developed by Priestley and Kowalsky (1998). In their work the maximum displacement $\Delta_{d}$ for a substitute structure is obtained to satisfy the two limit states; damage control limit state as well as serviceability limit state. The damping is estimated from the expected ductility demand and the effective period $T_{e}$ at maximum displacement response is obtained from a set of design displacement spectra corresponding to different damping ratios. The effective stiffness is calculated from $K_{e}=4 \pi^{2} m_{e} / T_{e}^{2}$, where $m_{e}$ is the effective mass. The design base shear is given by $V_{B}=$ $\mathrm{K}_{\mathrm{e}} \Delta_{\mathrm{d}}$. A good agreement was obtained between the actual and the target displacement envelops.

\subsection{Software used in the analysis}

Opensees is the software package used for running the modal, modal pushover and rigorous nonlinear time history analysis for the symmetric and unsymmetric buildings whose design is presented in this thesis. Opensees is the acronym for Open System for Earthquake Engineering Simulation. The software was developed by a wide research community of the United States. Each one of the researchers who worked on its development wrote a subroutine that added a different element or analysis algorithm or material to the domain and sent those subroutines to the software developers of Opensees at Berkeley University. The latter added those subroutines to the source code of the program and described the manner in which such subroutines could be used in the 
program. The program documentations also listed some references that the users of the software could read to learn the theoretical background of the subroutines.

Opensees provides a framework for sophisticated computational work. Under this frame work the Tcl programming language builds the finite element models by calling the subroutines that generate the nodes, elements, materials, constraints etic. It also calls the subroutines that perform different types of analysis (modal, modal pushover and rigorous nonlinear time history analysis). $\mathrm{Tcl}$ is a modern programming language with object oriented algorithm and file manipulation techniques. It helps the users of Opensees to organize their computational work.

The following are the strengths of Opensees:

1- There are thousands of subroutines that add to the domain different elements, materials, constraints, and analysis algorithms, which allows the users to have many options for finite element modeling. This facility makes the software a very powerful computational tool.

2- Opensees provides an opportunity for members of the research community to share their own ideas because its source code is freely available online. Any researcher can download it and modify its code at his/her convenience.

The main shortcomings of Opensees are as follows: 
1- The program was not developed by one organization or one researcher. Consequently, it has not been thoughtfully tested and no organization guarantees its results. Therefore where possible sample analysis results obtained from the program should be compared with the results of a different software. In this work the results obtained from the analysis of symmetric buildings including modal analysis, modal pushover analysis and nonlinear response history analysis carried out by Opensees were compared with the results of a two dimensional model of the same symmetric building using computer program DRAIN_2DX and identical results were obtained.

2- The output of the program is not user friendly and may become hard to interpret.

\subsection{Objective and scope}

1-Development of a new displacement based design method for seismic design of symmetric buildings with multiple shear walls in which the shear walls have different sizes that is simple and easy to use for a design office.

2- Development of a new displacement based design method for seismic design of unsymmetric torsionally stiff buildings.

3-Evaluation of the proposed design method for symmetric buildings with multiple shear walls by comparing the different response parameters obtained from the modal pushover analysis of the DBSD with the peak response obtained from the rigorous nonlinear RHA for 20 ground motion records scaled to match the uniform hazard spectrum of the city of Vancouver. 
4-Evaluation of the proposed design method for torsionally stiff unsymmetric buildings by comparing the response of different response parameters at each edge of the building obtained from the modal pushover analysis of the DBSD with the peak response at each edge of the building obtained from the rigorous nonlinear RHA for the same 20 ground motion records.

\subsection{Thesis layout}

This report is organized as follows:

Chapter 1 presents an introduction, motivation for the study, an overview for performance based design, classification for unsymmeric buildings, and literature review for displacement based design and modal pushover analysis for symmetric and unsymmetric buildings.

Chapter 2 presents the mathematical derivation for linear and nonlinear modal pushover analysis for symmetric buildings, the theoretical background for the two displacement based design methods, the mathematical derivation for the relationship between maximum inter-storey drift ratio, concrete strain limit and roof displacement and development of inelastic demand spectrum.

Chapter 3 presents design examples for symmetric building with multiple shear walls and unsymmetric torsionally stiff building. 
Chapter 4 presents an evaluation of the two design methods using nonlinear response analyses for 20 ground motion records scaled to match the uniform hazard spectrum for Vancouver. Results of a statistical processing of the results is also presented.

Chapter 5 presents summary, conclusions and recommendation for future work. 


\begin{tabular}{|c|c|c|c|c|c|}
\hline & \multicolumn{4}{|c|}{ Building Performance Levels } \\
\hline & & $\begin{array}{c}\text { Fully } \\
\text { Operational }\end{array}$ & Operational & Lifo safe & Near Collapse \\
\hline \multirow{4}{*}{ 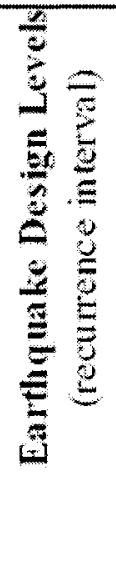 } & $\begin{array}{l}\text { Frequent } \\
\text { (43 Years) }\end{array}$ & & & & \\
\hline & $\begin{array}{l}\text { Oceasional } \\
\text { (72 Years) }\end{array}$ & & & & \\
\hline & $\begin{array}{c}\text { Rare } \\
\text { (475 Years) }\end{array}$ & & & & \\
\hline & $\begin{array}{l}\text { Very Rare } \\
\text { (970 Years) }\end{array}$ & & & & \\
\hline
\end{tabular}

Figure 1.1: Seismic Performance Design Objective Matrix SEAOC Vision 2000 [1995]

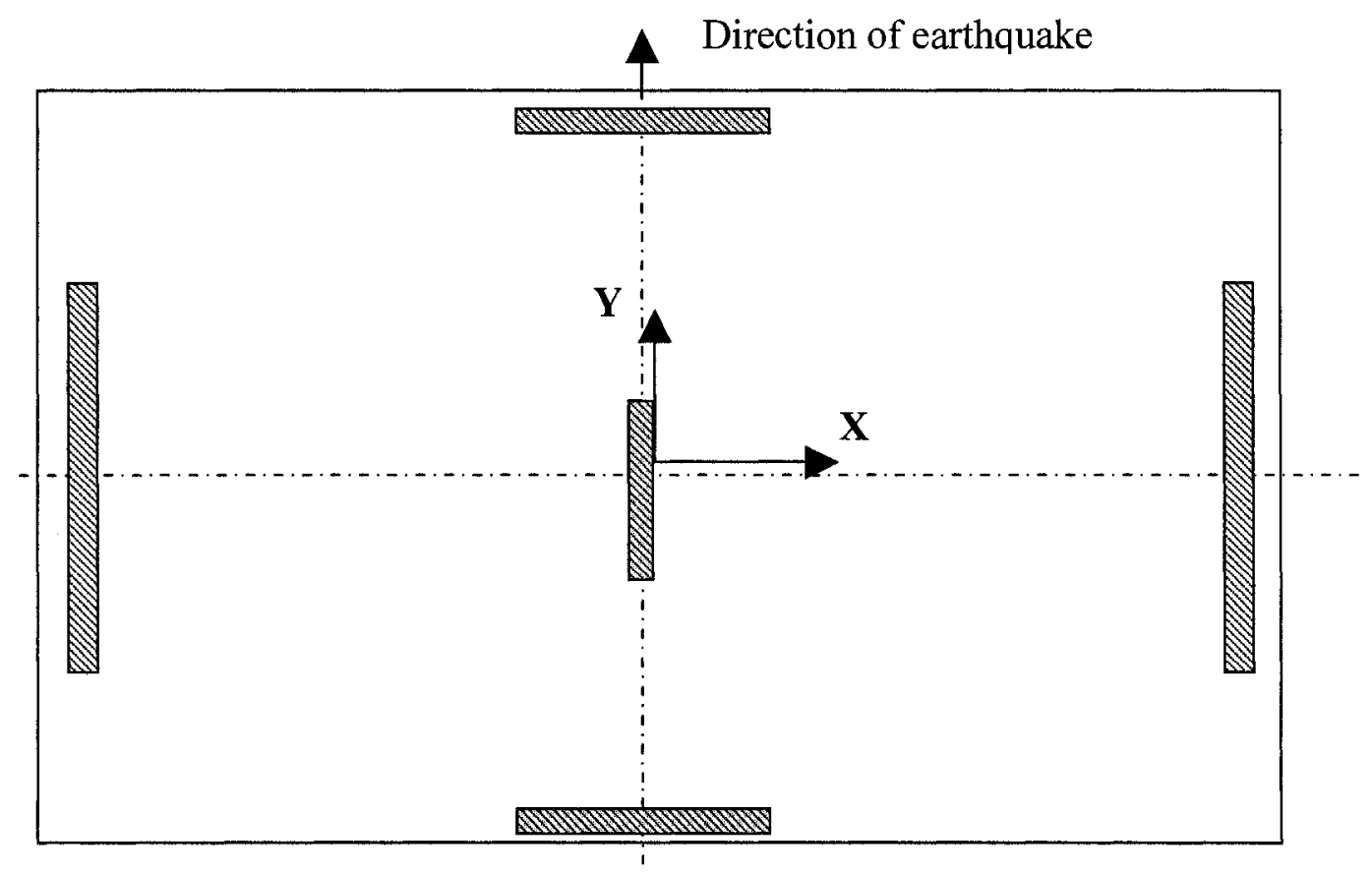

Figure 1.2: Plan view of symmetric shear wall building 


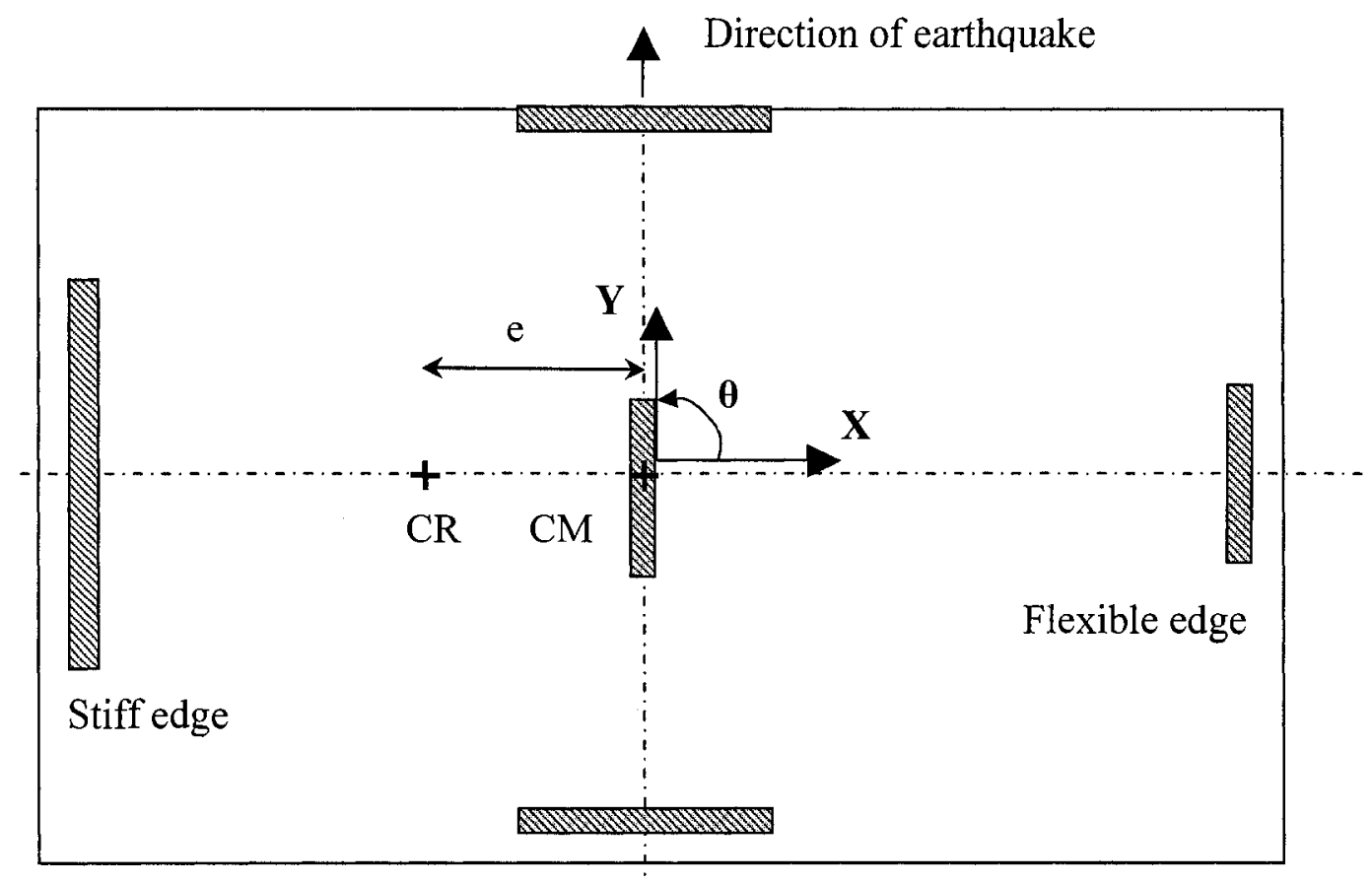

Figure 1.3: Plan view of unsymmetric shear wall building 

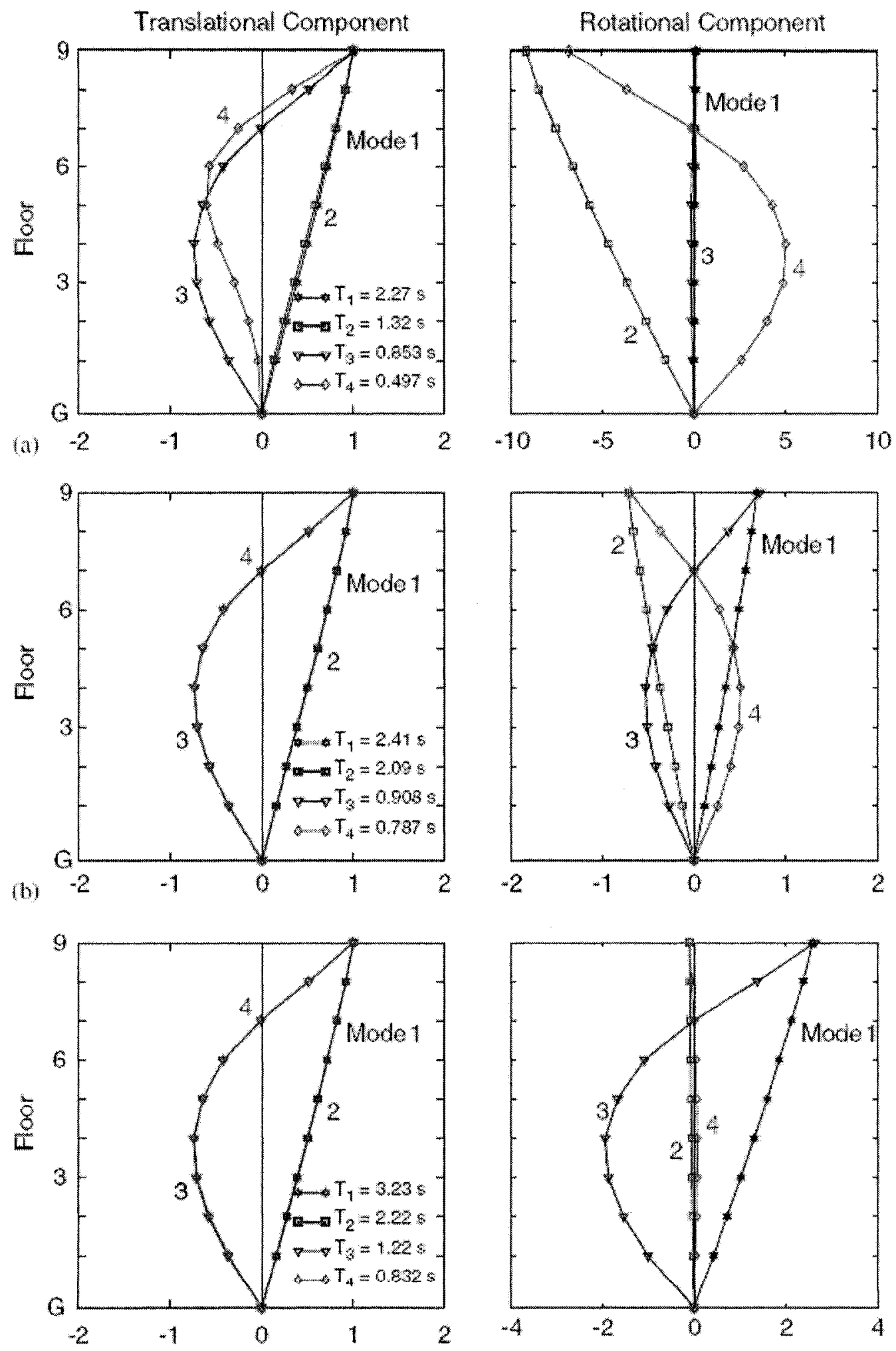

(1)
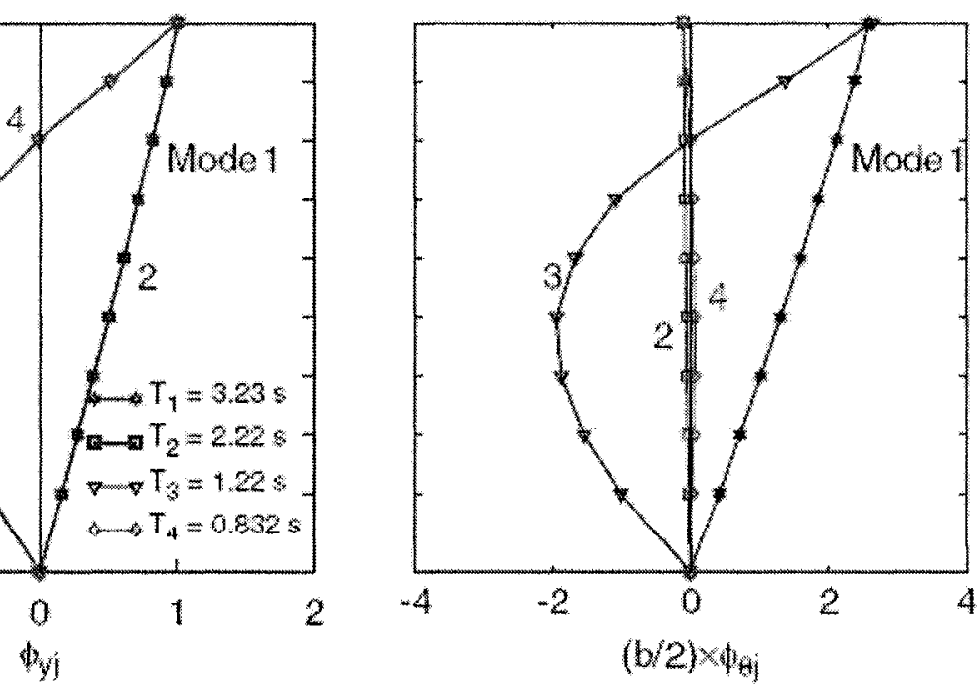

(b) 2 ) 14

Figure 1.4: Mode shapes for different unsymmetric buildings adopted by Chopra (2004) (a) Torsionally stiff system (b) Torsionally similarly stiff system (c) Torsionally flexible system 


\section{Chapter 2}

\section{Displacement-based seismic design}

\subsection{Introduction}

The most common and well-developed method for seismic design of buildings available in the current building codes is the forced-based method. Structures designed by this method usually do not have a uniform risk of failure. This is mainly because of the lack of a consistent relationship between strength and damage. Damage is strain or deformation related (for structural components), or drift related (for both structural and nonstructural components) and therefore damage control may not be achieved simply by providing a certain amount of strength. The displacement-based method of design (DBSD) combined with probabilistic seismic hazard analysis (PSHA) offers a method of seismic design that is better able to offer a uniform level of safety and meet the requirements of a performance-based design.

In this chapter displacement based seismic design methods are developed for application in the design of a symmetric building (rotational motion caused by natural and accidental torsion are ignored) with multiple reinforced concrete shear walls of different sizes and an unsymmetric torsionally stiff building in which the building will experience both translational motion and rotational torsion motion around its center of mass at each floor 
level. The two design methods can be applied to achieve any performance level, however the performance level that will be adopted in this thesis is the near collapse performance level. The corresponding seismic hazard for that performance level is defined in the 2005 National Building Code of Canada (NBCC) through uniform hazard spectra corresponding to $2 \%$ probability of exceedance in 50 years, or a recurrence interval of 2500 years.

The theoretical concept behind each step in the design methods is discussed in detail. The mathematical derivation for the analysis methodology used in the design procedure (modal push-over analysis) for symmetric and unsymmetric buildings based on the first principles of dynamics of structures is presented. A summary of each design method is presented at the end of this chapter. As stated earlier, the design methods presented in this thesis are adaptations of the capacity spectrum method whose concepts have been reported earlier in the literature.

\subsection{Displacement-based design}

The first step in the design process is to obtain estimates of the yield displacement and the acceptable ultimate displacement of a single degree of freedom system (SDOF) model of the structure. For a multi-storey structure this will require the selection of an assumed displacement shape and may require a pushover analysis which provides the relationship between the roof displacement and base shear. The ratio of the ultimate and yield displacements of the SDOF model provides the ductility requirement. The seismic 
demand curve is now obtained by determining the inelastic spectrum corresponding to the calculated ductility and plotting it in the acceleration-displacement format (Figure 2.3). The required capacity or strength is next determined by entering the demand curve at the ultimate displacement and measuring horizontally to get the spectral acceleration. The product of the spectral acceleration and effective modal mass of the equivalent SDOF system provides the strength or the base shear capacity of the structure.

\subsection{Estimates of yield and ultimate displacement}

The yield displacement is defined as the roof displacement at yield. For a cantilever shear wall, it is assumed that the curvature varies linearly across the height similar to a cantilever wall with only one concentrated load at its top (Figure 2.1).The stiffness of the wall $\mathrm{K}$ is then given by

$$
\mathrm{K}=\frac{3 \mathrm{E}_{\mathrm{c} \text { eff }}}{\mathrm{H}^{3}}
$$

where $E_{c}$ is the concrete modulus of elasticity, $\mathrm{I}_{\mathrm{eff}}$ is the effective moment of inertia of the shear wall section, and $\mathrm{H}$ is the wall height The yield displacement $\Delta_{\mathrm{y}}$ is given by

$$
\Delta_{y}=\frac{P_{y}}{K}
$$

where $\mathrm{P}_{\mathrm{y}}$ is the assumed force at the top of the cantilever wall which causes it to yield. The moment corresponding to yielding at the base of the cantilever wall $\mathrm{M}_{\mathrm{y}}$ is obtained from 


$$
\mathrm{M}_{\mathrm{y}}=\mathrm{P}_{\mathrm{y}} \mathrm{H}
$$

Substituting from Eqs. (2.1) and (2.3) in Equation (2.2)

$$
\Delta_{y}=\frac{M_{y} H^{2}}{3 E_{c \text { eff }}}
$$

Assuming that the neutral axis depth is $\mathrm{c}$ the yield curvature $\varphi_{\mathrm{y}}$ is given by

$$
\varphi_{y}=\frac{M_{y}}{E_{c} I_{\text {eff }}}=\frac{\varepsilon_{y}}{c}
$$

where $L_{w}$ is the wall length and $\varepsilon_{y}$ is the strain at yield for the reinforcement steel

Substituting from Equation (2.5) in Equation (2.4)

$$
\Delta_{y}=\frac{\varphi_{y} H^{2}}{3}=\frac{\varepsilon_{y} H^{2}}{3 c}
$$

Assuming that the curvature varies linearly across the height, the yield rotation $\theta_{\mathrm{y}}$ is given by

$$
\begin{aligned}
& \theta_{y}=\int_{0}^{\mathrm{H}} \varphi_{y}\left(1-\frac{\mathrm{L}}{\mathrm{H}}\right) \mathrm{dl} \\
& \theta_{\mathrm{y}}=\left.\varphi_{\mathrm{y}}\left(\mathrm{L}-\frac{\mathrm{L}^{2}}{2 \mathrm{H}}\right)\right|_{0} ^{\mathrm{H}} \\
& \theta_{y}=\varphi_{y} \frac{\mathrm{H}}{2}
\end{aligned}
$$

The ultimate displacement corresponding to the near collapse condition is the roof displacement after a plastic hinge has developed at the base of the wall. This displacement consists of two components, elastic displacement up to yield and plastic displacement following yield, and is given by

$$
\Delta_{u}=\Delta_{y}+\theta_{p}\left(H-0.5 L_{p}\right)
$$


where $\Delta_{u}$ is the ultimate displacement, $L_{p}$ is the length of the plastic hinge, and the plastic rotation $\theta_{\mathrm{p}}$ can be expressed as the product of the plastic curvature capacity and the length of the plastic hinge.

$$
\left.\theta_{p}=\mid \varphi_{u}-\varphi_{y}\right)_{p}
$$

As illustrated in Figure 2.1 the summation of the yield and the plastic rotations gives the ultimate rotation. Consequently the plastic rotation $\theta_{\mathrm{p}}$ can be expressed as

$$
\theta_{\mathrm{p}}=\theta_{\mathrm{u}}-\theta_{\mathrm{y}}
$$

At near collapse the acceptable ultimate displacement would be governed by one of the following limits:

(1) Drift limits specified by guidelines and codes

(2) Local ductility capacity

(3) Limit to preclude instability caused by $P-\Delta$ effect

\subsubsection{Drift limit specified in guidelines and codes}

Such a limit is prescribed to fulfill the selected performance objective (PO). Drift limit at near collapse level is meant to guard against structural collapse and non-structural damage that may jeopardize life safety. Both Vision 2000 SEAOC report (1995) and NBCC 2005 specify the near collapse drift limit as $2.5 \%$ and require that for basic performance objective this performance level should be achieved under a very rare earthquake. The difference is that the rare earthquake is defined by Vision 2000 as one with $5 \%$ probability of exceedance in 50 years or a return period of 970 years, while the 
NBCC defines it as one having a $2 \%$ probability of exceedance in 50 years or a return period of 2500 years (DeVall 2003).

For a cantilever shear wall the largest storey drift, $\theta_{\mathrm{u}}$ occurs at the roof and is obtained by substituting from Equation (2.7) in Equation (2.10)

$$
\theta_{u}=\frac{\phi_{y} \mathrm{H}}{2}+\theta_{p}
$$

Substituting from Equation (2.11) in Equation (2.8) with $\theta_{u}=0.025$ we get the limiting value of the ultimate displacement.

$\Delta_{u}=\Delta_{y}+\left(H-0.5 L_{p}\right)\left(0.025-\frac{\phi_{y} H}{2}\right)$

in which $\Delta_{y}$ is obtained from Equation (2.6).

\subsubsection{Local ductility capacity limit}

The ultimate displacement corresponding to the ductility capacity of an element depends on the inelastic behaviour of the shear wall at its most critical cross section. This section is usually located at the base of the wall. The inelastic behaviour is governed by the geometry of the section and characteristics of the materials, specifically the limiting compressive strain in the concrete $\varepsilon_{u}$. The ultimate curvature is given by $\phi_{u}=\varepsilon_{u} / c_{u}$, where $c_{u}$ is the depth of neutral axis when the concrete strain is $\varepsilon_{u}$. The ultimate displacement is obtained by inserting this value of $\phi_{u}$ in Equation (2.9) and then substituting the resulting $\theta p$ in Equation (2.8). Thus the ultimate displacement is given by

$$
\Delta_{u}=\Delta_{y}+L_{P}\left(\varphi_{u}-\varphi_{y}\right)\left(H-.5 L_{P}\right)
$$


It is of interest to determine which one of the two criteria, code specified drift limit, and the ductility capacity limit, control the selection of ultimate displacement. The governing limit will depend on the relative values of the plastic drift $\theta p$ The limiting strain in concrete, $\varepsilon_{u}$ is usually assumed as being 0.015 for confined concrete (UBC 1997) and 0.004 for unconfined concrete. The ultimate curvature is determined from $\varepsilon_{\mathrm{u}}$ and the neutral axis depth $c_{u}$. Moment curvature analyses using strain compatibility indicate that $\mathrm{c}_{\mathrm{u}}$ depends on steel ratio, concrete strain $\varepsilon_{\mathrm{u}}$, the ultimate tensile strain in steel $\varepsilon_{\mathrm{s}}$, and the axial load ratio. It is found that for confined concrete the drift limit prescribed by the codes will invariably be the controlling parameters. For unconfined concrete either of the ductility capacity or the code limit may govern.

It may be noted that it is often difficult and expensive to provide confinement to the longitudinal steel in a shear wall. Consequently, in practice, concrete is often considered as being unconfined and the local ductility capacity is obtained from maximum acceptable concrete compression strain value for unconfined concrete. An advantage of performance based design is that the designer has the freedom to choose the acceptable strain; the acceptable ultimate displacement is then computed on the basis of the selected strain limit.

\subsubsection{Limit to preclude instability caused by $P-\Delta$ effect}

The P- $\Delta$ effect, which is a function of the axial load and the height of the wall, decreases the stiffness of the structure and modifies its elastic and inelastic responses. If the 
structure is idealized by an elasto-plastic force displacement relationship, this effect will cause the stiffness to become negative as soon as yield takes place. This negative stiffness may cause instability in the structure and, theoretically, the structure should not be stressed beyond yield to prevent any chance of P- $\Delta$ instability. In other words, the structure should be designed to remain elastic. Nevertheless, it has been observed in previous studies (Chopra and Goel 1999, Chopra et al 2003) that the structure usually remains stable as long as the excursion into the zone of instability is not excessive. For example, a 10 to $15 \%$ reduction in the base shear strength caused by P- $\Delta$ effect may be quite acceptable.

At the beginning of design the structure would normally be designed to meet the drift limits specified by the code as well as that based on ductility capacity. During subsequent iterations in design the excursion into the zone of instability can be evaluated by taking the ratio of the base shear at maximum displacement to that at yield, and the design suitably modified if this excursion is too large.

\subsection{Equivalent SDOF system}

In order to apply the DBSD method to a multi-degree-of-freedom (MDOF) system the latter should first be represented by an equivalent SDOF system. The transformation of the MDOF system to an equivalent SDOF system will be done in different ways for symmetric and unsymmetric buildings. 


\subsubsection{Equivalent SDOF system for symmetric building}

The MDOF system of the symmetric building is represented by an equivalent SDOF system by selecting a displaced shape for the structure to represent its first mode shape. Any logical shape similar to the first mode shape including an inverted triangular shape could be selected. Assuming that the selected shape is represented by the vector $\varphi$, the following parameters are calculated:

$$
\begin{aligned}
& \Gamma_{1}=\frac{\varphi_{1}^{\mathrm{T}} \mathrm{M} 1}{\varphi_{1}^{\mathrm{T}} \mathrm{M} \varphi_{1}} \\
& M_{1}^{*}=\frac{\left(\varphi_{1}^{\mathrm{T}} \mathrm{M} 1\right)^{2}}{\left(\varphi_{1}^{\mathrm{T}} \mathrm{M} \varphi_{1}\right)}
\end{aligned}
$$

where $\mathbf{M}$ is the mass matrix, $\mathbf{1}$ is the unit vector, $\Gamma$ is the modal participation factor, and $\mathrm{M}^{*}$ is the effective modal mass. The yield and target displacements for the equivalent SDOF system are given by

$$
\begin{aligned}
& \delta_{y}=\frac{\Delta_{y}}{\Gamma \phi^{r}} \\
& \delta_{u}=\frac{\Delta_{u}}{\Gamma \phi^{r}}
\end{aligned}
$$

where $\phi^{\mathrm{r}}$ is the value of $\varphi$ at the roof.

\subsubsection{Equivalent SDOF system for unsymmetric building}

In order for the MDOF system of the unsymmetric building to be represented by an equivalent SDOF system of the first mode shape we should first determine the mode 
shapes of the unsymmetric building. We can assume that the stiffness of any wall in the unsymmetric building is a function of the wall length; consequently the relative values of the wall stiffnesses become known and it is possible to determine the mode shapes.

There will be two degrees of freedom at each floor level for a building that is unsymmetric about one axis and is excited by an earthquake along the axis of unsymmetry. One of the degrees of freedom will represent the lateral displacement motion; the other one will represent the rotational torsional motion. Consequently, there will be two components for each mode shape a lateral displacement component $\varphi_{\mathrm{y}}$ and a rotational torsional component $\varphi_{\theta}$ and each mode shape will be represented by a vector $\varphi$ that will include two Nx1 subvectors $\varphi_{y}, \varphi_{\theta}$. All mode shapes will be normalized so that the mode value in the lateral component is equal to 1 at the roof level.

For the unsymmetric torsionally stiff system whose design is presented in Chapter 3 the first, third and all the other odd modes are predominantly lateral, while the second, fourth and all the other even modes have large rotational torsional motion as shown in Figure 2.4. After finding the mode shapes we can obtain the effective modal mass $M_{1}^{*}$ and modal participation factor $\Gamma_{1}$ for the first mode shape.

$$
\begin{aligned}
& L_{n}=\varphi_{n}^{T} M 1 \\
& M_{n}=\varphi_{n}^{T} M \varphi_{n} \\
& \Gamma_{n}=\frac{L_{n}}{M_{n}} \\
& M_{n}^{*}=\Gamma_{n} L_{n}
\end{aligned}
$$


where $\mathrm{n}=1$ and $\mathbf{M}$ is a diagonal mass matrix that includes two diagonal submatrices $\mathbf{m}$ and $\mathbf{I}_{\mathbf{0}} ; \mathbf{m}$ is a diagonal matrix with $\mathrm{m}_{\mathrm{j} j}=\mathrm{m}_{\mathrm{j}}$, the mass lumped at the $\mathrm{j}$-th floor level diaphragm; $\mathbf{I}_{0}$ is a diagonal matrix with $\mathrm{I}_{\mathrm{jj}}=\mathrm{I}_{\mathrm{oj}}$, the polar moment of inertia of the $\mathrm{j}$-th floor diaphragm about a vertical axis through the $\mathrm{CM}$ and $\mathbf{1}$ is a vector that has unit values along the y degrees of freedom and zeros elsewhere.

The yield and target displacements at the center of mass corresponding to their values for a given wall $\mathrm{i}$ are obtained from

$$
\begin{aligned}
& \Delta_{y}=\frac{\Delta_{y i}}{\varphi_{y r}+X^{*} \varphi_{\theta r}} \\
& \Delta_{u}=\frac{\Delta_{u i}}{\varphi_{y r}+X^{*} \varphi_{\theta r}}
\end{aligned}
$$

where $\varphi_{\mathrm{yr}}$ and $\varphi_{\theta \mathrm{r}}$ are the lateral displacement and rotational torsional components of the selected mode shape at the roof, $\mathrm{x}$ is the distance from the center of mass to the wall parallel to the $\mathbf{X}$ axis as shown in Figure $2.5, \Delta_{\mathrm{yi}}$ and $\Delta_{\mathrm{ui}}$ are the yield and ultimate displacement of any wall in the unsymmetric building.

The yield and target displacements for the equivalent SDOF system based on the first mode are given by

$$
\begin{aligned}
& \delta_{y}=\frac{\Delta_{y}}{\Gamma} \\
& \delta_{u}=\frac{\Delta_{u}}{\Gamma}
\end{aligned}
$$

\subsection{Inelastic demand spectrum}


In this work the seismic demand is represented by the uniform hazard spectrum (UHS) for Vancouver city corresponding to $2 \%$ probability of exceedance in 50 years and $5 \%$ damping, as defined in NBCC 2005. The values are given in acceleration-period format at specified vibration periods, up to and including $2 \mathrm{~s}$, linear interpolation being used for intermediate values of the period. It is further suggested that the spectral acceleration at $4.0 \mathrm{~s}$ period be taken as half of that at $2.0 \mathrm{~s}$ period. The spectral values for periods greater than $4.0 \mathrm{~s}$ are not defined. In the present work we will assume that spectral accelerations for periods longer than $4.0 \mathrm{~s}$ are given by the following expression:

$S_{a}(T)=4 S_{a}(4) / T$ for $T \geq 4$

The UHS is converted to the acceleration-displacement (A-D) format so that it can be plotted on the same graph as the capacity diagram referred to earlier.

The UHS represents the elastic response of a SDOF system. When the structure develops inelastic deformations the demand curve is expressed in the form of a constant ductility inelastic spectrum. The inelastic spectrum provides the value of spectral acceleration $S_{a y}$, such that when the structure having the corresponding yield strength is subjected to the design earthquake it develops the specified ductility $\mu$. The ratio of $S_{a}$ to $S_{a y}$ is denoted by $R_{y}$. The construction of inelastic demand spectrum from the known elastic demand spectrum requires the definition of a relationship between $R_{y}, \mu$, and $T$. Chopra and Goel (1999) have studied three different such relationships and found that all three yield similar results. Among the three, the equation proposed by Krawinkler and Nassar (1992) represents an average. This equation is based on the response of bilinear systems and is given by 
$R_{y}=[c(\mu-1)+1]^{1 / c}$

where

$c=\frac{T^{a}}{1+T^{a}}+\frac{b}{T}$

and parameters $a$ and $b$ depend on post-yield stiffness. In the present work we assume that the force-displacement relationship is elasto-plastic, in which case $a=1$ and $b=0.42$.

The displacement of the inelastic system is given

$S_{d}=\frac{\mu}{R_{y}}\left(\frac{T}{2 \pi}\right)^{2} S_{a}$

where $S_{a}$ is the elastic spectral acceleration at the period T. The inelastic spectrum can thus be defined for a constant ductility factor with displacements obtained from (2.22) and accelerations given by $\mathrm{S}_{\mathrm{a}} / \mathrm{R}_{\mathrm{y}}$.

\subsection{Preliminary design}

For preliminary design of the structure, the yield displacement is obtained from Equation (2.6). The ultimate displacement is obtained from Equation (2.12), if the code specified limit governs, or from Equation (2.13) with an appropriate value of $\phi_{u}$ if the ductility capacity governs. The system is now converted into an equivalent SDOF system based on the first mode shape. The ductility demand is given by the ratio $\Delta_{u} / \Delta_{y}$ or, equivalently, $\delta_{\mathrm{u}} / \delta_{\mathrm{y}}$. The inelastic demand spectrum for the calculated ductility is now obtained. On 
entering this spectrum with $\delta_{u}$ we obtain the spectral acceleration $\mathrm{S}_{\mathrm{ay}}$. The design base shear for the structure is given by

$$
\mathrm{V}=\mathrm{A}_{\mathrm{y}} \mathrm{M}^{*}
$$

The base shear is distributed across the height of the structure in proportion to the elements of the vector $\mathbf{M} \varphi$ where $\boldsymbol{\varphi}$ is the assumed first mode shape vector. For the symmetric building $M \varphi$ will provide the lateral storey level forces; for the unsymmetric building it also provides the torsional moments to be applied through the center of mass of each storey level. An elastic analysis of the structure is now carried out for the storey level forces, determined as above, to obtain the design moments in the shear wall and the reinforcement is selected to provide the required moment capacity.

\subsection{Moment curvature relationship}

In order to run the modal analysis and the modal pushover analysis for subsequent design iterations we should first find a more refined estimate of the resistant moment capacity as well as the effective moment of inertia of the shear walls. For that purpose a moment curvature analysis needs to be carried out and a moment curvature diagram plotted for the rectangular reinforced concrete section of each shear wall. Yavari (2001) has studied the

moment curvature relationship for rectangular reinforced concrete sections. The slope of the moment curvature diagram as illustrated in (Figure 2.6) before concrete cracking is $E_{c} I_{t}$ where $E_{c}$ is the concrete modulus of elasticity, $I_{t}$ is the moment of inertia of the transformed section and the neutral axis is at the geometric center. When the applied moment reaches the cracked moment of concrete $\mathrm{M}_{\mathrm{cr}}$, the concrete below the neutral axis 
is cracked and is assumed not to carry any stress; consequently the slope of the moment curvature curve is reduced. Then, as the applied moment is increased first yield occurs, at which time the steel in the layer farthest from the neutral axis starts to yield. When that happens the slope of the moment curvature relationship starts to decrease progressively especially as more layers of steel start to yield until failure occurs either through concrete crashing or steel fracture. The resulting moment curvature diagram can be idealized as a bilinear curve as shown by a dashed line in Figure 2.6.

In order to carry out the moment curvature analysis we should first define the material properties of the shear wall. In another words we should define the stress strain relationship for both concrete and steel material. An idealized stress-strain curve that follows the Hognestad's model is used for concrete (Figure 2.7). The effect of confinement on the stress-strain relationship is ignored, because confinement of concrete in shear walls is very expensive and not practical. An idealized tri-ilinear stress strain curve is used for steel (Figure 2.8). Beyond the onset of strain hardening the stress-strain curve for steel is represented as a straight line.

A computer program developed using MATLAB by Humar (personal communication) was used for carrying out the moment curvature analysis. The main parameters obtained from the moment curvature analysis are the effective moment of inertia and the resistant moment capacity, and the yield and ultimate curvatures that will allow us to obtain a more refined estimate for the ultimate displacement for subsequent iterations in design. 
The effective moment of inertia and the resistant moment capacity for the shear walls are used for carrying out the modal analysis and the modal pushover analysis.

\subsection{Modal pushover analysis}

In the preliminary design, the symmetric and unsymmetric buildings are designed on the basis of yield and ultimate roof displacements obtained from the empirical relationships derived in the previous sections. A major portion of the roof displacement response will be due to the effective earthquake forces in the first mode shape in any symmetric building and in an unsymmetric torsionally stiff building; contribution of the higher modes to the roof displacement response being very small. A modal pushover analysis (MPA) for a force distribution representing the first mode shape is carried out in order to determine the peak roof displacement and base shear responses. These parameters are then compared with the roof displacements that the building was designed for and the base shear demand in the first mode shape produced by the seismic hazard represented by the UHS for Vancouver. If the two response parameters (roof displacement and base shear) obtained from the preliminary design and the MPA for the first mode are close, the design process can be assumed to have converged. If they are not close, further iterations are carried out with the more refined estimates of the yield and ultimate roof displacements, obtained from the push over analysis as well as the moment-curvature relationships. 
In the present work modal push over analysis is also performed to determine the contribution of higher modes to the base shear. Such analysis must be carried out for several higher modes to include all major contributions.

In the MPA the peak value of any response parameter to the effective earthquake forces in a given mode is estimated by a nonlinear static analysis of the structure subjected to monotonically increasing lateral forces for symmetric buildings and lateral forces along with torsional moments for unsymmetric buildings with an invariant height-wise distribution until a predetermined roof displacement is reached. For a symmetric building the lateral forces are given by the product of the mass matrix $\mathbf{M}$ and the first mode shape $\varphi_{1}$.

$\mathbf{S}_{1}^{*}=\mathbf{M} \boldsymbol{\varphi}_{1}$

The same holds true for unsymmetric buildings; however this time the product of the mass matrix and the first mode shape gives lateral forces as well as torques.

$\mathbf{S}_{1}^{*}=\mathbf{M} \varphi_{1}=\left\{\begin{array}{l}\mathbf{m} \varphi_{\mathrm{y} 1} \\ \mathbf{I} \boldsymbol{\varphi}_{\theta 1}\end{array}\right\}$

The pushover curve is a bilinear curve with a break at the yield point and represents the base shear versus roof displacement relationship. When the modal pushover analysis is applied for elastic systems it is equivalent to the standard response spectral analysis. The mathematical derivation of the modal push-over analysis for elastic systems will be presented here for symmetric buildings. In order to apply the modal pushover analysis to inelastic systems, Chopra (2002) developed the UMRHA procedure (the uncoupled 
modal response history analysis). The derivation of the UMRHA is very similar to the derivation of the modal pushover analysis for elastic systems, except for some approximation and assumptions that are inherent in that procedure. Those approximations and assumptions will be discussed in detail.

The mathematical derivation of the modal pushover analysis for elastic and inelastic systems of unsymmetric buildings is very similar to the derivation for symmetric buildings. Consequently for the sake of brevity those derivations for unsymmetric buildings will not be presented here. Details have been presented by Chopra ( 2004 )

\subsubsection{Modal pushover analysis for elastic symmetric buildings}

As stated earlier, the modal pushover analysis for elastic systems is equivalent to the standard response spectral analysis (Chopra 2004). The mathematical derivation of the modal pushover analysis for elastic systems has been presented by Chopra (Chopra 2007 Chapter 12,13$)$. A summary is presented here.

The equations of motions for a linear symmetric building with classical damping subjected to earthquake induced ground motion will be given by

$$
\mathbf{M} \ddot{\mathbf{u}}+\mathbf{C} \dot{\mathbf{u}}+\mathbf{K u}=-\mathbf{M} \ddot{\mathbf{u}}_{\mathrm{g}}(\mathrm{t})
$$

where $\mathbf{C}$ is the damping matrix, $\mathbf{K}$ is the stiffeness matrix and $\mathbf{\imath}$ is a unit vector The vector $\mathbf{M} \mathbf{l}$ can be expressed as a sum of modal inertia force distribution vectors $\mathbf{S}_{\mathrm{n}}$ as follows: 
$\mathbf{M} \mathbf{l}=\sum_{\mathrm{n}=1}^{\mathrm{N}} \mathbf{S}_{\mathrm{n}}=\sum_{\mathrm{n}=1}^{\mathrm{N}} \alpha_{\mathrm{n}} \mathbf{M} \boldsymbol{\varphi}_{\mathrm{n}}$

Premultiplying both sides of equation 2.30 by $\varphi_{n}^{T}$ and using the orthognality properties of mode shapes we get

$\alpha_{n}=\frac{\varphi_{n}^{T} M \mathbf{l}}{\varphi_{n}^{T} M \varphi_{n}}=\Gamma_{n}$

Thus $\mathbf{S}_{\mathrm{n}}=\Gamma_{\mathrm{n}} \mathbf{M} \boldsymbol{\varphi}_{\mathrm{n}}$

The displacement $\mathbf{u}$, velocity $\mathbf{u}$ and acceleration vectors $\ddot{\mathbf{u}}$ of a MDOF can be expanded in terms of modal contributions.

$$
\begin{aligned}
& \mathbf{u}(\mathrm{t})=\sum_{i=1}^{N} \boldsymbol{\varphi}_{i} \mathrm{q}_{i}(\mathrm{t})=\boldsymbol{\Phi} \mathrm{q}(\mathrm{t}) \\
& \dot{\mathbf{u}}(\mathrm{t})=\sum_{\mathrm{i}=1}^{\mathrm{N}} \boldsymbol{\varphi}_{i} \dot{\mathrm{q}}_{\mathrm{i}}(\mathrm{t})=\boldsymbol{\Phi} \dot{\mathrm{q}}(\mathrm{t}) \\
& \ddot{\mathbf{u}}(\mathrm{t})=\sum_{\mathrm{i}=1}^{\mathrm{N}} \boldsymbol{\varphi}_{i} \ddot{\mathrm{q}}_{\mathrm{i}}(\mathrm{t})=\dot{\boldsymbol{\Phi}} \ddot{\mathrm{q}}(\mathrm{t})
\end{aligned}
$$

where $\boldsymbol{\varphi}$ is the modal matrix

Substituting from Equation (2.33) in Equation (2.29), multiplying Equation (2.29) by $\Phi^{\mathbf{t}}$ and using the orthogonality property of modes, the equations of motions in the modal coordinates become

$$
\varphi_{n}^{\mathrm{t}} M \varphi_{n} \ddot{\mathrm{q}}_{\mathrm{n}}(\mathrm{t})+\varphi_{n}^{\mathrm{t}} \mathrm{C} \varphi_{n} \dot{\mathrm{q}}_{\mathrm{n}}(\mathrm{t})+\varphi_{n}^{\mathrm{t}} \mathrm{K} \varphi_{n} \mathrm{q}_{\mathrm{n}}(\mathrm{t})=-\varphi_{n}^{\mathrm{t}} \mathbf{M} \ddot{\mathrm{u}}_{\mathrm{g}}(\mathrm{t})
$$

where

$$
\varphi_{n}^{\mathrm{t}} M \varphi_{n}=M_{n} \quad \varphi_{n}^{\mathrm{t}} \mathrm{C} \varphi_{n}=\mathrm{C}_{\mathrm{n}} \quad \varphi_{n}^{\mathrm{t}} \mathrm{K} \varphi_{\mathrm{n}}=\mathrm{K}_{\mathrm{n}} \quad \varphi_{\mathrm{n}}^{\mathrm{t}} \mathrm{Ml}=\mathrm{L}_{\mathrm{n}}
$$

and 


$$
\frac{C_{n}}{M_{n}}=2 \zeta_{n} \omega_{n} \quad \frac{K_{n}}{M_{n}}=\omega_{n}^{2} \quad \frac{L_{n}}{M_{n}}=\Gamma_{n}
$$

Dividing Equation (2.31) by $M_{n}$ gives

$$
\ddot{q}_{n}(t)+2 \zeta_{n} \omega_{n} \dot{q}_{n}(t)+\omega_{n}^{2} q_{n}(t)=-\Gamma_{n} \ddot{u}_{g}(t)
$$

The equation for the $\mathrm{n}^{\text {th }}$ mode of the MDOF system can be expressed as

$$
\ddot{D}_{n}(t)+2 \zeta_{n} \omega_{n} \dot{D}_{n}(t)+\omega_{n}^{2} D_{n}(t)=-\ddot{u}_{g}(t)
$$

where $D_{n}(t)=\frac{q_{n}(t)}{\Gamma_{n}}$

The lateral forces in the $\mathrm{n}^{\text {th }}$ mode dynamic response are given by

$$
\mathbf{f}_{\mathrm{n}}(\mathrm{t})=\mathbf{K} \mathbf{u}_{\mathrm{n}}(\mathrm{t})
$$

Substituting $\mathbf{u}_{n}(t)=\varphi_{n} q_{n}(t)$ in Equation (2.37) gives

$$
f_{n}(t)=K \varphi_{n} q_{n}(t)
$$

Since $K \varphi_{n}=\omega_{n}^{2} \mathbf{M} \varphi_{n}$ Equation (2.38) becomes

$\mathbf{f}_{n}(t)=\omega_{n}^{2} \mathbf{M} \varphi_{n} q_{n}(t)$

Since $q_{n}(t)=\Gamma_{n} D_{n}(t)$ Equation (2.39) becomes

$$
\mathbf{f}_{n}(t)=\Gamma_{n} \mathbf{M} \varphi_{n} \omega_{n}^{2} D_{n}(t)
$$

Substituting $A_{n}(t)=\omega_{n}^{2} D_{n}(t)$ in Equation (2.40) and using Equation (2.32) we get

$$
\mathbf{f}_{n}(t)=S_{n} A_{n}(t)
$$


where $A_{n}(t)$ is the pseudo spectrum acceleration obtained from the design elastic spectrum

The contribution of the $\mathrm{n}^{\text {th }}$ mode to any response parameter $\mathrm{r}(\mathrm{t})$ will be obtained by static analysis or linear modal pushover analysis of the structure subjected to the equivalent static forces of the $n^{\text {th }}$ mode $\mathbf{f}_{n}(t)$.

As illustrated in Figure 2.9 when a static analysis is carried out using the $\mathrm{n}^{\text {th }}$ mode force distribution $\mathbf{S}_{\mathbf{n}}$ the static value of any response parameter in the $n^{\text {th }}$ mode, $r_{n}^{\text {st }}$ will be obtained and the contribution of the $\mathrm{n}^{\text {th }}$ mode to the dynamic response will be given by the product of the static response and the pseudo spectral acceleration

$\mathrm{r}_{\mathrm{n}}=\mathrm{r}_{\mathrm{n}}^{\mathrm{st}} \mathrm{A}_{\mathrm{n}}(\mathrm{t})$

The static base shear $V_{b n}^{\text {st }}$ in the $n^{\text {th }}$ mode is given by the summation of all the elements of the force vector $\mathbf{S}_{\mathbf{n}}$

$$
\begin{aligned}
& \mathrm{V}_{\mathrm{bn}}^{\mathrm{st}}=\mathbf{S}_{\mathrm{n}}^{\mathrm{T}} \mathbf{l} \\
& \mathrm{V}_{\mathrm{bn}}^{\mathrm{st}}=\Gamma_{\mathrm{n}} \boldsymbol{\varphi}_{\mathrm{n}}^{\mathrm{t}} \mathbf{M l}=\Gamma_{\mathrm{n}} L_{\mathrm{n}}=M_{\mathrm{n}}^{*}
\end{aligned}
$$

We call the static base shear $\mathrm{V}_{\mathrm{bn}}^{\text {st }}$ in the $n^{\text {th }}$ mode the effective modal mass $M_{n}^{*}$ which is one of the most important parameters for any given mode shape. The effective modal mass gives an indication of the contribution of a mode shape to any of the response parameters. Mode shapes with large effective modal masses will make significant contribution in all the response parameters. Mode shapes with relatively small effective 
modal masses can be neglected in the multi-modal pushover analysis because they will not make much contribution to any of the response parameters.

A modal pushover analysis for elastic systems can be carried out by:

1- Obtaining the effective modal mass from Equation (2.43) for any $\mathrm{n}^{\text {th }}$ mode.

2- Multiplying the effective modal mass by the spectral acceleration obtained from the acceleration period format of the elastic design spectrum in order to calculate the contribution of the $\mathrm{n}^{\text {th }}$ mode to the base shear.

3- Running an elastic static analysis (pushover analysis) using the contribution of the $\mathrm{n}^{\text {th }}$ mode $\mathbf{S}_{\mathbf{n}}$ to the spatial distribution of the effective earthquake forces $\mathbf{M l}$ until we get the base shear obtained in the previous step.

4- Finding from the pushover data base the contribution of the $\mathrm{n}^{\text {th }}$ mode to any response parameter we are interested in corresponding to the base shear obtained earlier.

\subsubsection{Modal pushover analysis for inelastic symmetric buildings}

The main problem in dealing with the equations of motions for inelastic systems is the fact that the stiffness matrix changes when structures start to experience inelastic deformation. Consequently the mode shapes change as well through out the analysis. Even if one assumed that the mode shapes do not change when structures experience inelastic deformation, the change in the stiffness matrix will make the equations of motion coupled in the modal coordinates. 
The equations of motion for inelastic systems are given by

$$
M \ddot{u}+C \dot{u}+f_{s}(u, s i g n \dot{u})=M i \ddot{u}_{g}(t)
$$

The history of lateral forces $\mathbf{f}_{\mathbf{s}}$ generated in an inelastic system due to a ground motion record will depend on the ground motion history and the extent of inelasticity experienced by the structure. For that reason the lateral forces $\mathbf{f}_{\mathbf{s}}$ cannot be expressed any longer as the product of a constant stiffness matrix and a displacement vector. Instead they would be expressed as a function of the displacement vector and the state of the structure in its response history as shown in Equation (2.44).

If the mode shapes are assumed not to change and the equations of motions are transformed into the modal coordinates the equations of motions in the modal coordinates become

$$
\ddot{q}_{n}(t)+2 \zeta_{n} \omega_{n} \dot{q}_{n}(t)+\frac{F_{S_{n}}}{M_{n}}=-\Gamma_{n} \ddot{u}_{g}(t)
$$

in which $\mathrm{F}_{\mathrm{sn}}$ is a function of all the modal coordinates and the equations of motion stay coupled. In order to solve the coupling problem Chopra (2002) developed the UMRHA procedure, an uncoupled modal response history analysis in which it is assumed that $F_{\mathrm{sn}}$ will still be a function of only one modal coordinate, or in another words, the equations of motions for inelastic systems will still be uncoupled similar to that for elastic systems. In order to evaluate the errors associated with that approximation Chopra carried out the nonlinear time history analyses using each modal contribution to the effective earthquake forces, $\mathbf{S}_{\mathrm{n}} \ddot{\mathrm{u}}_{\mathrm{g}}(\mathrm{t})$, and found that in an analysis the major contribution was still in the $\mathrm{n}^{\text {th }}$ 
mode;. the contribution from other modes was very small. Consequently, assumption that the modal equations of motions for inelastic systems can be treated as being uncoupled is a very reasonable approximation.

The equation for the $\mathrm{n}^{\text {th }}$ mode of a MDOF system can be expressed as

$\ddot{D}_{n}(t)+2 \zeta_{n} \omega_{n} \dot{D}_{n}(t)+\frac{F_{s n}}{L_{n}}=-\ddot{u}_{g}(t)$

When the coupling between the modes is neglected the force at yield for the $\mathrm{n}^{\text {th }}$ mode can be obtained from the inelastic response spectrum for the given ductility.

$\frac{F_{s n}^{y}}{L_{n}}=A_{n}^{y}=\omega_{n}^{2} D_{n}^{y}$

Thus the main approximations in the modal pushover analysis for inelastic systems and the UMRHA procedure are as follows

1- Mode shapes will not change and consequently modal transformation is possible.

2- The equations of motion in the modal coordinates are uncoupled.

3- The resultant response can be obtained by taking the square root of the sum of the squares of the modal responses.

\subsection{Subsequent iterations of design}

In order to obtain a more refined design, one or more iterations need to be performed after the preliminary design has been completed using more refined estimates for different design parameters obtained from the pushover analysis as well as the moment 
curvature analysis. The pushover curve provides the relationship between the roof displacement and the base shear. It is idealized by a bi-linear curve and provides the yield displacement $\Delta_{y}$. The moment-curvature analysis of the wall section gives the yield curvature $\varphi_{y}$ and the ultimate curvature $\varphi_{u}$. These parameters permit a more precise evaluation of the acceptable ultimate displacement. The limit corresponding to ductility capacity is obtained from Equation (2.13) with $\Delta_{y}$ equal to that obtained from the pushover analysis. The limit corresponding to code-specified value of storey drift is given by Equation (2.12) again with $\Delta_{y}$ obtained from the pushover analysis. The smaller of the two limits governs the design.

The ductility requirement is now determined and the inelastic demand spectrum corresponding to this value of ductility obtained. The MDOF system is converted to an equivalent SDOF system using the first mode. The yield and ultimate displacements of the SDOF are calculated. The intersection between the vertical from $\delta_{u}$ and the inelastic demand spectrum gives the performance point.

The inelastic spectral acceleration corresponding to the performance point, which is the intersection between the demand curve and the vertical through the ultimate displacement, times the effective modal mass, $\mathrm{M}^{*}$, gives a new base shear. The DBSD converges when this new base shear is close or equal to the yield base shear obtained from the pushover curve. If the difference between these two base shears is substantial, a new base moment must be calculated and the wall section redesigned. The process is repeated until convergence is achieved. 
When convergence is achieved the excursion into the zone of instability caused by P- $\Delta$ effect can be evaluated by taking the ratio of the base shear at maximum displacement to that at yield, and the design is modified if this excursion is too large. As mentioned earlier a 10 to $15 \%$ reduction in the base shear strength caused by P- $\Delta$ effect may be quite acceptable.

\subsection{Multi-mode pushover analysis}

On convergence the DBSD procedure based on the first mode provides a good estimate of the design moments and drifts. However, the shear forces are not accurate, and the contribution of higher modes must be considered for obtaining better estimates of such forces. The multi-mode pushover analysis (MPA) proposed by Chopra and Goel (2002, 2004) provides a simple and reasonably accurate method of considering the higher mode contribution. The MPA procedure uses pushover analyses based on the first few mode shapes, and combines the modal responses so obtained, assuming that they are uncoupled. In general the higher modes respond in an elastic manner. Thus the response of higher modes may be obtained from the elastic response spectra. The multi-mode pushover analysis is summarized as follows:

1- Obtain the peak response for different response parameters (base shear, roof displacement, maximum inter-storey drift ratio) from the nonlinear modal pushover analysis of the first mode shape. 
2- Calculate the effective modal mass for all the higher modes that make significant contribution in to any response parameter, and particularly to the shears.

3- Carry out a push over analysis for each higher mode included to determine the capacity diagram for that mode

4- Find the spectral acceleration for each higher mode included in the multi-modal pushover analysis by plotting the demand curve in the acceleration displacement format and determining the performance point from the intersection of the demand curve and the capacity curve determined in the previous step. Multiply the spectral acceleration by the effective modal mass to get the base shear. When the higher mode response is elastic the spectral acceleration can be determined from the elastic response spectral value corresponding to the period of the given mode.

5- Run the MPA for all the higher modes and obtain from the pushover data different response parameters corresponding to the base shear obtained earlier.

6- Combine the different response parameters for all the higher modes and for the first mode using the SRSS combination rule to obtain the total response for different response parameters.

7- The shear walls should be designed to carry the total base shear obtained from the multi-modal pushover analysis.

\subsection{Summary}

In this chapter two displacement based seismic design methods are developed. The first one is for a symmetric building (rotational torsion motion due to natural and accidental 
torsion are ignored) with multiple shear walls in which the shear walls have different sizes. The second one is for an unsymmetric torsionaly stiff building in which the building will experience both translational motion and rotational torsion motion around its center of mass at each floor level. The two buildings are designed to achieve the near collapse performance, keeping the ductility demand within ductility capacity and ensuring stability under P-Delta effects. The complete step by step design process for the two design methods is as follows:

\subsubsection{DBSD for symmetric buildings with different wall sizes}

1- Obtain a preliminary estimate for the yield and ultimate displacement from Equations (2.6), (2.12), (2.13) for all the shear walls.

2- Obtain the global yield displacement of the system by assuming that the strengths of walls are proportional to the wall length or the square of the wall length.

$$
\Delta_{y}=\frac{V_{b}}{\sum k_{i}}=\frac{V_{b}}{V_{y i} / \Delta_{y i}}
$$

3- Calculate the ductility requirement.

4- Assume the first mode shape is in the form of an inverted triangle and calculate the effective modal mass and the modal participation factor. Alternatively, since the relative stiffnesses of the walls are known a modal analysis could be performed to find the first mode shape.

5- Find the yield and ultimate displacements for the equivalent SDOF system of the first mode using Equations (2.16) and (2.17). 
6- Draw the inelastic demand spectrum in A-D format for the corresponding ductility obtained in step 3 and find from it the spectral acceleration corresponding to the ultimate displacement of the equivalent SDOF system of the first mode.

7- Calculate the base shear which is the product of the effective modal mass and the spectral acceleration.

8- Distribute this base shear along the height according to the product of the mass matrix and the assumed first mode shape and find the base moment. That base moment will be distributed over the walls in proportion to the square of the wall length.

9- Design the shear wall sections and carry out a moment curvature analysis. Obtain from the moment curvature analysis the effective inertia, the moment capacity of the walls and more refined estimates for the yield and ultimate curvature

10- Carry out a modal analysis and calculate the effective modal mass and the modal participation factor.

11-Run a nonlinear modal pushover analysis for the first mode and find the yield displacement and the base shear. If they are not close to the yield displacement and the base shear obtained from the preliminary design then additional iterations need to be carried out.

12- The new iteration will start by finding more refined estimates for the ultimate displacement using, yield curvature and ultimate curvature obtained in steps 9. Then using the yield displacement obtained in step 11 find a new estimate for the ductility capacity. 
13-Repeat steps from 5 to 12 until the base shear and yield displacement from to consecutive iterations become close.

14- After convergence carry out a multi-modal pushover analysis in order to consider the contribution of higher modes to different response parameters, especially the base shear.

\subsection{2. DBSD for unsymmetrical torsionaly stiff building}

1- Obtain a preliminary estimate for the yield and ultimate displacement from Equations (2.6), (2.12), (2.13) for all the shear walls.

2- Assume that the stiffness of any wall in the unsymmetric building is proportional to the wall length or the square of wall length, consequently the relative values of the wall stiffnesses will be known. Using the relative stiffness values carry out a modal analysis to find the mode shapes.

3- Find the yield and target displacements at the center of mass considering each wall in turn and using Equations (2.19) and (2.20).

4- Considering that the wall strengths are proportional to the wall lengths the effective yield displacement is obtained from.

$$
\begin{aligned}
& \mathrm{k}_{\text {eff }}=\sum \frac{\mathrm{V}_{\mathrm{i}}}{\Delta_{\mathrm{i}}} \\
& \Delta_{\text {yeff }}=\frac{\mathrm{V}}{\mathrm{k}_{\text {eff }}}
\end{aligned}
$$

5- Calculate the ductility requirement by taking the ratio of the target displacement and the yield displacement both measured at the center of mass. 
6- Find the yield and ultimate displacement for the equivalent SDOF system of the first mode using Equation (2.21).

7- Draw the inelastic demand spectrum for the ductility obtained in step 5 and find from it the spectral acceleration corresponding to the ultimate displacement of the equivalent SDOF system of the first mode.

8- Calculate the base shear which will be the product of the effective modal mass and the spectral acceleration.

9- Distribute the base shear obtained in step 8 across the height in proportion to $\mathbf{M} \boldsymbol{\varphi}_{1}$. Obtain the base moments produced by these forces.

10- Design the shear wall sections and carry out a moment curvature analysis. Obtain from the moment curvature analysis the effective inertia, the moment capacity of the walls and more refined estimates for the yield and ultimate curvature

11- Carry out modal analysis and calculate the effective modal mass and the modal participation factor.

12-Run a nonlinear modal pushover analysis for the first mode and find the yield displacement for each wall and the yield displacement at the center of mass corresponding to it and also the base shear. If these parameters are close to the values obtained earlier, the design has converged, otherwise further iterations must be performed

13- A new iteration will start by finding a more refined estimate for the yield displacement obtained from the modal push over analysis and a better estimate for the ultimate displacement using more refined estimates for the, yield curvature and 
ultimate curvature obtained from the moment curvature analysis. Find a new estimate for the ductility capacity.

14- Find the yield and ultimate displacement for the equivalent SDOF system of the first mode using Equations (2.21).

15-Draw the inelastic demand spectrum for the ductility obtained in step 13 and find from it the spectral acceleration corresponding to the ultimate displacement of the equivalent SDOF system of the first mode.

16-Calculate the base shear which will be the product of the effective modal mass and the spectral acceleration.

17- Run a modal pushover analysis until the base shear obtained in the previous step is reached. From the pushover data base obtain the design moments.

18-Design the shear wall sections and carry out a moment curvature analysis. Obtain from the moment curvature analysis the effective inertia, the moment capacity of the walls and more refined estimates for the yield and ultimate curvature

19- Carry out a modal analysis and calculate the effective modal mass and the modal participation factor.

20-Run the nonlinear modal pushover analysis for the first mode and find the yield displacement for each wall and the corresponding yield displacement at the center of mass and also the base shear.

21-Repeat steps from 13 to 20 until the base shear and yield displacement from two consecutive iterations become very close. 
22-After convergence carry out a multi-modal pushover analysis in order to consider the contribution of higher modes to different response parameters, especially the base shear. 

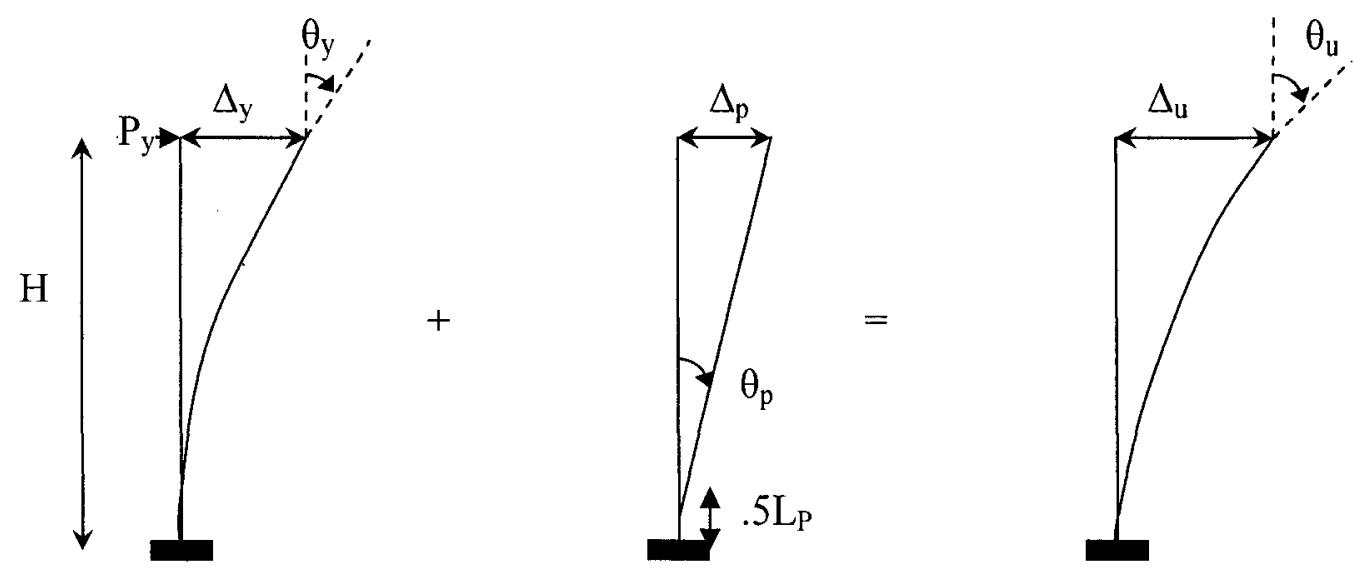

Figure 2.1: Yield, plastic and ultimate displacement and rotations for a cantilever shear wall
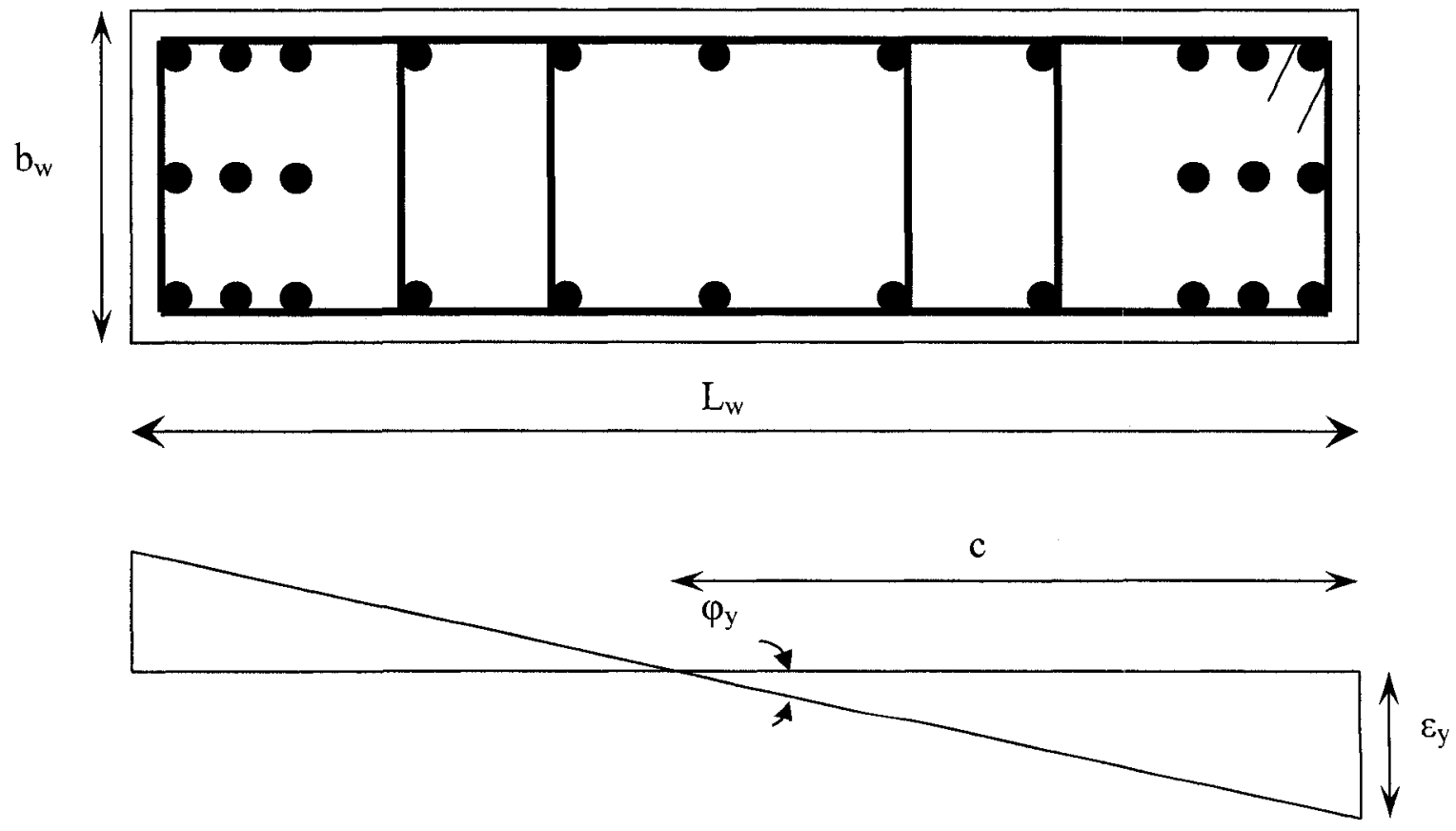

Figure 2.2: Shear wall section 


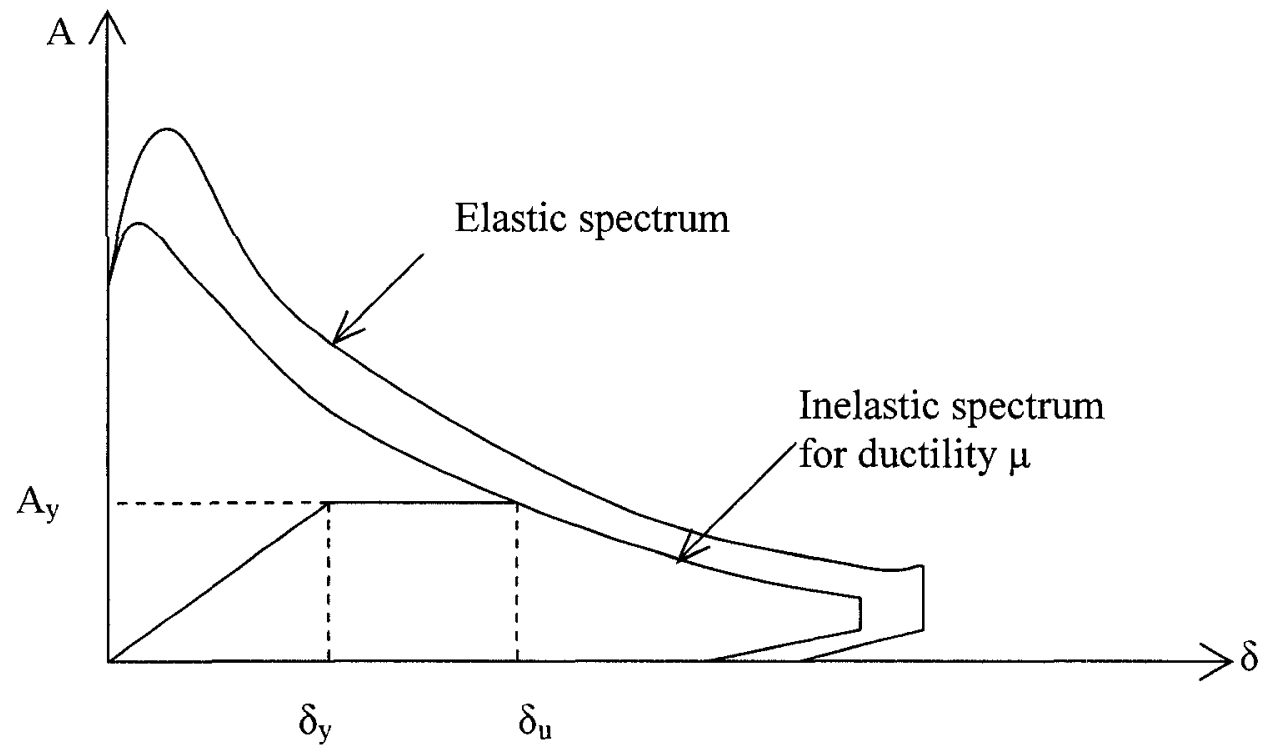

Figure 2.3: Demand and capacity diagram for equivalent SDOF system.
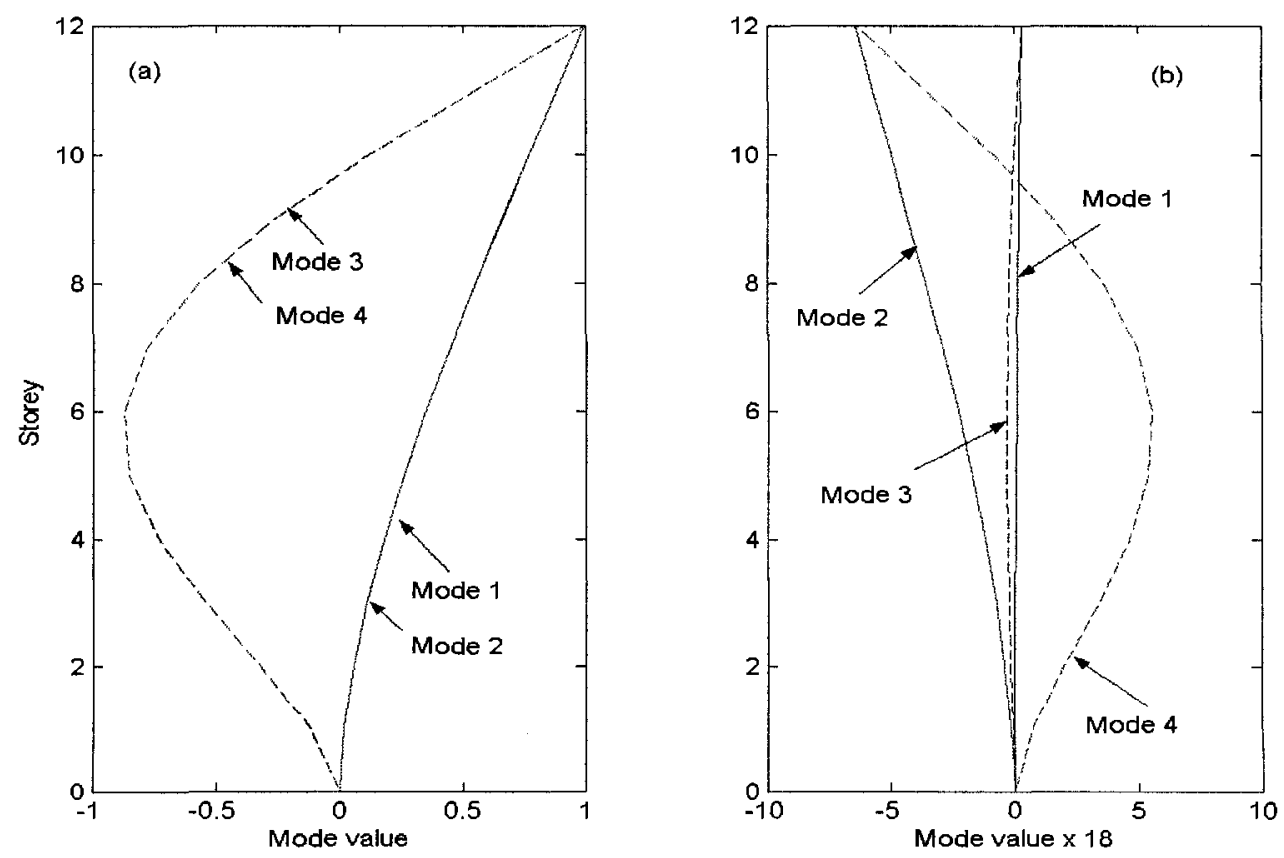

Figure 2.4: Mode shapes of unsymmetric torsionaly stiff building: (a) lateral displacement component, (b) rotation angle $\mathrm{x} b / 2$ 


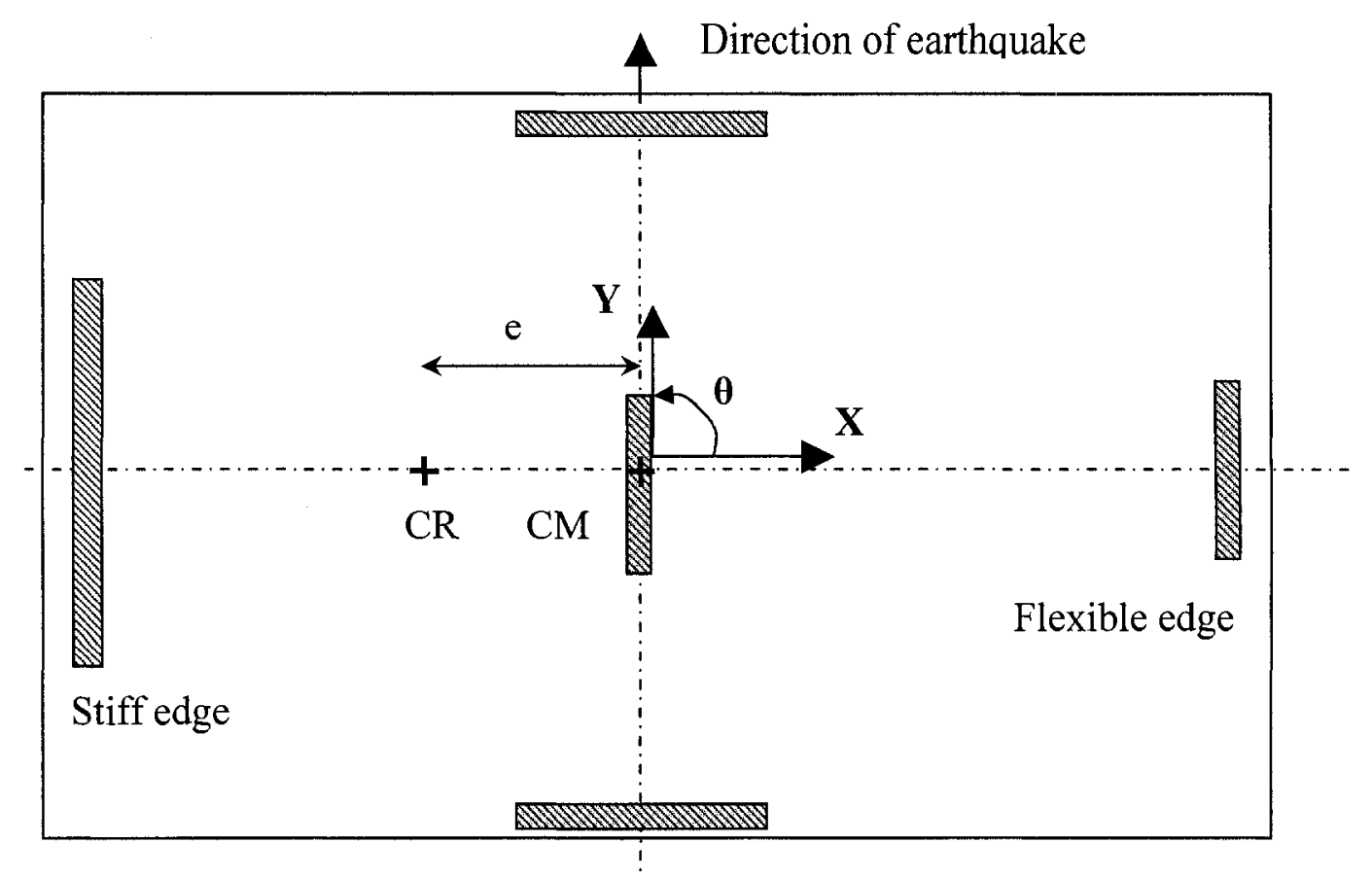

Figure 2.5: Plan view of unsymmetric shear wall building

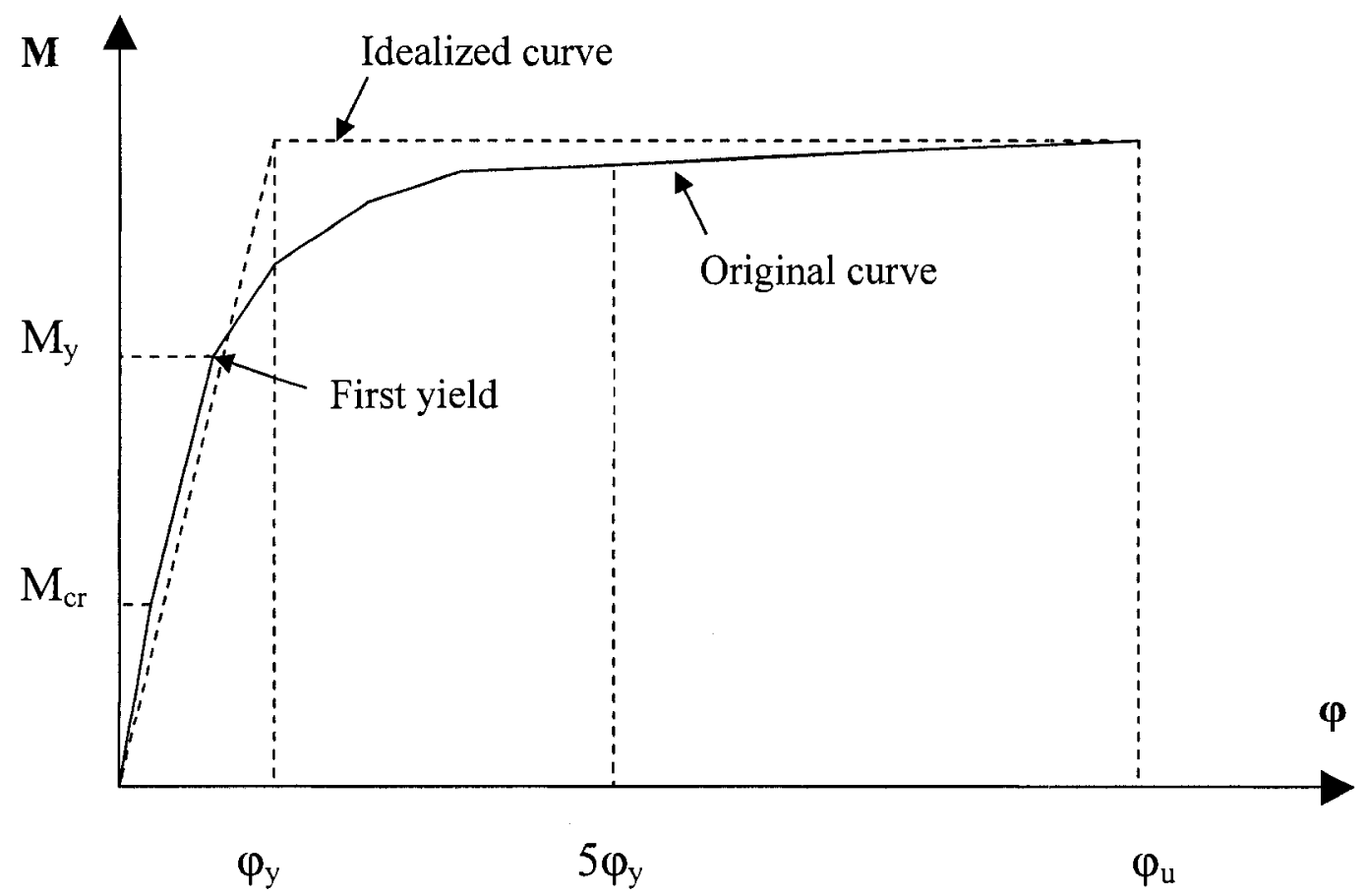

Figure 2.6: Moment curvature relationship adapted from (Yavari 2001) 




Figure 2.7: Idealized stress-strain curve for concrete in uniaxial compression

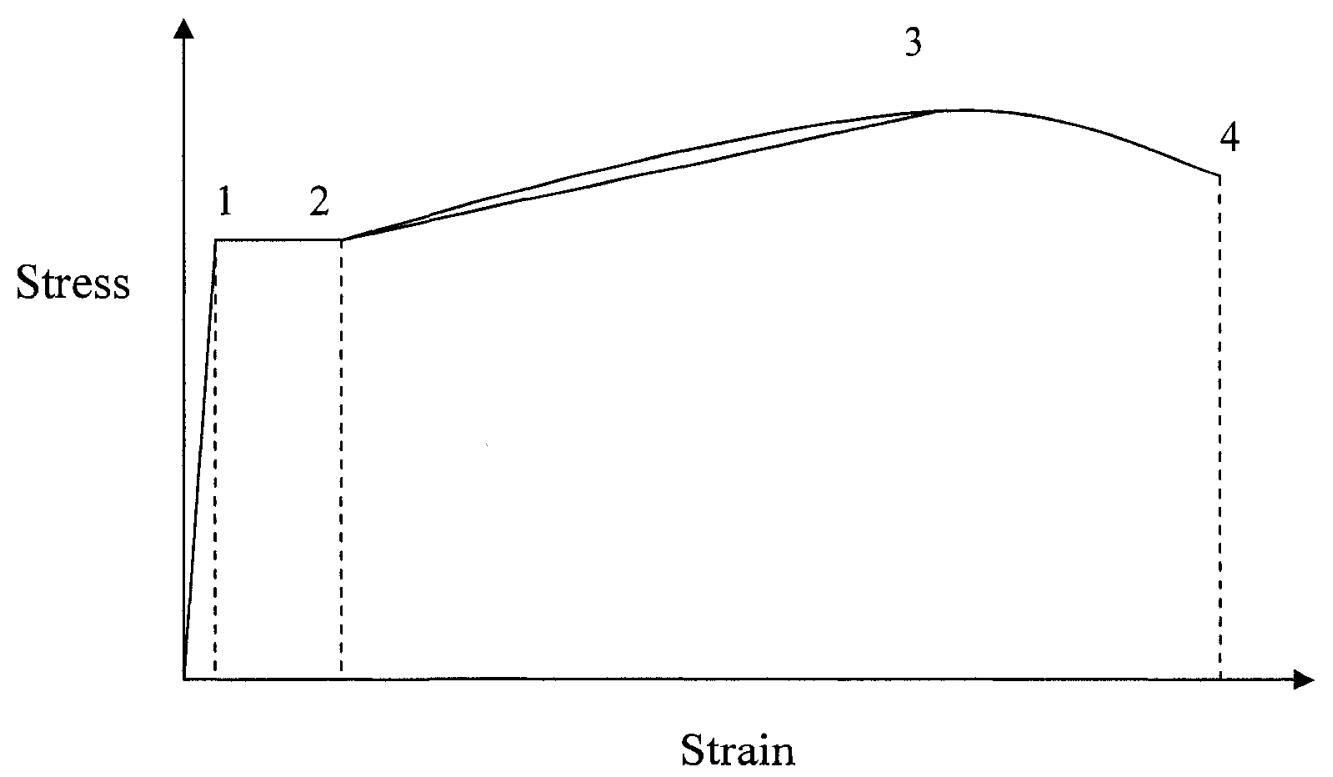

Figure 2.8: Realistic tri-linear stress-strain relationship for reinforcing steel 


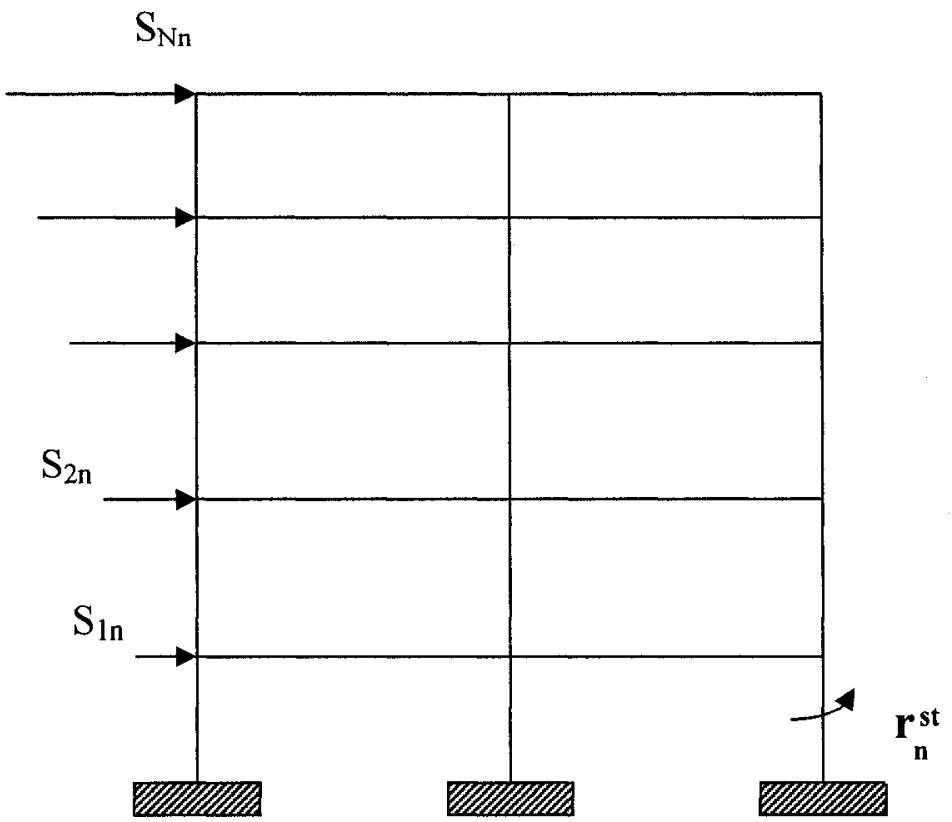

Figure 2.9: Static response of the $\mathrm{n}^{\text {th }}$ mode 


\section{Chapter 3}

\section{Applications of the Displacement-based seismic design methods developed in this thesis}

\subsection{Introduction}

This Chapter describes applications of the displacement-based seismic design methods developed in Chapter 2 in the design of two different 12-storey shear wall buildings. The first one is for a symmetric building (rotational motion due to natural and accidental torsion is ignored) with multiple shear walls in which the shear walls have different sizes. The second one is for an unsymmetric torsionaly stiff building in which the building will experience both translational motion and rotational torsion motion around its center of mass at each floor level. The two buildings will be designed to achieve the near collapse performance level, keeping the ductility demand within ductility capacity and ensuring stability under P-Delta effects. The two buildings are assumed to be located in Vancouver city on a site of class C as defined in the NBCC 2005. The modal analysis and modal push-over analysis for the symmetric building were carried out using a three dimensional model and the computer program Opensees (www.opensees.berkeley.edu) and a two dimensional model along with computer program Drain2Dx (Prakash et al.1993). Identical results were obtained from the two programs. Only three dimensional models 
can be used in the design and analysis of an unsymmetric building, consequently only the computer program Opensees was used to carry out the modal analysis and modal pushover analysis for the unsymmtric torsionally stiff building.

\subsection{Displacement based design for a 12-storey symmetric building}

\subsubsection{Building description}

The building shown in Figure 3.1, located in Vancouver city, is 12 storeys high and has three bays, each $8 \mathrm{~m}$ wide, in the E-W direction. In the N-S direction there are 6 bays each $6 \mathrm{~m}$ wide. The first storey is $4.85 \mathrm{~m}$ in height, all other storeys are $3.65 \mathrm{~m}$. The structural framing consists of $200 \mathrm{~mm}$ thick RC flat slab resting on $500 \times 500 \mathrm{RC}$ columns. Lateral resistance in the E-W direction is provided by $3 \mathrm{RC}$ shear walls located in the $2^{\text {nd }}, 4^{\text {th }}$, and $6^{\text {th }}$ framing lines. The walls are $6 \mathrm{~m}, 4 \mathrm{~m}$, and $6 \mathrm{~m}$ long, respectively, and are assumed to be $400 \mathrm{~mm}$ thick for the first pass of design.

\subsubsection{Load definition}

\section{Dead load}

Partitions

Electrical, mechanical, ceiling
$0.5 \mathrm{kN} / \mathrm{m}^{2}$

$0.5 \mathrm{kN} / \mathrm{m}^{2}$ 


$$
\text { Roof insulation and water proofing } \quad 0.5 \mathrm{kN} / \mathrm{m}^{2}
$$

\section{Live load}

Snow load on roof

Floor load
$2.2 \mathrm{kN} / \mathrm{m}^{2}$

$2.4 \mathrm{kN} / \mathrm{m}^{2}$

\subsubsection{Material properties}

\section{Concrete}

Concrete strength $f_{c}$

Strain corresponding to $f_{c}, \varepsilon_{0}$

Performance factor of concrete $\varphi_{\mathrm{c}}$

Factored rupture strength of concrete $f_{\text {cr }}$

Modulus of elasticity of concrete $E_{c}$

Self weight, $\gamma_{\mathrm{rc}}$
$30 \mathrm{MPa}$

0.002

0.6

$3.29 \mathrm{MPa}$

$24,500 \mathrm{MPa}$

$24 \mathrm{KN} / \mathrm{m}^{3}$

\section{Steel}

Steel yield strength $\mathrm{f}_{\mathrm{y}}$

$400 \mathrm{MPa}$

Performance factor of steel $\varphi_{y}$

Steel strain at onset of strain hardening $\varepsilon_{\mathrm{st}} \quad 0.02$ 
Modulus of elasticity of steel $E_{s}$

$200,000 \mathrm{MPa}$

Factored ultimate steel strength $f_{\text {su }}$

$600 \mathrm{MPa}$

\subsubsection{Load calculations}

\subsubsection{Floor dead load}

Slab

$$
\frac{200 \times 24}{1000}=4.8
$$

Partitions

0.5

Ceiling, mechanical, electrical.

0.5

Total

$5.8 \mathrm{kN} / \mathrm{m}^{2}$

The roof dead load is also $5.8 \mathrm{kN} / \mathrm{m}^{2}$ since partition load is replaced by an equal amount of insulation and roofing load.

\subsubsection{Load due to self weight}

$$
\begin{aligned}
& \text { Floor columns } \quad \frac{22 \times 0.5 \times 0.5 \times 3.65 \times 24}{36 \times 24}=0.558 \mathrm{kN} / \mathrm{m}^{2} \\
& 1^{\text {st }} \text { level columns } \quad \frac{22 \times 0.5 \times 0.5 \times 4.25 \times 24}{36 \times 24}=0.649 \mathrm{kN} / \mathrm{m}^{2} \\
& \text { Roof columns } \\
& \frac{22 \times 0.5 \times 0.5 \times 1.825 \times 24}{36 \times 24}=0.279 \mathrm{kN} / \mathrm{m}^{2}
\end{aligned}
$$




$$
\begin{array}{ll}
\text { Floor walls } & \frac{16 \times 0.4 \times 3.65 \times 24}{36 \times 24}=0.649 \mathrm{kN} / \mathrm{m}^{2} \\
1^{\text {st }} \text { level walls } & \frac{16 \times 0.4 \times 4.25 \times 24}{36 \times 24}=0.756 \mathrm{kN} / \mathrm{m}^{2} \\
\text { Roof level walls } & \frac{16 \times 0.4 \times 1.825 \times 24}{36 \times 24}=0.324 \mathrm{kN} / \mathrm{m}^{2}
\end{array}
$$

\subsubsection{Total dead load and mass for each floor}

The dead load for each floor will be due to the weight of columns, walls, concrete slabs and floor cover. The snow load is taken as $25 \%$ of the specified value and added to the weight of the roof.

$\begin{array}{llll}\text { Roof dead load } & 0.25 \times 2.2+0.279+0.324+5.8=6.95 \mathrm{kN} / \mathrm{m}^{2} & \text { Total } & 6007.4 \mathrm{kN} \\ \text { Floor dead load } & 0.558+0.649+5.8=7.01 \mathrm{kN} / \mathrm{m}^{2} & \text { Total } & 6054.0 \mathrm{kN} \\ \text { First level dead } & 0.649+0.756+5.8=7.21 \mathrm{kN} / \mathrm{m}^{2} & \text { Total } & 6225.1 \mathrm{kN}\end{array}$

Total dead load $6007.4+10 \times 6054.0+6225.1=72772.5 \mathrm{kN}$

Total mass $=7418.2$ tonne

The dead loads and masses for each floor level are shown in Table 3.1 


\subsubsection{Gravity load calculation for each wall}

The tributary area that will contribute gravity load on each shear wall is $96 \mathrm{~m}^{2}$. The dead loads estimates are shown in the following

\section{6-meter wall}

$\begin{array}{ll}\text { Bottom of top storey } & 96 \times 5.8+0.4 \times 6 \times 3.65 \times 24+0.25 \times 2.2 \times 96=819.8 \mathrm{kN} \\ \text { Bottom of typical storey } & 96 \times 5.8+0.4 \times 6 \times 3.65 \times 24=767.0 \mathrm{kN} \\ \text { Base level } & 96 \times 5.8+0.4 \times 6 \times 4.85 \times 24=836.2 \mathrm{kN}\end{array}$

\section{4-meter wall}

$\begin{array}{ll}\text { Bottom of top storey } & 96 \times 5.8+0.4 \times 4 \times 3.65 \times 24+0.25 \times 2.2 \times 96=749.8 \mathrm{kN} \\ \text { Bottom of typical storey } & 96 \times 5.8+0.4 \times 4 \times 3.65 \times 24=697.0 \mathrm{kN} \\ \text { Base level } & 96 \times 5.8+0.4 \times 4 \times 4.85 \times 24=743.0 \mathrm{kN}\end{array}$

The live load will act on the same $96 \mathrm{~m}^{2}$ tributary area and will be reduced by the live load reduction factor LLRF defined in the NBCC 2005 by:

$\mathrm{LLRF}=.3+\sqrt{\frac{9.8}{\mathrm{CA}_{\text {trib }}}}$ 
where $\mathrm{CA}_{\text {trib }}$ is the cumulative tributary area in $\mathrm{m}^{2}$. Two different load combinations will be used in the design of the shear walls $1.25 \mathrm{D}+1.5 \mathrm{~L}$ and $\mathrm{D}+0.5 \mathrm{~L}+\mathrm{E}$. The gravity load calculations and load combinations for the two $6 \mathrm{~m}$ walls and the $4 \mathrm{~m}$ wall are shown in Table 3.2, Table 3.3 and Table 3.4.

\subsubsection{Axial load for P-delta effect}

The effective yield and ultimate displacement based on P- $\Delta$ instability can be worked out from a pushover analysis. For carrying out the pushover analysis with $\mathrm{P}-\Delta$ effect included we need the dead load as well as the live load reduced by tributary area reduction factor as in the previous section. The dead loads for each floor level were determined earlier, the live load calculations are presented in Table 3.5 in which the tributary area at each level is taken as the area of the entire floor. In calculating the axial gravity loads for P- $\Delta$ effect the $\mathrm{D}+.5 \mathrm{~L}$ load combination will be used.

\subsubsection{Preliminary design}

\subsubsection{Yield displacement and curvature}

6-meter wall

$$
\begin{aligned}
& \phi_{y}=\frac{2 \varepsilon_{y}}{1_{w}}=\frac{2 \times 400 \times 0.85}{200000 \times 6000}=5.67 \times 10^{-7} \\
& \Delta_{y}=\frac{\phi_{y} H^{2}}{3}=\frac{5.670 \times 10^{-7} \times 45000^{2}}{3}=382.7 \mathrm{~mm}
\end{aligned}
$$


4-meter wall

$$
\begin{aligned}
& \phi_{y}=\frac{2 \varepsilon_{y}}{l_{w}}=\frac{2 \times 400 \times 0.85}{200000 \times 4000}=8.5 \times 10^{-7} \\
& \Delta_{y}=\frac{\phi_{y} H^{2}}{3}=\frac{8.5 \times 10^{-7} \times 45000^{2}}{3}=573.8 \mathrm{~mm}
\end{aligned}
$$

The designer has certain flexibility in assigning the relative wall strengths. When wall strengths are taken as being proportional to the square of the wall length the steel ratios in the different walls are approximately equal. In this example we assume that the strengths of walls are proportional to the square of the wall length. Thus the strength of each 6meter wall is $0.409 V_{b}$, and the strength of 4-meter wall is $0.182 \mathrm{~V}_{\mathrm{b}}$, where $\mathrm{V}_{\mathrm{b}}$ is the total

design base shear. Considering that the three walls can be represented by springs in parallel, the yield displacement of the system may be calculated as follows:

$$
\Delta_{\mathrm{y}}=\frac{\mathrm{V}_{\mathrm{b}}}{\sum \mathrm{k}_{\mathrm{i}}}=\frac{\mathrm{V}_{\mathrm{b}}}{\mathrm{V}_{\mathrm{yi}} / \Delta_{\mathrm{yi}}}=\frac{\mathrm{V}_{\mathrm{b}}}{0.409 \mathrm{~V}_{\mathrm{b}} / 382.7+0.182 \mathrm{~V}_{\mathrm{b}} / 573.8+0.409 \mathrm{~V}_{\mathrm{b}} / 382.7}=407.4
$$

\subsubsection{Ultimate displacement}

\subsection{Limit on storey drift}

The ultimate roof displacement to satisfy the storey drift limit is given by

$$
\Delta_{\mathrm{u}}=\frac{\phi_{\mathrm{y}} \mathrm{h}_{\mathrm{w}}^{2}}{3}+\left(\mathrm{h}_{\mathrm{w}}-\frac{\mathrm{L}_{\mathrm{p}}}{2}\right)\left(0.025-\frac{\phi_{\mathrm{y}} \mathrm{h}_{\mathrm{w}}}{2}\right)
$$


When we assume that $L p=1_{w} / 2$ and substitute the values of all the other parameters for the $6 \mathrm{~m}$ wall in the previous equation we get

$$
\Delta_{u}=915.3 \mathrm{~mm}
$$

On the other hand, if we use the data for 4-meter wall we get

$$
\Delta_{u}=832.3 \mathrm{~mm}
$$

\subsection{Limit on ductility capacity}

This limit depends on the maximum concrete strain that can be accepted. If the concrete is treated as being unconfined, a strain limit of 0.004 may be considered as being appropriate. The ultimate roof displacement to satisfy the limit on ductility capacity is given by

$$
\Delta_{u}=\frac{\phi_{y} h_{w}^{2}}{3}+\left(h_{w}-\frac{L_{p}}{2}\right)\left(\phi_{u}-\phi_{y}\right) L_{p}
$$

The ultimate curvature $\varphi_{\mathbf{u}}$ is calculated by assuming that the neutral axis depth is $0.31_{\mathrm{w}}$ and is given by

$$
\phi_{u}=\frac{0.004}{0.31_{w}}
$$

\section{6-meter wall}

For a concrete strain of 0.004 we get $\phi_{u}=2.22 \times 10^{-6}$ and $\Delta_{u}=598.7 \mathrm{~mm}$

\section{4-meter wall}

For a concrete strain of 0.004 we get $\phi_{u}=3.333 \times 10^{-6}$ and $\Delta_{u}=792.3 \mathrm{~mm}$ 


\subsubsection{Ductility demand}

We base the design on a yield displacement of $407.4 \mathrm{~mm}$ and ultimate displacement of $598.7 \mathrm{~mm}$; the corresponding value of ductility demand is $\mu=\frac{598.7}{407.4}=1.47$

\subsubsection{Equivalent SDOF system}

To obtain the capacity diagram for the first mode equivalent SDOF system, we assume the first mode shape to be in the form of an inverted triangle. Thus

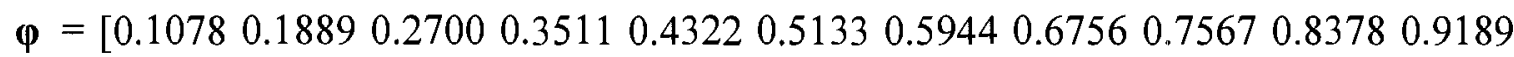
$1.0000]^{\mathrm{T}}$

The diagonal of the mass matrix is $\left[\begin{array}{llllllllllll}634.6 & 617.1 & 617.1 & 617.1 & 617.1 & 617.1 & 617.1 & 617.1 & 617.1 & 617.1 & 617.1 & 612.4\end{array}\right]$ tonne The participation factor and participating mass for the first mode equivalent SDOF system are given by

$$
\begin{aligned}
& \Gamma=\frac{\varphi^{\mathrm{T}} \mathbf{M} 1}{\varphi^{\mathrm{T}} \mathbf{M} \varphi}=1.440 \\
& \mathrm{M}^{*}=\frac{\left(\varphi^{\mathrm{T}} \mathbf{M} 1\right)^{2}}{\varphi^{\mathrm{T}} \mathbf{M} \varphi}=5899.4
\end{aligned}
$$

The participating mass of the first mode equivalent SDOF system is $79.5 \%$ of the total mass of 7418.2 tonne of the building.

The yield and ultimate displacement of the first mode equivalent SDOF system are given by 


$$
\begin{aligned}
& \delta_{y}=\frac{\Delta_{y}}{\Gamma}=\frac{407.4}{1.44}=282.9 \mathrm{~mm} \\
& \delta_{u}=\frac{\Delta_{u}}{\Gamma}=\frac{598.7}{1.44}=415.8 \mathrm{~mm}
\end{aligned}
$$

\subsubsection{Seismic demand}

The seismic demand is represented by the UHS for Vancouver as given by NBCC 2005 .

The demand and capacity diagrams are plotted in Figure 3.2 in A-D format. From this diagram the design base shear, without accounting for any overstrength, is given by

$$
\mathrm{V}=0.0552 \times 9.81 \times 5899.4=3194.6 \mathrm{kN}
$$

When this base shear is distributed according to the inverted triangle shape we get a design base moment of $99,884 \mathrm{kNm}$. The 6-meter wall should thus be designed for moment of $0.409 \times 99,884=40,850 \mathrm{kNm}$, and the 4-meter wall should be designed for a moment of $0.182 \times 99,884=18,180 \mathrm{kNm}$

\subsubsection{Design of shear wall sections}

\section{6-m wall}

We design the 6-m wall for combination of a base moment of $40,850 \mathrm{kNm}$ and axial load of $9827.8 \mathrm{kN}$ obtained from the $\mathrm{D}+0.5 \mathrm{~L}$ load combination. We provide concentrated reinforcement consisting of two outer layers of $3000 \mathrm{~mm}^{2}$ and a third layer of $2100 \mathrm{~mm}^{2}$. In addition we provide on each face $10 \mathrm{~mm}$ vertical bars spaced at $200 \mathrm{~mm}$. This gives 
the moment-curvature diagram shown in Figure 3.3 and the following parameters are obtained:

Moment capacity, $\mathrm{M}_{\mathrm{c}}$

Yield curvature, $\varphi_{y}$

Ultimate curvature, $\varphi_{u}$

The ratio between the effective moment of inertia

and the gross moment of inertia
$40,610 \mathrm{kN} \mathrm{m}$

$5.919 \times 10^{-7}$ per $\mathrm{mm}$

$2.150 \times 10^{-6}$ per $\mathrm{mm}$

0.389

\section{4-m wall}

We design the 4-m wall for combination of a base moment of $18,180 \mathrm{kNm}$ and axial load of $8,965.5 \mathrm{kN}$ obtained from the $\mathrm{D}+0.5 \mathrm{~L}$ load combination. We provide concentrated reinforcement consisting of one outer layer of $2100 \mathrm{~mm}^{2}$ and two additional layers of $1500 \mathrm{~mm}^{2}$. In addition we provide on each face $10 \mathrm{~mm}$ vertical bars spaced at $200 \mathrm{~mm}$. This gives the moment-curvature diagram shown in Figure 3.4 and the following parameters are obtained:

Moment capacity, $\mathrm{M}_{\mathfrak{c}}$

$18,800 \mathrm{kNm}$

Yield curvature, $\varphi_{\mathrm{y}}$

$9.31 \times 10^{-7}$ per $\mathrm{mm}$

Ultimate curvature, $\varphi_{u}$

$2.475 \times 10^{-6}$ per mm

The ratio between the effective moment of inertia

and the gross moment of inertia

0.387 


\subsubsection{First iteration}

For the next iteration in design we need new estimates of the yield and ultimate displacements. These are to be derived from the results of moment-curvature analyses described in section 3.2.5.6 and a push over analysis. For the latter we need the shape of the first mode.

A modal analysis, using the effective moments of inertia determined from momentcurvature relationships and not including P- $\Delta$ effect, gives the following properties:

$$
\begin{aligned}
& \mathrm{T}_{1}=4.107 \mathrm{~s} \\
& \boldsymbol{\varphi}_{1}^{\mathrm{T}}=\left[\begin{array}{llllllllllll}
.019 & .056 & .110 & .179 & .260 & .351 & .450 & .554 & .663 & .774 & .887 & 1.000
\end{array}\right] \\
& \Gamma_{1}=1.486 \\
& \mathrm{M}_{1}^{*}=4855 \mathrm{kN}
\end{aligned}
$$

A modal push-over analysis is carried out for lateral load distribution corresponding to the first mode; the pushover curve is shown in Figure 3.5. The yield displacement is seen to be $390 \mathrm{~mm}$. The idealized curve including the effect of P- $\Delta$, shown by the dashed line, shows that the maximum base shear strength is approximately $2,600 \mathrm{kN}$. If a $10 \%$ reduction in the strength is assumed as the limit beyond which instability may result, the limit strength works out to $2,340 \mathrm{kN}$ and the corresponding displacement is $650 \mathrm{~mm}$.

New estimates for the ultimate displacements of the two walls are obtained using the new estimates of the yield and ultimate curvatures obtained after designing the two walls according to the following equation. 
$\Delta_{u}=\frac{\phi_{y} h_{w}^{2}}{3}+\left(h_{w}-\frac{L_{p}}{2}\right)\left(\phi_{u}-\phi_{y}\right) L_{p}$

The ultimate displacement for the 6-meter wall works out to $603 \mathrm{~mm}$; the corresponding value for the 4-m wall is $764 \mathrm{~mm}$. In conclusion the governing ultimate displacement is $603 \mathrm{~mm}$, which is the least of the ultimate displacements of the two walls and the P-Delta instability limit of $650 \mathrm{~mm}$, and the ductility requirement are given by

$\mu=\frac{603}{390}=1.546$

The yield and ultimate displacements for the equivalent SDOF system are given by

$\delta_{\mathrm{y}}=\frac{\Delta_{\mathrm{y}}}{\Gamma}=\frac{390}{1.486}=262 \mathrm{~mm}$

$\delta_{u}=\frac{\Delta_{u}}{\Gamma}=\frac{603}{1.486}=406 \mathrm{~mm}$

The new demand and capacity curves are shown in Figure 3.6. The spectral acceleration at yield is observed to be $0.0508 \mathrm{~g}$. The required base shear strength is given by

$\mathrm{V}=0.0508 \times 9.81 \times 4855=2421 \mathrm{kN}$

The base shear is distributed across the height in proportion to $\mathbf{M} \phi_{1}$ where $\mathbf{M}$ is the mass matrix and $\phi_{1}$ is the first mode shape. The resulting base moment is $82,220 \mathrm{kNm}$. The design moment for the 6 -meter wall is $0.409 \times 82,220=33,630 \mathrm{kNm}$ and that for the 4-meter wall is $14,960 \mathrm{kNm}$. 


\section{6-m wall}

We provide concentrated reinforcement consisting of three outer layers of $2100 \mathrm{~mm}^{2}$. In addition we provide on each face $10 \mathrm{~mm}$ vertical bars spaced at $200 \mathrm{~mm}$. This gives the following parameters:

Moment capacity, $\mathrm{M}_{\mathrm{c}}$

Yield curvature, $\varphi_{\mathrm{y}}$

Ultimate curvature, $\varphi_{\mathrm{u}}$

The ratio between the effective moment of inertia

and the gross moment of inertia
$37,090 \mathrm{kNm}$

$5.944 \times 10^{-7}$ per $\mathrm{mm}$

$2.151 \times 10^{-6}$ per $\mathrm{mm}$

0.354

\section{4-m wall}

We provide concentrated reinforcement consisting of three outer layers of $1000 \mathrm{~mm}^{2}$. In addition we provide on each face $10 \mathrm{~mm}$ vertical bars spaced at $200 \mathrm{~mm}$. This gives the following parameters:

Moment capacity, $\mathrm{M}_{\mathrm{c}}$

Yield curvature, $\varphi_{\mathrm{y}}$

Ultimate curvature, $\varphi_{\mathrm{u}}$

The ratio between the effective moment of inertia

and the gross moment of inertia
$16,180 \mathrm{kNm}$

$9.36 \times 10^{-7}$ per $\mathrm{mm}$

$2.474 \times 10^{-6}$ per mm

0.331

The new estimate of governing ultimate displacement corresponds to a concrete strain of 0.004 in the 6-meter wall and does not change much, being $604 \mathrm{~mm}$. The yield displacement of the system obtained from the new MPA is $390 \mathrm{~mm}$ which is the same as 
determined earlier. The design process has thus converged. We now need to carry out a multi-modal pushover analysis using, say the first three modes, to determine more accurate values of the design base shears.

\subsubsection{Multi-modal pushover analysis}

It is unlikely that higher modes will cause any inelastic deformation to our system. In order to prove that we can run the modal pushover analysis for higher modes and find from it the base shear at yield, then compare it with the base shear obtained from the elastic response spectra for the corresponding period of each mode. As illustrated in Table 3.6 the base shear at yield for all higher mode is always larger than the base shear obtained from the elastic response spectra, consequently higher modes will not cause any inelastic deformation for the symmetric building and can always be treated as being elastic. Thus we can study the higher mode contribution to different response parameters by carrying out the modal pushover analysis for each mode until we get the base shear obtained from the elastic response spectra and find from the pushover data any response parameter we are interested in corresponding to that base shear. As shown in the Table 3.6 higher modes will make significant contribution in to the base shear and only a small contribution in to the roof displacement and maximum inter-storey drift ratio. 


\subsection{Displacement based design for a 12-storey unsymmetric building}

\subsubsection{Building description}

The building (Figure 3.7) located in Vancouver is 12 storeys high and has three bays, each $8 \mathrm{~m}$ wide, in the E-W direction. In the N-S direction there are 6 bays each $6 \mathrm{~m}$ wide. The first storey is $4.85 \mathrm{~m}$ high, all other storeys are $3.65 \mathrm{~m}$. The structural framing consists of $200 \mathrm{~mm}$ thick $\mathrm{RC}$ flat slab resting on $500 \times 500 \mathrm{RC}$ columns. Lateral resistance in the E-W direction is provided by $3 \mathrm{RC}$ shear walls located at the edges and the centre line. The walls are $7 \mathrm{~m}, 5 \mathrm{~m}$, and $5 \mathrm{~m}$ long, respectively, and are assumed to be $400 \mathrm{~mm}$ thick for the first pass of design. In the N-S direction there are 2 walls, each $7 \mathrm{~m}$ by $400 \mathrm{~mm}$ thick located at the edges.

\subsubsection{Load definition}

\section{Dead load}
Partitions
$0.5 \mathrm{kN} / \mathrm{m}^{2}$
Electrical, mechanical, ceiling
$0.5 \mathrm{kN} / \mathrm{m}^{2}$
Roof insulation and water proofing $\quad 0.5 \mathrm{kN} / \mathrm{m}^{2}$

\section{Live load}


Snow load on roof

Floor load
$2.2 \mathrm{kN} / \mathrm{m}^{2}$

$2.4 \mathrm{kN} / \mathrm{m}^{2}$

\subsubsection{Material properties}

\section{Concrete}

Concrete strength $f_{c}$

Strain corresponding to $\mathrm{f}_{\mathrm{c}}, \varepsilon_{0}$

Performance factor of concrete $\varphi_{\mathrm{c}}$

Factored rupture strength of concrete $f_{c r}$

Modulus of elasticity of concrete $\mathrm{E}_{\mathrm{c}}$

Self weight, $\gamma_{\mathrm{rc}}$
$30 \mathrm{MPa}$

0.002

0.6

$3.29 \mathrm{MPa}$

$24,500 \mathrm{MPa}$

$24 \mathrm{KN} / \mathrm{m}^{3}$

\section{Steel}

Steel yield strength fy

Performance factor of steel $\varphi_{\mathrm{y}}$

Steel strain at onset of strain hardening $\varepsilon_{\mathrm{st}} \quad 0.02$

Modulus of elasticity of steel $E_{\mathrm{s}}$

Factored ultimate steel strength $\mathrm{f}_{\text {su }}$
$400 \mathrm{MPa}$

0.85 $200,000 \mathrm{MPa}$

$600 \mathrm{MPa}$ 


\subsubsection{Load calculations}

\subsubsection{Floor dead load}

Slab

$\frac{200 \times 24}{1000}=4.8$

Partitions

0.5

Ceiling, mechanical, electrical.

0.5

Total

$5.8 \mathrm{kN} / \mathrm{m}^{2}$

The roof dead load is also $5.8 \mathrm{kN} / \mathrm{m}^{2}$ since partition load is replaced by an equal amount of insulation and roofing load.

\subsubsection{Load due to self weight}

Floor columns

$1^{\text {st }}$ level columns

Roof columns

Floor walls

$1^{\text {st }}$ level walls

Roof level walls

$$
\begin{aligned}
& \frac{20 \times 0.5 \times 0.5 \times 3.65 \times 24}{36 \times 24}=0.507 \mathrm{kN} / \mathrm{m}^{2} \\
& \frac{20 \times 0.5 \times 0.5 \times 4.25 \times 24}{36 \times 24}=0.590 \mathrm{kN} / \mathrm{m}^{2} \\
& \frac{20 \times 0.5 \times 0.5 \times 1.825 \times 24}{36 \times 24}=0.254 \mathrm{kN} / \mathrm{m}^{2}
\end{aligned}
$$

$$
\frac{31 \times 0.4 \times 3.65 \times 24}{36 \times 24}=1.257 \mathrm{kN} / \mathrm{m}^{2}
$$

$$
\frac{31 \times 0.4 \times 4.25 \times 24}{36 \times 24}=1.465 \mathrm{kN} / \mathrm{m}^{2}
$$

$$
\frac{31 \times 0.4 \times 1.825 \times 24}{36 \times 24}=0.629 \mathrm{kN} / \mathrm{m}^{2}
$$




\subsubsection{Total dead load and mass for each floor}

The dead load for each floor level is due to the weight of columns, walls, concrete slabs and floor cover. The snow load is taken as $25 \%$ of the specified value and added to the weight of the roof.

Roof dead load $\quad 0.25 \times 2.2+0.254+0.629+5.8=7.233 \mathrm{kN} / \mathrm{m}^{2} \quad$ Total $6249.3 \mathrm{kN}$

Floor dead load $\quad 0.507+1.257+5.8=7.564 \mathrm{kN} / \mathrm{m}^{2}$ Total $6535.3 \mathrm{kN}$

First level dead $\quad 0.590+1.465+5.8=7.855 \mathrm{kN} / \mathrm{m}^{2}$ Total $6786.7 \mathrm{kN}$

Total dead load $6249.3+10 \times 6535.3+6786.7=78390 \mathrm{kN}$

Total mass $=7990.8$ tonne

The dead loads, masses and mass moment of inertias for each floor level are shown in Table 3.7

\subsubsection{Gravity load calculation for each wall}

The tributary area that will contribute gravity load is $48 \mathrm{~m}^{2}$ for each of the two edge walls and $96 \mathrm{~m}^{2}$ for the central wall. The dead loads are as given in the following

\section{7-meter edge wall}

Bottom of top storey $\quad 48 \times 5.8+0.4 \times 7 \times 3.65 \times 24+0.25 \times 2.2 \times 48=550.0 \mathrm{kN}$

Bottom of typical storey $\quad 48 \times 5.8+0.4 \times 7 \times 3.65 \times 24=523.7 \mathrm{kN}$

Base level $\quad 48 \times 5.8+0.4 \times 7 \times 4.85 \times 24=604.3 \mathrm{kN}$ 


\section{5-meter central wall}

Bottom of top storey $\quad 96 \times 5.8+0.4 \times 5 \times 3.65 \times 24+0.25 \times 2.2 \times 96=784.8 \mathrm{kN}$

Bottom of typical storey $\quad 96 \times 5.8+0.4 \times 5 \times 3.65 \times 24=732.0 \mathrm{kN}$

Base level

$96 \times 5.8+0.4 \times 5 \times 4.85 \times 24=789.6 \mathrm{kN}$

\section{5-meter edge wall}

Bottom of top storey $\quad 48 \times 5.8+0.4 \times 5 \times 3.65 \times 24+0.25 \times 2.2 \times 48=480.0 \mathrm{kN}$

Bottom of typical storey $48 \times 5.8+0.4 \times 5 \times 3.65 \times 24=453.6 \mathrm{kN}$

Base level $48 \times 5.8+0.4 \times 5 \times 4.85 \times 24=511.2 \mathrm{kN}$

Similar to the dead load the live load will act on $96 \mathrm{~m}^{2}$ tributary area for the central wall and $48 \mathrm{~m}^{2}$ tributary area for the edge walls. The live load is reduced by the live load reduction factor LLRF defined in the NBCC 2005 by:

$\mathrm{LLRF}=.3+\sqrt{\frac{9.8}{\mathrm{CA}_{\text {trib }}}}$

where $\mathrm{CA}_{\text {trib }}$ is the cumulative tributary area in $\mathrm{m}^{2}$. The following load combinations are used in the design of the shear walls: 1.25 D+1.5 L and D + 0.5 L+E. The gravity loads calculations and load combinations for the two $5 \mathrm{~m}$ walls and the $7 \mathrm{~m}$ wall are shown in Table 3.8, Table 3.9 and Table 3.10, Table 3.11, Table 3.12 and Table 3.13.

\subsubsection{Preliminary design}




\subsubsection{Yield displacement and curvature}

\section{7-meter wall}

$$
\begin{aligned}
& \phi_{y}=\frac{2 \varepsilon_{y}}{l_{w}}=\frac{2 \times 400 \times 0.85}{200000 \times 7000}=4.857 \times 10^{-7} \\
& \Delta_{y}=\frac{\phi_{y} H^{2}}{3}=\frac{4.857 \times 10^{-7} \times 45000^{2}}{3}=327.9 \mathrm{~mm}
\end{aligned}
$$

\section{5-meter wall}

$$
\begin{aligned}
& \phi_{y}=\frac{2 \varepsilon_{y}}{1_{w}}=\frac{2 \times 400 \times 0.85}{200000 \times 5000}=6.8 \times 10^{-7} \\
& \Delta_{y}=\frac{\phi_{y} H^{2}}{3}=\frac{6.8 \times 10^{-7} \times 45000^{2}}{3}=459.0 \mathrm{~mm}
\end{aligned}
$$

\subsubsection{Ultimate displacement}

\subsection{Limit on storey drift}

The ultimate roof displacement to satisfy the storey drift limit is given by

$$
\Delta_{u}=\frac{\phi_{y} h_{w}^{2}}{3}+\left(h_{w}-\frac{L_{p}}{2}\right)\left(0.025-\frac{\phi_{y} h_{w}}{2}\right)
$$

When we assume that $L p=l_{w} / 2$ and substitute the values of all the other parameters for the $7 \mathrm{~m}$ wall in the previous equation we get

$$
\Delta_{\mathrm{u}}=936.4
$$


On the other hand, if we use the data for 5-meter wall we get

$\Delta_{\mathrm{u}}=883.4 \mathrm{~mm}$

\subsection{Limit on ductility capacity}

This limit depends on the maximum concrete strain that can be accepted. If the concrete is treated as being unconfined, a strain limit of 0.0035 to 0.004 may be considered as being appropriate. In this example we use a strain limit of 0.0035 . The ultimate roof displacement to satisfy the limit on ductility capacity is given by

$$
\Delta_{u}=\frac{\phi_{y} h_{w}^{2}}{3}+\left(h_{w}-\frac{L_{p}}{2}\right)\left(\phi_{u}-\phi_{y}\right) L_{p}
$$

The ultimate curvature will be calculated by assuming the neutral axis depth to be $0.3 l_{w}$ and is given by

$\phi_{u}=\frac{0.004}{.31_{w}}$

\section{7-meter wall}

For a concrete strain of 0.0035 we get $\Delta_{u}=506.6 \mathrm{~mm}$

\section{4-meter wall}

For a concrete strain of 0.0035 we get $\Delta_{\mathrm{u}}=639.8 \mathrm{~mm}$

\subsubsection{Equivalent SDOF system}


As stated earlier, the designer has some flexibility in selecting the relative strengths of the walls. In this example we choose to assign strengths in proportion to the wall lengths. The stiffness of a wall is given by $\mathrm{k}=\frac{\mathrm{V}_{\mathrm{y}}}{\Delta_{\mathrm{y}}}$

Since $V_{y}$ is proportional to wall length and $\Delta_{y}$ is inversely proportional to wall length, the stiffness will be proportional to the square of the wall length. The magnitude of $V_{y}$ is not yet known, hence the magnitude of the stiffness of a wall is not determined. However, the relative values of the wall stiffnesses are known, hence it is possible to determine the mode shapes. The first four mode shapes are shown in Figure 3.8. All modes have been normalized so that the mode value in the translational component is equal to 1 at the roof level. The first and third modes are predominantly lateral, while the second and fourth modes have large torsional motion. To continue the preliminary design we assume that the response is only in the first mode. The modal properties are:

$$
\begin{aligned}
& \phi_{1}^{\mathrm{T}}=\left[\begin{array}{llllllllll}
0.0193 & 0.0566 & 0.1109 & 0.1797 & 0.2607 & 0.3516 & 0.4503 & 0.5548 & 0.6634 \\
0.7745 & 0.8870 & 1.0000 & 0.0003 & 0.0010 & 0.0020 & 0.0032 & 0.0047 & 0.0063 \\
0.0081 & 0.0100 & 0.0120 & 0.0140 & 0.0160 & 0.0181
\end{array}\right] \\
& L_{1}=\varphi_{1}^{\mathrm{T}} \mathbf{M} 1=3507.9 \\
& M_{1}=\varphi_{1}^{\mathrm{T}} \mathbf{M} \varphi_{1}=2473.6 \\
& \Gamma_{1}=\frac{L_{1}}{M_{1}}=1.4181 \\
& M_{1}^{*}=\Gamma_{1} L_{1}=4974.6
\end{aligned}
$$


In the above vector $\mathbf{1}$ has unit values along the y degrees of freedom and zeros elsewhere. The effective mass in the first mode is $62.25 \%$ of the total mass of 7990.8 tonne. The roof level mode shape elements are 1.0 and 0.0181 , respectively, in translation and rotation measured at the $\mathrm{CM}$. The roof translation at the centre of mass, which is at the centroid in this case, corresponding to a yield displacement of $459 \mathrm{~mm}$ at the flexible edge in 5-meter wall is derived as follows:

$$
\Delta_{\mathrm{y} 1}=\frac{459.0}{(1+18 * 0.0181)}=346.2 \mathrm{~mm}
$$

In a similar manner, the roof translation corresponding to the stiff edge 7-meter wall yield displacement of 327.9 is obtained from

$$
\Delta_{y 2}=\frac{327.9}{\left(1-18^{*} 0.0181\right)}=486.4 \mathrm{~mm}
$$

The translation corresponding to the yield of 5-meter wall at the centroid is $459.0 \mathrm{~mm}$. Considering that the wall strengths are proportional to the wall lengths, the effective yield displacement is obtained from

$$
\begin{aligned}
& \mathrm{k}_{\text {eff }}=\frac{0.4118 \mathrm{~V}}{486.4}+\frac{0.2941 \mathrm{~V}}{459.0}+\frac{0.2941 \mathrm{~V}}{346.2}=0.0023 \mathrm{~V} \\
& \Delta_{\text {yeff }}=\frac{\mathrm{V}}{\mathrm{k}_{\text {eff }}}=427.9 \mathrm{~mm}
\end{aligned}
$$

Using the ultimate displacement limits of 639.8 and $506.6 \mathrm{~mm}$ for the 5 -meter and 7meter walls, respectively, we get the following limits measured at the CM

$$
\begin{aligned}
& \Delta_{\mathrm{u} 1}=\frac{639.8}{\left(1+18^{*} 0.0181\right)}=482.6 \\
& \Delta_{\mathrm{u} 2}=\frac{506.6}{\left(1-18^{*} 0.0181\right)}=751.4
\end{aligned}
$$

Thus the limit of $482.6 \mathrm{~mm}$ governs, and the corresponding ductility requirement is 
$\mu=\frac{482.6}{427.9}=1.128$

For the equivalent SDOF system, we get

$$
\begin{aligned}
& \delta_{y}=\frac{\Delta_{y}}{\Gamma}=\frac{427.9}{1.418}=301.7 \mathrm{~mm} \\
& \delta_{u}=\frac{\Delta_{u}}{\Gamma}=\frac{482.6}{1.418}=340.3 \mathrm{~mm}
\end{aligned}
$$

\subsubsection{Seismic demand}

The seismic demand is represented by the UHS for Vancouver as given by NBCC 2005.

The demand and capacity diagrams are plotted in Figure 3.9 in A-D format. From this diagram the design base shear, without accounting for any overstregth, is given by

$\mathrm{V}=0.084 \times 9.81 \times 4974.6=4099.3 \mathrm{kN}$

This base shear is distributed across the height in proportion to $\mathbf{M} \boldsymbol{\varphi}_{1}$ and an elastic push over analysis carried out which gives the following base moments in the three walls: $50513.3 \mathrm{kNm}$ in the 7 -meter wall, $38044.6 \mathrm{kNm}$ in the central 5 -meter wall and 50295.3 $\mathrm{kNm}$ in the edge 5-meter wall. The shears in the three walls are $1536.7 \mathrm{kN}, 1117.9 \mathrm{kN}$, and $1444.6 \mathrm{kN}$, respectively and the roof displacements are $325.0 \mathrm{~mm}, 481.6 \mathrm{~mm}$ and $638.3 \mathrm{~mm}$. Clearly the required wall strengths are not proportional to the wall lengths, an assumption we made earlier. The preliminary design can not therefore be expected to be accurate, and we need to carry out further iterations 


\subsubsection{Design of shear wall sections}

\section{7-m stiff edge wall}

We design the 7-m wall for combination of a base moment of $50513.3 \mathrm{kNm}$ and axial load of $6666.7 \mathrm{kN}$ obtained from the $\mathrm{D}+0.5 \mathrm{~L}$ load combination. We provide concentrated reinforcement consisting of three layers of $4000 \mathrm{~mm}^{2}$ at each end of the wall In addition we provide on each face $10 \mathrm{~mm}$ vertical bars spaced at $200 \mathrm{~mm}$. This gives the moment-curvature diagram shown in Figure 3.10 and the following parameters are obtained:

Moment capacity, $\mathrm{M}_{\mathrm{c}}$ $51638 \mathrm{kNm}$

Yield curvature, $\varphi_{\mathrm{y}}$ 4.672e-07 per mm

Ultimate curvature, $\varphi_{\mathrm{u}}$ 2.492e-06 per mm

The ratio between the effective moment of inertia and the gross moment of inertia

0.396

\section{5-m flexible edge wall}

We design the 5-m flexible edge wall for combination of a base moment of $50295.3 \mathrm{kNm}$ and axial load of $5896.7 \mathrm{kN}$ obtained from the $\mathrm{D}+.5 \mathrm{~L}$ load combination. We provide concentrated reinforcement consisting of 4 layers of $6000 \mathrm{~mm}^{2}$ at each end of the wall. In addition we provide on each face $10 \mathrm{~mm}$ vertical bars spaced at $200 \mathrm{~mm}$. This gives the moment-curvature diagram shown in Figure 3.11 and the following parameters are obtained:

Moment capacity, $\mathrm{M}_{\mathrm{c}}$

$50318 \mathrm{kNm}$ 
Yield curvature, $\varphi_{\mathrm{y}}$

Ultimate curvature, $\varphi_{\mathrm{u}}$

The ratio between the effective moment of inertia

and the gross moment of inertia
$7.059 \mathrm{e}-87$ per mm

2.91e-06per mm

0.7

\section{5-m central wall}

We design the $5-\mathrm{m}$ central wall for combination of a base moment of $38044.6 \mathrm{kNm}$ and axial load of $9396.6 \mathrm{kN}$ obtained from the $\mathrm{D}+.5 \mathrm{~L}$ load combination. We provide concentrated reinforcement consisting of three layers of $4000 \mathrm{~mm}^{2}$ at each end of the wall. In addition we provide on each face $10 \mathrm{~mm}$ vertical bars spaced at $200 \mathrm{~mm}$. This gives the moment-curvature diagram shown in Figure 3.12 and the following parameters are obtained:

Moment capacity, $\mathrm{M}_{\mathrm{c}}$

Yield curvature, $\varphi_{\mathrm{y}}$

Ultimate curvature, $\varphi_{u}$

The ratio between the effective moment of inertia

and the gross moment of inertia
$37000 \mathrm{kNm}$

7.094e-07 per mm

$1.992 \mathrm{e}-06$ per mm

0.5

\subsubsection{Further iterations}

Modal analysis is now carried out with the new stiffness properties. The following results are obtained: 


$$
\begin{aligned}
& \phi_{1}^{\mathrm{T}}=\left[\begin{array}{lllllllll}
0.0194 & 0.0568 & 0.1111 & 0.1799 & 0.2608 & 0.3517 & 0.4504 & 0.5549 & 0.6635 \\
0.7746 & 0.8870 & 1.0000 & 0.0003 & 0.0008 & 0.0015 & 0.0025 & 0.0036 & 0.0049 \\
0.0062 & 0.0077 & 0.0092 & 0.0107 & 0.0123 & 0.0139
\end{array}\right] \\
& L_{1}=\boldsymbol{\varphi}_{1}^{\mathrm{T}} \mathbf{M} 1=3508.8 \\
& M_{1}=\boldsymbol{\varphi}_{1}^{\mathrm{T}} \mathbf{M} \boldsymbol{\varphi}_{1}=2425.06 \\
& \Gamma_{1}=\frac{L_{1}}{M_{1}}=1.4469 \\
& M_{1}^{*}=\Gamma_{1} L_{1}=5077.3
\end{aligned}
$$

A push over analysis with forces distributed according to $\mathbf{M} \varphi_{1}$ gives the curves shown in Figure 3.13, which shows the base shears as function of the lateral displacement at the centre of mass.

The 7-meter wall yields at a roof displacement at the top of wall equal to $278.2 \mathrm{~mm}$ corresponding to a roof dispalcement at the $\mathrm{CM}$ equal to $374 \mathrm{~mm}$. The central 5-meter wall yields at a roof displacement of $380 \mathrm{~mm}$ at $\mathrm{CM}$. The edge 5-meter wall yields at a roof displacement of $427.4 \mathrm{~mm}$ at the top of wall corresponding to a roof displacement at $\mathrm{CM}$ equal to $342 \mathrm{~mm}$. The effective yield displacement at the $\mathrm{CM}$ is $380 \mathrm{~mm}$ as obtained from the pushover curve.

The permissible ultimate displacement for the 7-meter wall is obtained from:

$$
\begin{aligned}
& \Delta_{u}=\Delta_{y}+\left(h_{w}-\frac{L_{p}}{2}\right)\left(\phi_{u}-\phi_{y}\right) L_{p} \\
& =278.2+(45000-0.25 * 7000)\left(2.492 \times 10^{-06}-4.672 \times 10^{-07}\right) \times 3500 \\
& =584.7 \mathrm{~mm}
\end{aligned}
$$

The ultimate displacement for the central 5-meter wall is 
$380+(45000-0.25 * 5000)\left(1.992 \times 10^{-06}-7.094 \times 10^{-07}\right) \times 2500$

$=520.3 \mathrm{~mm}$

The ultimate displacement for the 5-meter edge wall is

$427.4+(45000-0.25 * 5000)\left(2.91 \times 10^{-06}-7.059 \times 10^{-07}\right) \times 2500$

$=668.5 \mathrm{~mm}$

Using the ultimate displacement limits of 668.5 and $584.7 \mathrm{~mm}$ for the 5 -meter and 7meter walls, respectively, we get the following limits measured at the $\mathrm{CM}$

$$
\begin{aligned}
& \Delta_{\mathrm{u} 1}=\frac{668.5}{\left(1+18^{*} 0.0139\right)}=534.7 \\
& \Delta_{\mathrm{u} 2}=\frac{584.7}{\left(1-18^{*} 0.0139\right)}=779.8
\end{aligned}
$$

Thus the governing ultimate displacement is $520.3 \mathrm{~mm}$, and the ductility requirement is $\mu=\frac{534.7}{380}=1.407$

The yield and ultimate displacements for the equivalent SDOF system are

$$
\begin{aligned}
& \delta_{y}=\frac{\Delta_{y}}{\Gamma}=\frac{380.0}{1.447}=262.6 \mathrm{~mm} \\
& \delta_{u}=\frac{\Delta_{u}}{\Gamma}=\frac{520.3}{1.447}=359.6 \mathrm{~mm}
\end{aligned}
$$

The revised demand capacity diagram is plotted in Figure 3.14. The design base shear is given by

$\mathrm{V}_{\mathrm{y}}=0.063 \times 9.81 \times 5077.3=3138.0 \mathrm{kN}$

\subsubsection{Second iteration}

From the push over data base we get the base moment for each wall corresponding to the base shear obtained earlier from the UHS. For the 7-meter wall the base moment is 39643 
$\mathrm{kNm}$, the base moment for the central 5-meter wall is $24423 \mathrm{kNm}$ and for the 5-meter edge wall it is $42211 \mathrm{kNm}$.

\section{7-m stiff edge wall}

We design the 7-m wall for combination of a base moment of $39643 \mathrm{kNm}$ and axial load of $6666.7 \mathrm{kN}$ obtained from the $\mathrm{D}+0.5 \mathrm{~L}$ load combination. We provide concentrated reinforcement consisting one layer of $2700 \mathrm{~mm}^{2}$ followed by two layers of $2100 \mathrm{~mm}^{2}$ each, at each edge of the wall. In addition we provide on each face $10 \mathrm{~mm}$ vertical bars spaced at $200 \mathrm{~mm}$. This gives the moment-curvature diagram shown in Figure 3.15 and the following parameters are obtained:

Moment capacity, $\mathrm{M}_{\mathrm{c}}$

$40645 \mathrm{kNm}$

Yield curvature, $\varphi_{\mathrm{y}}$

4.696e-07 per mm

Ultimate curvature, $\varphi_{u}$

$2.4427 \mathrm{e}-06$ per $\mathrm{mm}$

The ratio between the effective moment of inertia

and the gross moment of inertia

0.309

\section{5-m flexible edge wall}

We design the 5-m flexible edge wall for combination of a base moment of $42211 \mathrm{KNm}$ and axial load of $5896.7 \mathrm{kN}$ obtained from the $\mathrm{D}+0.5 \mathrm{~L}$ load combination. We provide concentrated reinforcement consisting of 3 layers of $6000 \mathrm{~mm}^{2}$ at each end of the wall. In addition we provide on each face $10 \mathrm{~mm}$ vertical bars spaced at $200 \mathrm{~mm}$. This gives the moment-curvature diagram shown in Figure 3.16 and the following parameters are obtained: 
Moment capacity, $\mathrm{M}_{\mathrm{c}}$

Yield curvature, $\varphi_{\mathrm{y}}$

Ultimate curvature, $\varphi_{\mathrm{u}}$

The ratio between the effective moment of inertia

and the gross moment of inertia
$42445 \mathrm{kNm}$

$6.8858 \mathrm{e}-07$ per $\mathrm{mm}$

$2.9095 \mathrm{e}-06$ per $\mathrm{mm}$

0.60

\section{5-m central wall}

We design the 5-m central wall for combination of a base moment of $24423 \mathrm{KNm}$ and axial load of $9396.6 \mathrm{kN}$ obtained from the $\mathrm{D}+0.5 \mathrm{~L}$ load combination. We provide concentrated reinforcement consisting of one layer of $2100 \mathrm{~mm}^{2}$ and two layers of 1500 $\mathrm{mm}^{2}$ each, at each edge of the wall. In addition we provide on each face $10 \mathrm{~mm}$ vertical bars spaced at $200 \mathrm{~mm}$. This gives the moment-curvature diagram shown in Figure 3.17 and the following parameters are obtained:

Moment capacity, $\mathrm{M}_{\mathrm{c}}$

Yield curvature, $\varphi_{\mathrm{y}}$

Ultimate curvature, $\varphi_{\mathrm{u}}$
$25534 \mathrm{kNm}$

$7.0206 \mathrm{e}-07$ per mm

$1.9918 \mathrm{e}-06$ per mm

The ratio between the effective moment of inertia

and the gross moment of inertia

Modal analysis is now carried out with the new stiffness properties. The following results are obtained:
$\phi_{1}^{\mathrm{T}}=[1.91 \mathrm{E}-02$
$5.63 \mathrm{E}-02$
1.11E-01
1.79E-01
2.60E-01
3.51E-01
4.50E-01
5.55E-01
6.63E-01
7.74E-01
8.87E-01
$1.00 \mathrm{E}+00$ 


$$
\begin{array}{lrrrrr}
1.86 \mathrm{E}-04 & 5.49 \mathrm{E}-04 & 1.08 \mathrm{E}-03 & 1.75 \mathrm{E}-03 & 2.54 \mathrm{E}-03 & 3.42 \mathrm{E}-03 \\
4.38 \mathrm{E}-03 & 5.40 \mathrm{E}-03 & 6.46 \mathrm{E}-03 & 7.54 \mathrm{E}-03 & 8.64 \mathrm{E}-03 & 9.74 \mathrm{E}-03] \\
\mathrm{L}_{1}=\varphi_{1}^{\mathrm{T}} \mathrm{M} 1=3505.94 & \\
\mathrm{M}_{1}=\varphi_{1}^{\mathrm{T}} \mathrm{M} \varphi_{1}=2387.3 \\
\Gamma_{1}=\frac{\mathrm{L}_{1}}{\mathrm{M}_{1}}=1.4685 \\
\mathrm{M}_{1}^{*}=\Gamma_{1} \mathrm{~L}_{1}=5148.74
\end{array}
$$

A push over analysis with forces distributed according to $\mathbf{M} \boldsymbol{\varphi}_{1}$ is now carried out. The 7meter stiff edge wall yields at a roof displacement at the top of wall equal to $282 \mathrm{~mm}$ corresponding to a roof displacement at the $\mathrm{CM}$ equal to $343 \mathrm{~mm}$. The central 5-meter wall yields at a roof displacement of $370 \mathrm{~mm}$ at $\mathrm{CM}$. The flexible edge 5-meter wall yields at a roof displacement of $414 \mathrm{~mm}$ at the top of wall corresponding to a roof displacement at $\mathrm{CM}$ equal to $354 \mathrm{~mm}$. The effective yield displacement at the $\mathrm{CM}$ is 370 $\mathrm{mm}$. The base shear is equal to $3206.14 \mathrm{KN}$.

The permissible ultimate displacement for the 7-meter wall is obtained from:

$$
\begin{aligned}
& \Delta_{u}=\Delta_{y}+\left(h_{w}-\frac{L_{p}}{2}\right)\left(\phi_{u}-\phi_{y}\right) L_{p} \\
& =282+(45000-0.25 * 7000)\left(2.443 \times 10^{-06}-4.696 \times 10^{-07}\right) \times 3500 \\
& =580.7 \mathrm{~mm}
\end{aligned}
$$

The ultimate displacement for the central 5-meter wall is

$$
\begin{aligned}
& 370+(45000-0.25 * 5000)\left(1.992 \times 10^{-06}-7.0214 \times 10^{-07}\right) \times 2500 \\
& =511.1 \mathrm{~mm}
\end{aligned}
$$

The ultimate displacement for the 5 -meter edge wall is 


$$
\begin{aligned}
& 417+(45000-0.25 * 5000)\left(2.91 \times 10^{-06}-6.886 \times 10^{-07}\right) \times 2500 \\
& =657.05 \mathrm{~mm}
\end{aligned}
$$

Using the ultimate displacement limits of 657.05 and $580.7 \mathrm{~mm}$ for the 5 -meter and 7meter walls, respectively, we get the following limits measured at the $\mathrm{CM}$

$$
\begin{aligned}
& \Delta_{\mathrm{u} 1}=\frac{657.05}{\left(1+18^{*} 0.00974\right)}=559.03 \\
& \Delta_{\mathrm{u} 2}=\frac{580.7}{\left(1-18^{*} 0.00974\right)}=704.15
\end{aligned}
$$

Thus the governing ultimate displacement is $511.1 \mathrm{~mm}$, and the ductility requirement is $\mu=\frac{511.1}{370}=1.38$

The yield and ultimate displacements for the equivalent SDOF system are

$$
\begin{aligned}
& \delta_{y}=\frac{\Delta_{y}}{\Gamma}=\frac{370.0}{1.4685}=251.95 \mathrm{~mm} \\
& \delta_{u}=\frac{\Delta_{u}}{\Gamma}=\frac{511.1}{1.4685}=348.04 \mathrm{~mm}
\end{aligned}
$$

The revised demand capacity curve is shown in Figure 3.18. The required base shear strength is given by

$$
V_{y}=0.0665 \times 9.81 \times 5148.74=3358.85 \mathrm{kN}
$$

This is $5 \%$ higher than the last estimate. From a push over analysis we get the following requirements for moment resistance: 7-meter stiff edge wall 45,231 kNm, central 5-meter wall $23071 \mathrm{kNm}$ and flexible edge 5-meter wall 45,541 kNm. 


\subsubsection{Third iteration}

\section{7-m stiff edge wall}

We design the 7-m wall for combination of a base moment of 45,231 kNm kNm and axial load of $6666.7 \mathrm{kN}$ obtained from the $\mathrm{D}+0.5 \mathrm{~L}$ load combination. We provide concentrated reinforcement consisting of three layer of $3100 \mathrm{~mm}^{2}$ at each edge of the wall. In addition we provide on each face $10 \mathrm{~mm}$ vertical bars spaced at $200 \mathrm{~mm}$. This gives the moment-curvature diagram shown in Figure 3.19 and the following parameters are obtained:

Moment capacity, $\mathrm{M}_{\mathrm{c}}$

Yield curvature, $\varphi_{\mathrm{y}}$

Ultimate curvature, $\varphi_{\mathrm{u}}$

The ratio between the effective moment of inertia

and the gross moment of inertia
$45541 \mathrm{kNm}$

4.716e-7 per mm

$2.458 \mathrm{e}-6$ per $\mathrm{mm}$

0.3447

\section{5-m flexible edge wall}

We design the 5-m flexible edge wall for combination of a base moment of $45,541 \mathrm{kNm}$ and axial load of $5896.7 \mathrm{kN}$ obtained from the $\mathrm{D}+0.5 \mathrm{~L}$ load combination. We need a fourth layer of $3000 \mathrm{~mm}^{2}$ in addition to the reinforcement provided earlier, at each edge of the wall. In addition we provide on each face $10 \mathrm{~mm}$ vertical bars spaced at $200 \mathrm{~mm}$. This gives the moment-curvature diagram shown in Figure 3.20 and the following parameters are obtained:

Moment capacity, $\mathrm{M}_{\mathrm{c}}$

$45565.15 \mathrm{kNm}$ 
Yield curvature, $\varphi_{\mathrm{y}}$

Ultimate curvature, $\varphi_{\mathrm{u}}$

The ratio between the effective moment of inertia

and the gross moment of inertia 7.04162e-7 per mm

2.921e-6 per mm

0.633

\section{5-m central wall}

The design for the 5-m central wall will not change.

Modal analysis is now carried out with the new stiffness properties. The following results are obtained:
$\phi_{1}^{\mathrm{T}}=[1.91 \mathrm{E}-02$
5.64E-02
1.11E-01
1.79E-01
2.60E-01
3.51E-01

$\begin{array}{llllll}4.50 \mathrm{E}-01 & 5.55 \mathrm{E}-01 & 6.63 \mathrm{E}-01 & 7.74 \mathrm{E}-01 & 8.87 \mathrm{E}-01 & 1.00 \mathrm{E}+00 \\ 2.23 \mathrm{E}-04 & 6.56 \mathrm{E}-04 & 1.29 \mathrm{E}-03 & 2.09 \mathrm{E}-03 & 3.03 \mathrm{E}-03 & 4.09 \mathrm{E}-03 \\ 5.24 \mathrm{E}-03 & 6.46 \mathrm{E}-03 & 7.72 \mathrm{E}-03 & 9.02 \mathrm{E}-03 & 1.03 \mathrm{E}-02 & 1.16 \mathrm{E}-02]\end{array}$

$\mathrm{L}_{1}=\boldsymbol{\varphi}_{1}^{\mathrm{T}} \mathbf{M 1}=3506$

$\mathrm{M}_{1}=\boldsymbol{\varphi}_{1}^{\mathrm{T}} \mathbf{M} \boldsymbol{\varphi}_{1}=2402.33$

$\Gamma_{1}=\frac{L_{1}}{M_{1}}=1.4594$

$\mathrm{M}_{1}^{*}=\Gamma_{1} \mathrm{~L}_{1}=5116.72$

A push over analysis with forces distributed according to $\mathbf{M} \varphi_{1}$ is now carried out. The 7meter wall yields at a roof displacement at the top of wall equal to $282 \mathrm{~mm}$ corresponding to a roof dispalcement at the CM equal to $358 \mathrm{~mm}$. The central 5 -meter wall yields at a roof displacement of $374 \mathrm{~mm}$ at CM. The edge 5-meter wall yields at a roof displacement of $425 \mathrm{~mm}$ at the top of wall corresponding to a roof displacement at CM equal to $352 \mathrm{~mm}$. The effective yield displacement at the CM is $374 \mathrm{~mm}$. The base shear is equal to $3442.77 \mathrm{KN}$. 
The permissible ultimate displacement for the 7-meter wall is obtained from:

$$
\begin{aligned}
& \Delta_{u}=\Delta_{y}+\left(h_{w}-\frac{L_{p}}{2}\right)\left(\phi_{u}-\phi_{y}\right) L_{p} \\
& =282+(45000-0.25 * 7000)\left(2.458 \times 10^{-06}-4.716 \times 10^{-07}\right) \times 3500 \\
& =582.7 \mathrm{~mm}
\end{aligned}
$$

The ultimate displacement for the central 5-meter wall is

$374+(45000-0.25 * 5000)\left(1.992 \times 10^{-06}-7.0214 \times 10^{-07}\right) \times 2500$

$$
=515.1 \mathrm{~mm}
$$

The ultimate displacement for the 5 -meter edge wall is

$$
425+(45000-0.25 * 5000)\left(2.92 \times 10^{-06}-7.04 \times 10^{-07}\right) \times 2500
$$

$=667.4 \mathrm{~mm}$

Using the ultimate displacement limits of 667.4 and $582.7 \mathrm{~mm}$ for the 5 -meter and 7meter walls, respectively, we get the following limits measured at the $\mathrm{CM}$

$$
\begin{aligned}
& \Delta_{\mathrm{u} 1}=\frac{667.4}{\left(1+18^{*} 0.0116\right)}=552.11 \\
& \Delta_{\mathrm{u} 2}=\frac{582.7}{\left(1-18^{*} 0.0116\right)}=736.5
\end{aligned}
$$

Thus the governing ultimate displacement is $515.1 \mathrm{~mm}$, and the ductility requirement is

$$
\mu=\frac{515.1}{374}=1.377
$$

The yield and ultimate displacements for the equivalent SDOF system are

$$
\begin{aligned}
& \delta_{y}=\frac{\Delta_{y}}{\Gamma}=\frac{374.0}{1.459}=256.33 \mathrm{~mm} \\
& \delta_{u}=\frac{\Delta_{u}}{\Gamma}=\frac{515.1}{1.459}=353.05 \mathrm{~mm}
\end{aligned}
$$


The revised demand capacity curve is shown in Figure 3.21. The required base shear strength is given by

$\mathrm{V}_{\mathrm{y}}=0.0657 \times 9.81 \times 5116.72=3297.8 \mathrm{kN}$

This is $4 \%$ lower than the last estimate from the pushover analysis and thus the capacity is little bit higher than the demand. So the design has converged.

\subsubsection{Multimodal pushover analysis}

\subsubsection{Rotation dominant modes}

As shown in Table 3.14 the modal masses of rotation dominant modes are very small, especially when they are compared to the effective modal mass of the translation dominant modes. Consequently the contribution of the rotation dominant modes to the response parameters is taken as being negligible.

\subsubsection{Translation dominant modes}

The translation dominant modes make significant contribution to the base shear. It is also found that the response in the higher mode is elastic. The properties of the first three translation dominant modes are shown in Table 3.15. The base shear for each mode is obtained by multiplying its effective modal mass by the elastic spectral acceleration corresponding to the mode period. The spectral acceleration is obtained from the 
acceleration period format of the response spectrum of the city of Vancouver. An elastic response spectrum analysis will, in fact, provide the base shear as well as other response parameters. Alternatively, a modal push over analysis can be carried out for each mode, in which the building is pushed under a lateral force distribution given by the product of mass matrix and the mode shape until the base shear for that mode is reached. The response parameters of interest are now obtained from the push over data base. The modal values of the roof displacement and maximum inter-storey drift ratio at each edge for each are combined using the SRSS combination rule and the results are presented in Tables 3.16 and 3.17 . 
Table 3.1: Dead loads and masses for each floor level for 12-storey symmetric building

\begin{tabular}{|c|c|c|}
\hline Storey & Dead load & Mass \\
\hline Number & (kN) & (tonne) \\
\hline $\mathbf{1}$ & 6225.1 & 634.56 \\
\hline $\mathbf{2}$ & 6054 & 617.12 \\
\hline $\mathbf{3}$ & 6054 & 617.12 \\
\hline $\mathbf{4}$ & 6054 & 617.12 \\
\hline $\mathbf{5}$ & 6054 & 617.12 \\
\hline $\mathbf{6}$ & 6054 & 617.12 \\
\hline $\mathbf{7}$ & 6054 & 617.12 \\
\hline $\mathbf{8}$ & 6054 & 617.12 \\
\hline $\mathbf{9}$ & 6054 & 617.12 \\
\hline $\mathbf{1 0}$ & 6054 & 617.12 \\
\hline $\mathbf{1 1}$ & 6054 & 617.12 \\
\hline $\mathbf{1 2}$ & 6007.4 & 612.37 \\
\hline
\end{tabular}

Table 3.2: Gravity load calculations 6-meter wall of the 12-storey symmetric building

\begin{tabular}{|c|c|c|c|c|c|c|c|}
\hline Floor & $\begin{array}{l}\text { Dead } \\
\text { load, } \\
\mathbf{k N}\end{array}$ & $\begin{array}{l}\text { Cumulative } \\
\text { dead load, } \\
\mathbf{k N}\end{array}$ & $\begin{array}{l}\text { Live } \\
\text { load, } \\
\mathbf{k N}\end{array}$ & $\begin{array}{l}\text { Cumulative } \\
\text { live load, } \\
\mathbf{k N}\end{array}$ & $\begin{array}{l}\text { Cumulative } \\
\text { tributary } \\
\text { area, } \mathbf{~ m}^{\mathbf{2}}\end{array}$ & $\mathbf{L L R F}$ & $\begin{array}{l}\text { Reduced } \\
\text { live } \\
\mathbf{l o a d , ~ k N ~}\end{array}$ \\
\hline $\mathbf{1 2}$ & 819.8 & 819.8 & - & - & - & - & - \\
\hline $\mathbf{1 1}$ & 767.0 & 1586.8 & 230.4 & 230.4 & 96 & 0.62 & 142.8 \\
\hline $\mathbf{1 0}$ & 767.0 & 2353.8 & 230.4 & 460.8 & 192 & 0.526 & 242.4 \\
\hline $\mathbf{9}$ & 767.0 & 3120.8 & 230.4 & 691.2 & 288 & 0.484 & 334.5 \\
\hline $\mathbf{8}$ & 767.0 & 3887.8 & 230.4 & 921.6 & 384 & 0.460 & 423.9 \\
\hline $\mathbf{7}$ & 767.0 & 4654.8 & 230.4 & 1152.0 & 480 & 0.443 & 510.3 \\
\hline $\mathbf{6}$ & 767.0 & 5421.8 & 230.4 & 1382.4 & 576 & 0.430 & 594.4 \\
\hline $\mathbf{5}$ & 767.0 & 6188.8 & 230.4 & 1612.8 & 672 & 0.421 & 679.0 \\
\hline $\mathbf{4}$ & 767.0 & 6955.8 & 230.4 & 1843.2 & 768 & 0.413 & 761.2 \\
\hline $\mathbf{3}$ & 767.0 & 7722.8 & 230.4 & 2073.6 & 864 & 0.407 & 844.0 \\
\hline $\mathbf{2}$ & 767.0 & 8489.8 & 230.4 & 2304.0 & 960 & 0.401 & 923.9 \\
\hline $\mathbf{1}$ & 836.2 & 9326.0 & 230.4 & 2534.4 & 1056 & 0.396 & 1003.6 \\
\hline
\end{tabular}


Table 3.3: Gravity load combinations for 6-meter wall of 12-storey symmetric building

\begin{tabular}{|c|c|c|c|c|}
\hline Floor & $\begin{array}{c}\text { Cumulative } \\
\text { dead load, kN }\end{array}$ & $\begin{array}{c}\text { Cumulative } \\
\text { live load, kN }\end{array}$ & $\begin{array}{c}\mathbf{1 . 2 5 D}+\mathbf{1 . 5 L} \\
\mathbf{~ k N}\end{array}$ & $\begin{array}{c}\mathbf{D}+\mathbf{0 . 5 L} \\
\mathbf{k N}\end{array}$ \\
\hline $\mathbf{1 2}$ & 819.8 & - & 1025.0 & 819.8 \\
\hline $\mathbf{1 1}$ & 1586.8 & 142.8 & 2198.0 & 1658.2 \\
\hline $\mathbf{1 0}$ & 2353.8 & 242.4 & 3306.0 & 2475.0 \\
\hline $\mathbf{9}$ & 3120.8 & 334.5 & 4403.0 & 3288.1 \\
\hline $\mathbf{8}$ & 3887.8 & 423.9 & 5496.0 & 4099.8 \\
\hline $\mathbf{7}$ & 4654.8 & 510.3 & 6584.0 & 4910.0 \\
\hline $\mathbf{6}$ & 5421.8 & 594.4 & 7669.0 & 5719.0 \\
\hline $\mathbf{5}$ & 6188.8 & 679.0 & 8754.0 & 6528.3 \\
\hline $\mathbf{4}$ & 6955.8 & 761.2 & 9837.0 & 7336.4 \\
\hline $\mathbf{3}$ & 7722.8 & 844.0 & 10920.0 & 8144.8 \\
\hline $\mathbf{2}$ & 8489.8 & 923.9 & 11998.0 & 8951.8 \\
\hline $\mathbf{1}$ & 9326.0 & 1003.6 & 13163.0 & 9827.8 \\
\hline
\end{tabular}

Table 3.4: Gravity load combinations for 4-meter wall of 12 -storey symmetric building

\begin{tabular}{|c|c|c|c|c|}
\hline Floor & $\begin{array}{c}\text { Cumulative } \\
\text { dead load, kN }\end{array}$ & $\begin{array}{c}\text { Cumulative } \\
\text { live load, kN }\end{array}$ & $\begin{array}{c}\mathbf{1 . 2 5 D}+\mathbf{1 . 5 L} \\
\mathbf{k N}\end{array}$ & $\begin{array}{c}\mathbf{D + 0 . 5 L} \\
\mathbf{k N}\end{array}$ \\
\hline $\mathbf{1 2}$ & 749.8 & - & 937.0 & 749.8 \\
\hline $\mathbf{1 1}$ & 1446.8 & 142.8 & 2023.0 & 1518.2 \\
\hline $\mathbf{1 0}$ & 2143.8 & 242.4 & 3043.0 & 2265.0 \\
\hline $\mathbf{9}$ & 2840.8 & 334.5 & 4053.0 & 3008.1 \\
\hline $\mathbf{8}$ & 3537.8 & 423.9 & 5058.0 & 3749.8 \\
\hline $\mathbf{7}$ & 4234.8 & 510.3 & 6059.0 & 4489.9 \\
\hline $\mathbf{6}$ & 4931.8 & 594.4 & 7056.0 & 5229.0 \\
\hline $\mathbf{5}$ & 5628.8 & 679.0 & 8055.0 & 5968.3 \\
\hline $\mathbf{4}$ & 6325.8 & 761.2 & 9049.0 & 6706.4 \\
\hline $\mathbf{3}$ & 7022.8 & 844.0 & 10045.0 & 7444.8 \\
\hline $\mathbf{2}$ & 7719.8 & 923.9 & 11036.0 & 8181.7 \\
\hline $\mathbf{1}$ & 8463.8 & 1003.6 & 12085.0 & 8965.6 \\
\hline
\end{tabular}


Table 3.5: Calculation of live load to be included in a pushover analysis with P- $\Delta$ effect included for 12-storey symmetric building

\begin{tabular}{|c|c|c|c|c|c|}
\hline Floor & $\begin{array}{c}\text { Cum. } \\
\text { Area }\end{array}$ & LLRF & Cum. LL & $\begin{array}{c}\text { Reduced } \\
\text { LL }\end{array}$ & Floor load \\
\hline & $\mathbf{m}^{\mathbf{2}}$ & & $\mathbf{k N}$ & $\mathbf{k N}$ & $\mathbf{k N}$ \\
\hline $\mathbf{1 2}$ & -- & -- & -- & -- & -- \\
\hline $\mathbf{1 1}$ & 864 & 0.4065 & 2074 & 842.9 & 842.9 \\
$\mathbf{1 0}$ & 1728 & 0.3753 & 4147 & 1556.5 & 713.6 \\
$\mathbf{9}$ & 2592 & 0.3615 & 6221 & 2248.7 & 692.3 \\
$\mathbf{8}$ & 3456 & 0.3533 & 8294 & 2930.0 & 681.3 \\
$\mathbf{7}$ & 4320 & 0.3476 & 10368 & 3604.2 & 674.2 \\
$\mathbf{6}$ & 5184 & 0.3435 & 12442 & 4273.4 & 669.2 \\
$\mathbf{5}$ & 6048 & 0.3403 & 14515 & 4938.9 & 665.4 \\
$\mathbf{4}$ & 6912 & 0.3377 & 16589 & 5601.3 & 662.4 \\
$\mathbf{3}$ & 7776 & 0.3355 & 18662 & 6261.2 & 660.0 \\
$\mathbf{2}$ & 8640 & 0.3337 & 20736 & 6919.2 & 657.9 \\
$\mathbf{1}$ & 9504 & 0.3321 & 22810 & 7575.3 & 656.2 \\
\hline
\end{tabular}

Table 3.6: Total response for roof displacement, maximum inter-storey drift ratio and base shear for 12-storey symmetric building

\begin{tabular}{|c|c|c|c|c|c|c|c|}
\hline $\begin{array}{c}\text { Mode } \\
\text { shape }\end{array}$ & $\begin{array}{c}\text { Period } \\
\text { sec }\end{array}$ & $\begin{array}{c}\text { Base shear } \\
\text { at yield from } \\
\text { MPA } \\
\text { kN }\end{array}$ & $\begin{array}{c}\text { Effective } \\
\text { modal } \\
\text { mass } \\
M^{*} \text { tonne }\end{array}$ & $\begin{array}{c}\text { Spectral } \\
\text { acceleration } \\
\mathbf{g}\end{array}$ & $\begin{array}{c}\text { Base } \\
\text { shear } \\
\text { KN }\end{array}$ & $\begin{array}{c}\text { Roof } \\
\text { displacement } \\
\text { m }\end{array}$ & $\begin{array}{c}\text { Storey } \\
\text { drift } \\
\text { ratio }\end{array}$ \\
\hline First & 4.306 & 2252 & 4850 & 0.0508 & 2252.00 & 0.604 & .0167 \\
\hline Second & 0.684 & 9171 & 1480 & 0.5422 & 7872.09 & 0.056 & .0058 \\
\hline Third & 0.243 & 14298 & 503 & 0.9084 & 4482.43 & 0.010 & .0012 \\
\hline $\begin{array}{c}\text { Total } \\
\text { response } \\
\text { using } \\
\text { SRSS }\end{array}$ & & & & & 9334.53 & 0.606 & .0178 \\
\hline
\end{tabular}


Table 3.7: Dead loads, masses and mass moment of inertias for each floor level for 12-storey unsymmetric building

\begin{tabular}{|c|c|c|c|}
\hline Storey & $\begin{array}{c}\text { Dead } \\
\text { load }\end{array}$ & Mass & $\begin{array}{c}\text { Mass moment } \\
\text { of inertia } \mathbf{I}_{\mathbf{p}} \\
\text { tonne. }^{\mathbf{P}}\end{array}$ \\
\hline Number & $\mathbf{( k N )}$ & (tonne) & 107923.05 \\
\hline $\mathbf{1}$ & 6786.7 & 691.81 & 107 \\
\hline $\mathbf{2}$ & 6535.3 & 666.18 & 103925.25 \\
\hline $\mathbf{3}$ & 6535.3 & 666.18 & 103925.25 \\
\hline $\mathbf{4}$ & 6535.3 & 666.18 & 103925.25 \\
\hline $\mathbf{5}$ & 6535.3 & 666.18 & 103925.25 \\
\hline $\mathbf{6}$ & 6535.3 & 666.18 & 103925.25 \\
\hline $\mathbf{7}$ & 6535.3 & 666.18 & 103925.25 \\
\hline $\mathbf{8}$ & 6535.3 & 666.18 & 103925.25 \\
\hline $\mathbf{9}$ & 6535.3 & 666.18 & 103925.25 \\
\hline $\mathbf{1 0}$ & 6535.3 & 666.18 & 103925.25 \\
\hline $\mathbf{1 1}$ & 6535.3 & 666.18 & 103925.25 \\
\hline $\mathbf{1 2}$ & 6249.3 & 637.03 & 99377.24 \\
\hline
\end{tabular}

Table 3.8: Gravity load calculations for 7-meter edge wall of 12-storey unsymmetric building

\begin{tabular}{|c|l|c|c|c|c|c|c|}
\hline Floor & $\begin{array}{l}\text { Dead } \\
\text { load, } \\
\mathbf{k N}\end{array}$ & $\begin{array}{l}\text { Cumulative } \\
\text { dead load, } \\
\mathbf{k N}\end{array}$ & $\begin{array}{l}\text { Live } \\
\text { load, } \\
\mathbf{k N}\end{array}$ & $\begin{array}{l}\text { Cumulative } \\
\text { live load, } \\
\mathbf{k N}\end{array}$ & $\begin{array}{l}\text { Cumulative } \\
\text { tributary } \\
\text { area, } \mathbf{~}^{\mathbf{2}}\end{array}$ & $\mathbf{L L R F}$ & $\begin{array}{l}\text { Reduced } \\
\text { live load, } \\
\mathbf{k N}\end{array}$ \\
\hline $\mathbf{1 2}$ & 550.0 & 550.0 & - & - & - & - & - \\
\hline $\mathbf{1 1}$ & 523.7 & 1073.7 & 115.2 & 115.2 & 48 & 0.7518 & 86.6 \\
\hline $\mathbf{1 0}$ & 523.7 & 1597.4 & 115.2 & 230.4 & 96 & 0.6195 & 142.7 \\
\hline $\mathbf{9}$ & 523.7 & 2121.1 & 115.2 & 345.6 & 144 & 0.5609 & 193.8 \\
\hline $\mathbf{8}$ & 523.7 & 2644.8 & 115.2 & 460.8 & 192 & 0.5259 & 242.3 \\
\hline $\mathbf{7}$ & 523.7 & 3168.5 & 115.2 & 576.0 & 240 & 0.5021 & 289.2 \\
\hline $\mathbf{6}$ & 523.7 & 3692.2 & 115.2 & 691.2 & 288 & 0.4845 & 334.9 \\
\hline $\mathbf{5}$ & 523.7 & 4215.9 & 115.2 & 806.4 & 336 & 0.4708 & 379.6 \\
\hline $\mathbf{4}$ & 523.7 & 4739.6 & 115.2 & 921.6 & 384 & 0.4598 & 423.7 \\
\hline $\mathbf{3}$ & 523.7 & 5263.3 & 115.2 & 1036.8 & 432 & 0.4506 & 467.2 \\
\hline $\mathbf{2}$ & 523.7 & 5787.0 & 115.2 & 1152.0 & 480 & 0.4429 & 510.2 \\
\hline $\mathbf{1}$ & 604.3 & 6391.3 & 115.2 & 1267.2 & 528 & 0.4362 & 552.7 \\
\hline
\end{tabular}


Table 3.9: Gravity load combinations 7-meter edge wall of 12-storey unsymmetric building

\begin{tabular}{|c|c|c|c|c|}
\hline Floor & $\begin{array}{c}\text { Cumulative } \\
\text { dead load, kN }\end{array}$ & $\begin{array}{c}\text { Cumulative } \\
\text { live load, kN }\end{array}$ & $\begin{array}{c}\mathbf{1 . 2 5 D + 1 . 5 L} \\
\mathbf{k N}\end{array}$ & $\begin{array}{c}\mathbf{D}+\mathbf{0 . 5} \mathbf{L} \\
\mathbf{k N}\end{array}$ \\
\hline $\mathbf{1 2}$ & 550.0 & - & 687.5 & 550.0 \\
\hline $\mathbf{1 1}$ & 1073.7 & 86.6 & 1472.0 & 1117.0 \\
\hline $\mathbf{1 0}$ & 1597.4 & 142.7 & 2210.9 & 1668.8 \\
\hline $\mathbf{9}$ & 2121.1 & 193.8 & 2942.1 & 2218.0 \\
\hline $\mathbf{8}$ & 2644.8 & 242.3 & 3669.5 & 2766.0 \\
\hline $\mathbf{7}$ & 3168.5 & 289.2 & 4394.4 & 3313.1 \\
\hline $\mathbf{6}$ & 3692.2 & 334.9 & 5117.5 & 3859.6 \\
\hline $\mathbf{5}$ & 4215.9 & 379.6 & 5839.3 & 4405.7 \\
\hline $\mathbf{4}$ & 4739.6 & 423.7 & 6560.1 & 4951.5 \\
\hline $\mathbf{3}$ & 5263.3 & 467.2 & 7279.9 & 5496.9 \\
\hline $\mathbf{2}$ & 5787.0 & 510.2 & 7999.1 & 6042.1 \\
\hline $\mathbf{1}$ & 6391.3 & 552.7 & 8818.3 & 6667.7 \\
\hline
\end{tabular}

Table 3.10: Gravity load calculations for 5-meter edge wall of 12-storey unsymmetric building

\begin{tabular}{|c|l|l|l|l|l|l|l|}
\hline Floor & $\begin{array}{l}\text { Dead } \\
\text { load, } \\
\mathbf{k N}\end{array}$ & $\begin{array}{l}\text { Cumulative } \\
\text { dead load, } \\
\mathbf{k N}\end{array}$ & $\begin{array}{l}\text { Live } \\
\text { load, } \\
\mathbf{k N}\end{array}$ & $\begin{array}{l}\text { Cumulative } \\
\text { live load, } \\
\mathbf{k N}\end{array}$ & $\begin{array}{l}\text { Cumulative } \\
\text { tributary } \\
\text { area, } \mathbf{2}\end{array}$ & LLRF & $\begin{array}{l}\text { Reduced } \\
\text { live load, } \\
\mathbf{k N}\end{array}$ \\
\hline $\mathbf{1 2}$ & 480.0 & 480.0 & - & - & - & - & - \\
\hline $\mathbf{1 1}$ & 453.6 & 933.6 & 115.2 & 115.2 & 48 & 0.7518 & 86.6 \\
\hline $\mathbf{1 0}$ & 453.6 & 1387.2 & 115.2 & 230.4 & 96 & 0.6195 & 142.7 \\
\hline $\mathbf{9}$ & 453.6 & 1840.8 & 115.2 & 345.6 & 144 & 0.5609 & 193.8 \\
\hline $\mathbf{8}$ & 453.6 & 2294.4 & 115.2 & 460.8 & 192 & 0.5259 & 242.3 \\
\hline $\mathbf{7}$ & 453.6 & 2748.0 & 115.2 & 576.0 & 240 & 0.5021 & 289.2 \\
\hline $\mathbf{6}$ & 453.6 & 3201.6 & 115.2 & 691.2 & 288 & 0.4845 & 334.9 \\
\hline $\mathbf{5}$ & 453.6 & 3655.2 & 115.2 & 806.4 & 336 & 0.4708 & 379.6 \\
\hline $\mathbf{4}$ & 453.6 & 4108.8 & 115.2 & 921.6 & 384 & 0.4598 & 423.7 \\
\hline $\mathbf{3}$ & 453.6 & 4562.4 & 115.2 & 1036.8 & 432 & 0.4506 & 467.2 \\
\hline $\mathbf{2}$ & 453.6 & 5016.0 & 115.2 & 1152.0 & 480 & 0.4429 & 510.2 \\
\hline $\mathbf{1}$ & 604.3 & 5620.3 & 115.2 & 1267.2 & 528 & 0.4362 & 552.7 \\
\hline
\end{tabular}


Table 3.11: Gravity load combinations for 5-meter edge wall of 12 -storey unsymmetric building

\begin{tabular}{|c|c|c|c|c|}
\hline Floor & $\begin{array}{c}\text { Cumulative } \\
\text { dead load, kN }\end{array}$ & $\begin{array}{c}\text { Cumulative } \\
\text { live load, kN }\end{array}$ & $\begin{array}{c}\mathbf{1 . 2 5 D + 1 . 5 L} \\
\mathbf{k N}\end{array}$ & $\begin{array}{c}\mathbf{D}+\mathbf{0 . 5 L} \\
\mathbf{k N}\end{array}$ \\
\hline $\mathbf{1 2}$ & 480.0 & - & 600.0 & 480.0 \\
\hline $\mathbf{1 1}$ & 933.6 & 86.6 & 1296.9 & 976.9 \\
\hline $\mathbf{1 0}$ & 1387.2 & 142.7 & 1948.1 & 1458.6 \\
\hline $\mathbf{9}$ & 1840.8 & 193.8 & 2591.7 & 1937.7 \\
\hline $\mathbf{8}$ & 2294.4 & 242.3 & 3231.4 & 2415.6 \\
\hline $\mathbf{7}$ & 2748.0 & 289.2 & 3868.8 & 2892.6 \\
\hline $\mathbf{6}$ & 3201.6 & 334.9 & 4504.4 & 3369.0 \\
\hline $\mathbf{5}$ & 3655.2 & 379.6 & 5138.4 & 3845.0 \\
\hline $\mathbf{4}$ & 4108.8 & 423.7 & 5771.6 & 4320.7 \\
\hline $\mathbf{3}$ & 4562.4 & 467.2 & 6403.8 & 4796.0 \\
\hline $\mathbf{2}$ & 5016.0 & 510.2 & 7035.3 & 5271.1 \\
\hline $\mathbf{1}$ & 5620.3 & 552.7 & 7854.4 & 5896.7 \\
\hline
\end{tabular}

Table 3.12: Gravity load calculations for 5 -meter central wall of 12 -storey unsymmetric building

\begin{tabular}{|c|c|c|c|c|c|c|c|}
\hline Floor & $\begin{array}{l}\text { Dead } \\
\text { load, } \\
\mathbf{k N}\end{array}$ & $\begin{array}{l}\text { Cumulative } \\
\text { dead load, } \\
\mathbf{k N}\end{array}$ & $\begin{array}{l}\text { Live } \\
\text { load, } \\
\mathbf{k N}\end{array}$ & $\begin{array}{l}\text { Cumulative } \\
\text { live load, } \\
\mathbf{k N}\end{array}$ & $\begin{array}{l}\text { Cumulative } \\
\text { tributary } \\
\text { area, } \mathbf{~ m}^{\mathbf{2}}\end{array}$ & $\mathbf{L L R F}$ & $\begin{array}{l}\text { Reduced } \\
\text { live } \\
\text { load, kN }\end{array}$ \\
\hline $\mathbf{1 2}$ & 784.8 & 784.8 & - & - & - & - & - \\
\hline $\mathbf{1 1}$ & 732.0 & 1516.8 & 230.4 & 230.4 & 96 & 0.6195 & 142.7 \\
\hline $\mathbf{1 0}$ & 732.0 & 2248.8 & 230.4 & 460.8 & 192 & 0.5259 & 242.3 \\
\hline $\mathbf{9}$ & 732.0 & 2980.8 & 230.4 & 691.2 & 288 & 0.4845 & 334.9 \\
\hline $\mathbf{8}$ & 732.0 & 3712.8 & 230.4 & 921.6 & 384 & 0.4598 & 423.7 \\
\hline $\mathbf{7}$ & 732.0 & 4444.8 & 230.4 & 1152.0 & 480 & 0.4429 & 510.2 \\
\hline $\mathbf{6}$ & 732.0 & 5176.8 & 230.4 & 1382.4 & 576 & 0.4304 & 595.0 \\
\hline $\mathbf{5}$ & 732.0 & 5908.8 & 230.4 & 1612.8 & 672 & 0.4208 & 678.6 \\
\hline $\mathbf{4}$ & 732.0 & 6640.8 & 230.4 & 1843.2 & 768 & 0.4130 & 761.2 \\
\hline $\mathbf{3}$ & 732.0 & 7372.8 & 230.4 & 2073.6 & 864 & 0.4065 & 842.9 \\
\hline $\mathbf{2}$ & 732.0 & 8104.8 & 230.4 & 2304.0 & 960 & 0.4010 & 924.0 \\
\hline $\mathbf{1}$ & 604.3 & 8894.4 & 230.4 & 2534.4 & 1056 & 0.3963 & 1004.5 \\
\hline
\end{tabular}


Table 3.13: Gravity load combinations for 5-meter central wall of 12-storey unsymmetric building

\begin{tabular}{|c|c|c|c|c|}
\hline Floor & $\begin{array}{c}\text { Cumulative } \\
\text { dead load, kN }\end{array}$ & $\begin{array}{c}\text { Cumulative } \\
\text { live load, kN }\end{array}$ & $\begin{array}{c}\mathbf{1 . 2 5 D}+\mathbf{1 . 5 L} \\
\mathbf{~ k N}\end{array}$ & $\begin{array}{c}\mathbf{D}+\mathbf{0 . 5 L} \\
\mathbf{~ N N}\end{array}$ \\
\hline $\mathbf{1 2}$ & 784.8 & - & 981.0 & $\mathbf{7 8 4 . 8}$ \\
\hline $\mathbf{1 1}$ & 1516.8 & 142.7 & 2110.1 & 1588.2 \\
\hline $\mathbf{1 0}$ & 2248.8 & 242.3 & 3174.5 & 2370.0 \\
\hline $\mathbf{9}$ & 2980.8 & 334.9 & 4228.3 & 3148.3 \\
\hline $\mathbf{8}$ & 3712.8 & 423.7 & 5276.6 & 3924.7 \\
\hline $\mathbf{7}$ & 4444.8 & 510.2 & 6321.3 & 4699.9 \\
\hline $\mathbf{6}$ & 5176.8 & 595.0 & 7363.5 & 5474.3 \\
\hline $\mathbf{5}$ & 5908.8 & 678.6 & 8403.9 & 6248.1 \\
\hline $\mathbf{4}$ & 6640.8 & 761.2 & 9442.8 & 7021.4 \\
\hline $\mathbf{3}$ & 7372.8 & 842.9 & 10480.4 & 7794.2 \\
\hline $\mathbf{2}$ & 8104.8 & 924.0 & 11517.0 & 8566.8 \\
\hline $\mathbf{1}$ & 8894.4 & 1004.5 & 12624.8 & 9396.6 \\
\hline
\end{tabular}

Table 3.14: Periods, effective modal masses and modal participation factors for the rotation dominant mode shapes

\begin{tabular}{|c|c|c|c|}
\hline $\begin{array}{c}\text { Mode } \\
\text { shape }\end{array}$ & $\begin{array}{c}\text { Period } \\
\text { sec }\end{array}$ & $\begin{array}{c}\text { Effective modal } \\
\text { mass } M^{*} \text { tonne }\end{array}$ & $\begin{array}{c}\text { Modal participation } \\
\text { factor } \Gamma\end{array}$ \\
\hline Second & 2.340 & 108.28 & 0.0308 \\
\hline Fourth & 0.373 & 33.13 & 0.0150 \\
\hline Sixth & 0.133 & 11.24 & 0.0076 \\
\hline
\end{tabular}

Table 3.15: Periods, effective modal masses, modal participation factors and base shear for the translation dominant mode shapes

\begin{tabular}{|c|c|c|c|c|}
\hline Mode shape & $\begin{array}{c}\text { Period } \\
\text { sec }\end{array}$ & $\begin{array}{c}\text { Effective } \\
\text { modal } \\
\text { Mass } M^{*} \\
\text { tonne }\end{array}$ & $\begin{array}{c}\text { Modal } \\
\text { participation } \\
\text { factor } \Gamma\end{array}$ & $\begin{array}{c}\text { Base shear } \\
\mathbf{k N}\end{array}$ \\
\hline First & 3.840 & 5116.7 & 1.459 & 3442.77 \\
\hline Third & 0.612 & 1565.9 & 0.707 & 9037.33 \\
\hline fifth & 0.218 & 531.0 & 0.362 & 4888.22 \\
\hline $\begin{array}{c}\text { Base shear } \\
\text { SRSS }\end{array}$ & & & & 10836.08 \\
\hline
\end{tabular}


Table 3.16: Roof displacement for each mode shape at each edge and total roof displacement at each edge

\begin{tabular}{|c|c|c|c|}
\hline Mode shape & $\begin{array}{c}\text { Roof displacement } \\
\text { at the stiff edge } \\
\mathbf{m}\end{array}$ & $\begin{array}{c}\text { Roof displacement } \\
\text { at the central wall } \\
\mathbf{m}\end{array}$ & $\begin{array}{c}\text { Roof displacement } \\
\text { at the flexible edge } \\
\mathbf{m}\end{array}$ \\
\hline First & 0.437 & 0.515 & 0.592 \\
\hline Third & 0.030 & 0.039 & 0.047 \\
\hline Fifth & 0.003 & 0.004 & 0.004 \\
\hline $\begin{array}{c}\text { Total roof } \\
\text { Displacement } \\
\text { SRSS }\end{array}$ & 0.438 & 0.516 & \\
\hline
\end{tabular}

Table 3.17: Maximum inter-storey drift ratio for each mode shape at each edge and total maximum inter-storey drift ratio at each edge obtained using two combination rules

\begin{tabular}{|c|c|c|c|}
\hline Mode shape & $\begin{array}{c}\text { Maximum storey drift } \\
\text { at the stiff edge }\end{array}$ & $\begin{array}{c}\text { Maximum storey drift } \\
\text { at the central wall }\end{array}$ & $\begin{array}{c}\text { Maximum storey drift } \\
\text { at the flexible edge }\end{array}$ \\
\hline First & 0.0123 & 0.0147 & 0.0170 \\
\hline Third & 0.0037 & 0.0047 & 0.0057 \\
\hline Fifth & 0.0007 & 0.0009 & 0.0010 \\
\hline $\begin{array}{c}\text { Total storey } \\
\text { Drift SRSS }\end{array}$ & 0.0128 & 0.0154 & 0.0180 \\
\hline $\begin{array}{c}\text { Total storey } \\
\text { Drift ABSUM }\end{array}$ & 0.0167 & 0.0203 & 0.0239 \\
\hline
\end{tabular}



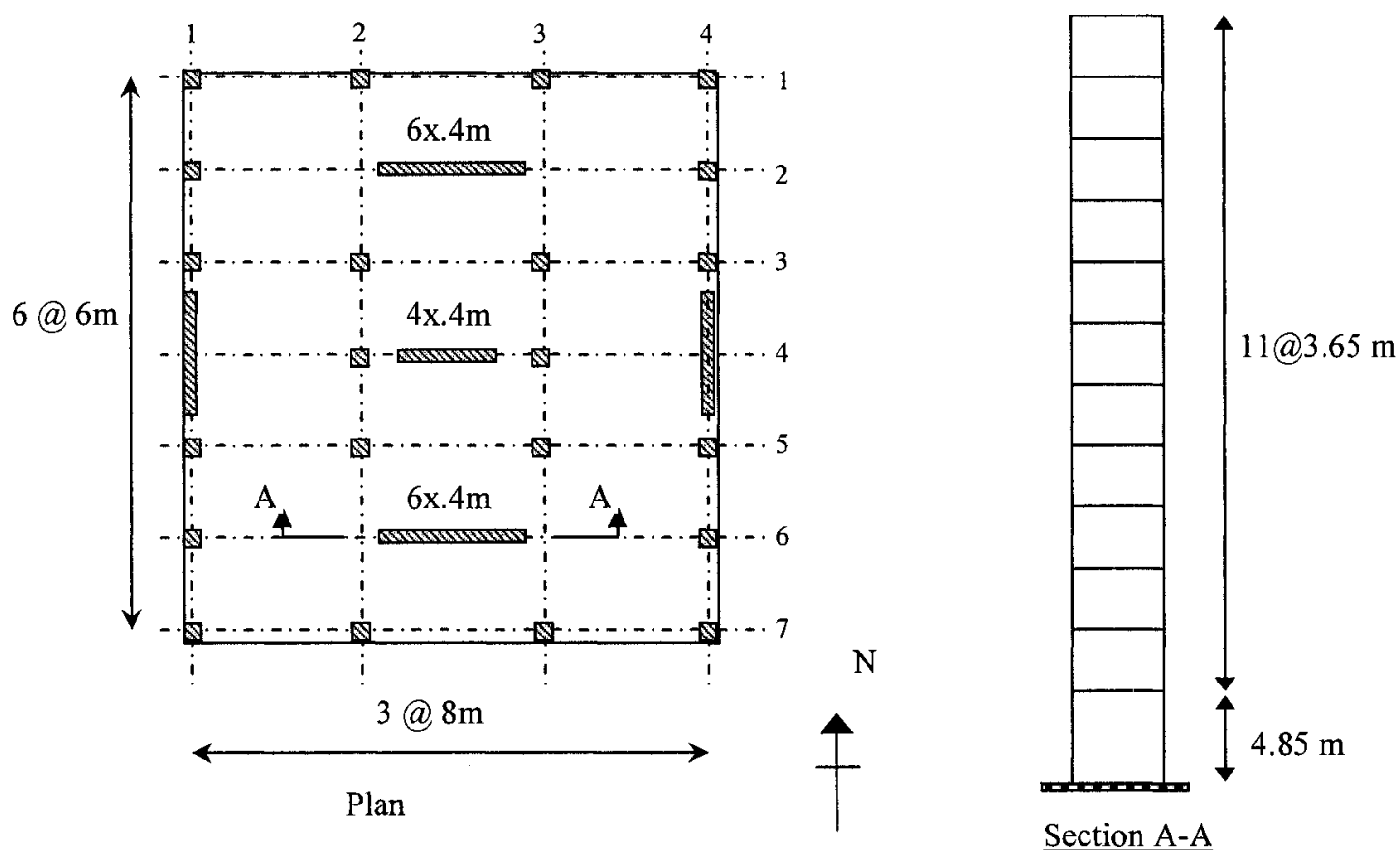

Figure 3.1: Plan and elevation of 12 -storey symmetric building

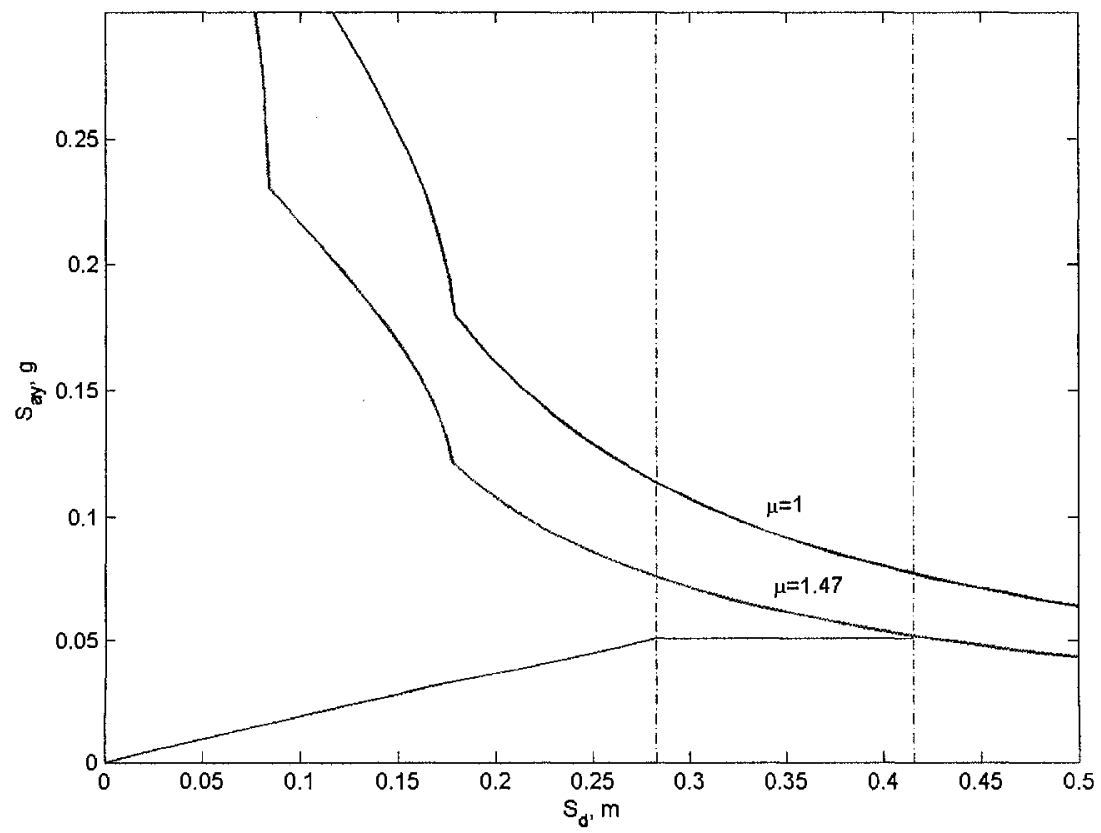

Figure 3.2: Preliminary; design demand and capacity diagrams for 12-storey symmetric building 


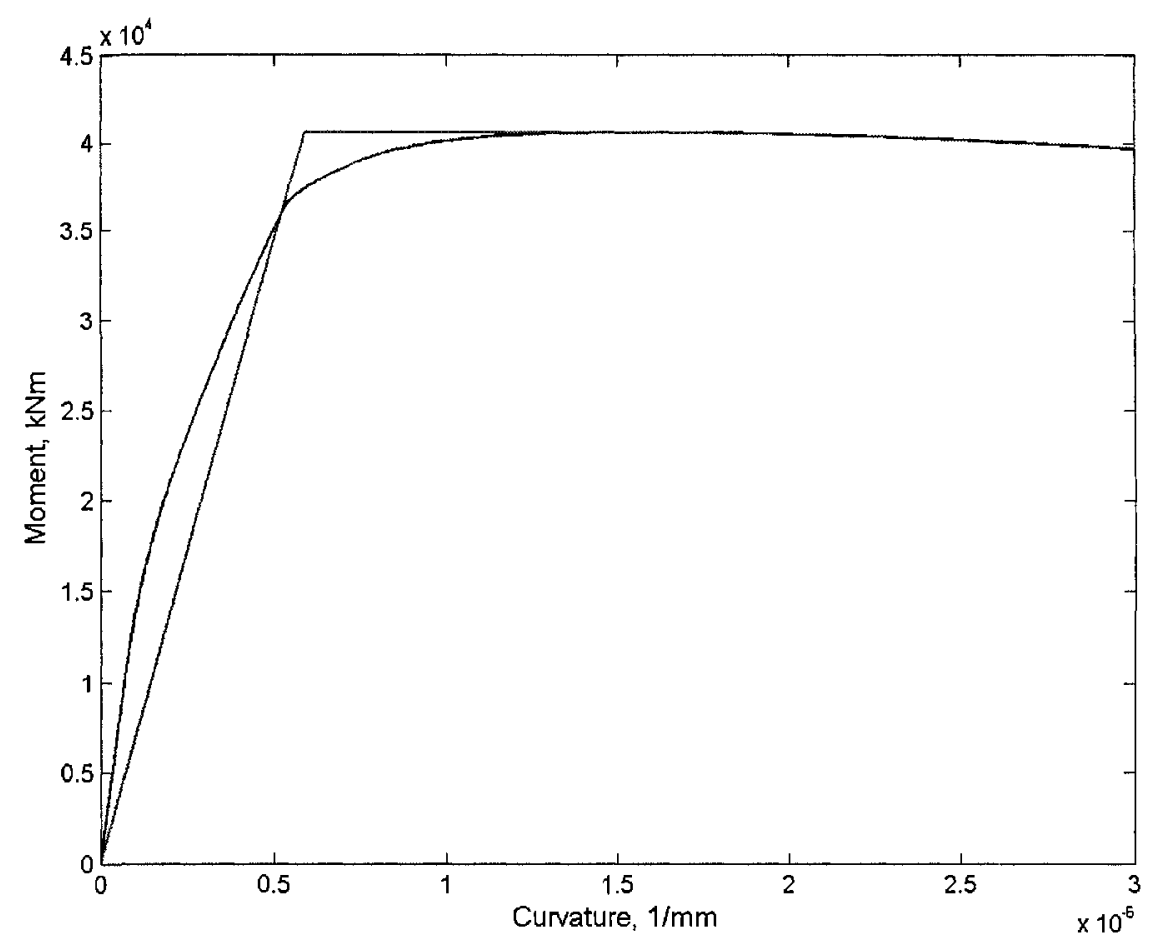

Figure 3.3: Preliminary design; moment-curvature relationship for 6-meter wall of the 12-storey symmetric building

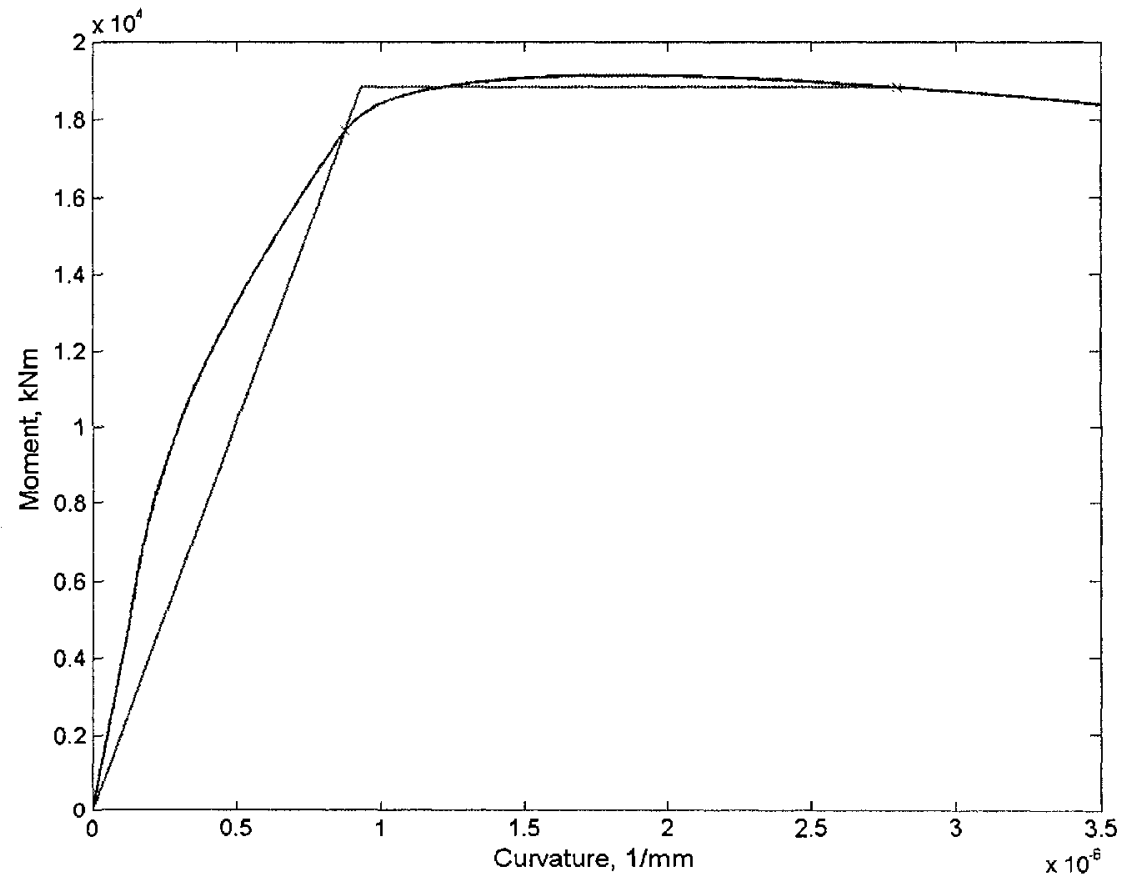

Figure 3.4: Preliminary design; moment-curvature relationship for 4-meter wall of the 12-storey symmetric building 


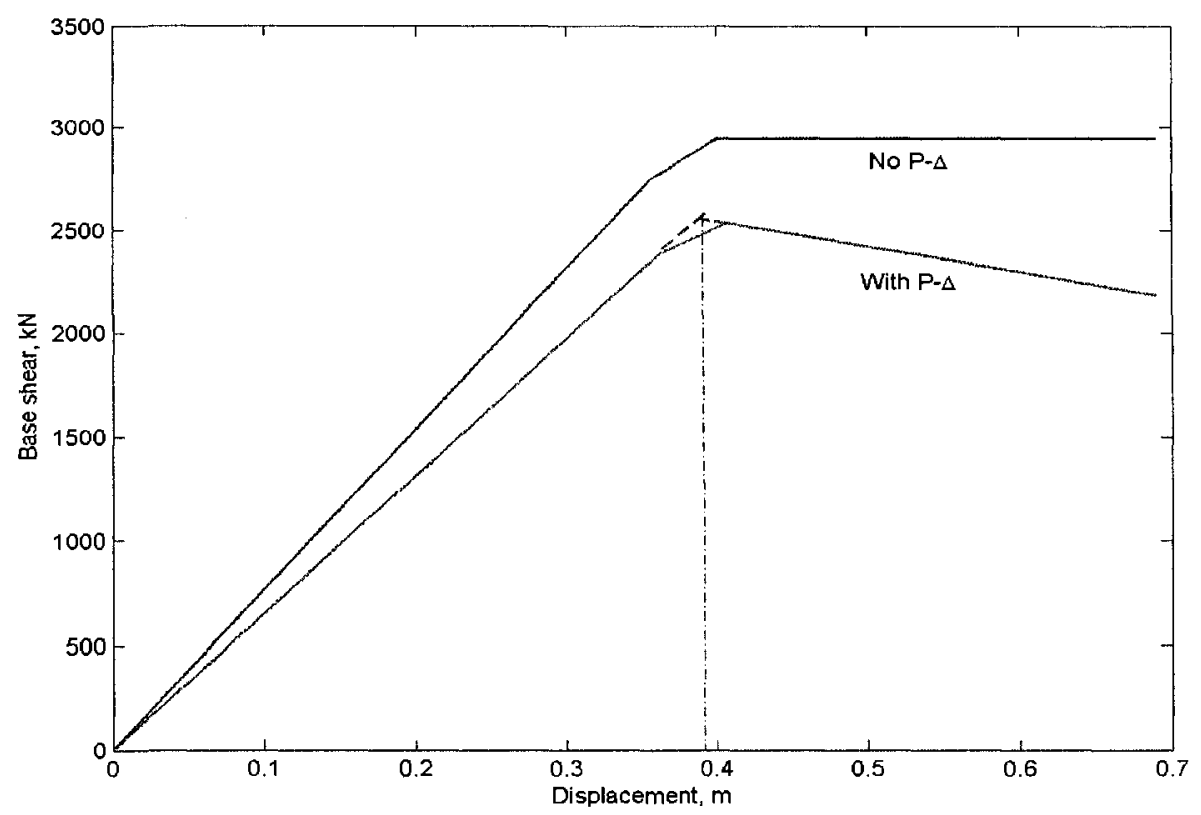

Figure 3.5: Push over curves showing the relationships between base shear and roof displacement with and without P-Delta effect included for 12-storey symmetric building

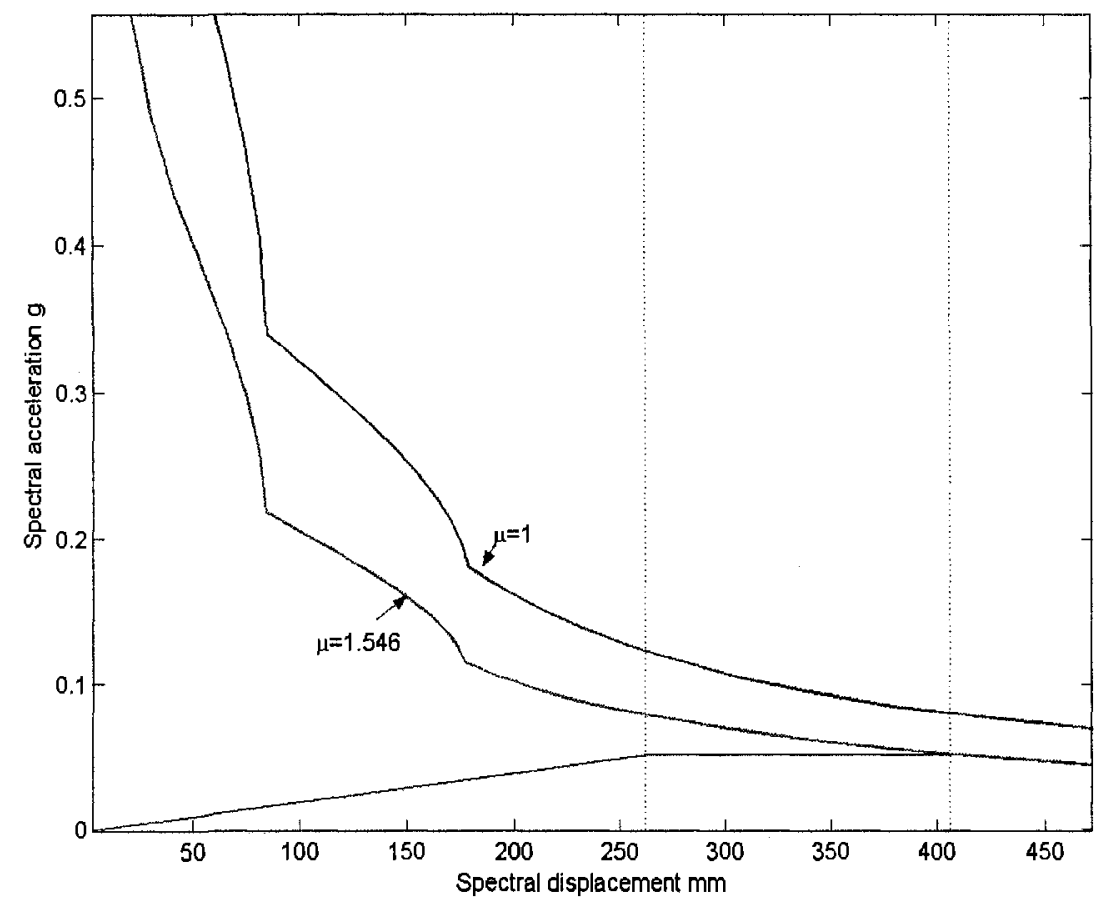

Figure 3.6: First design iteration; capacity and demand curves for 12-storey symmetric building 

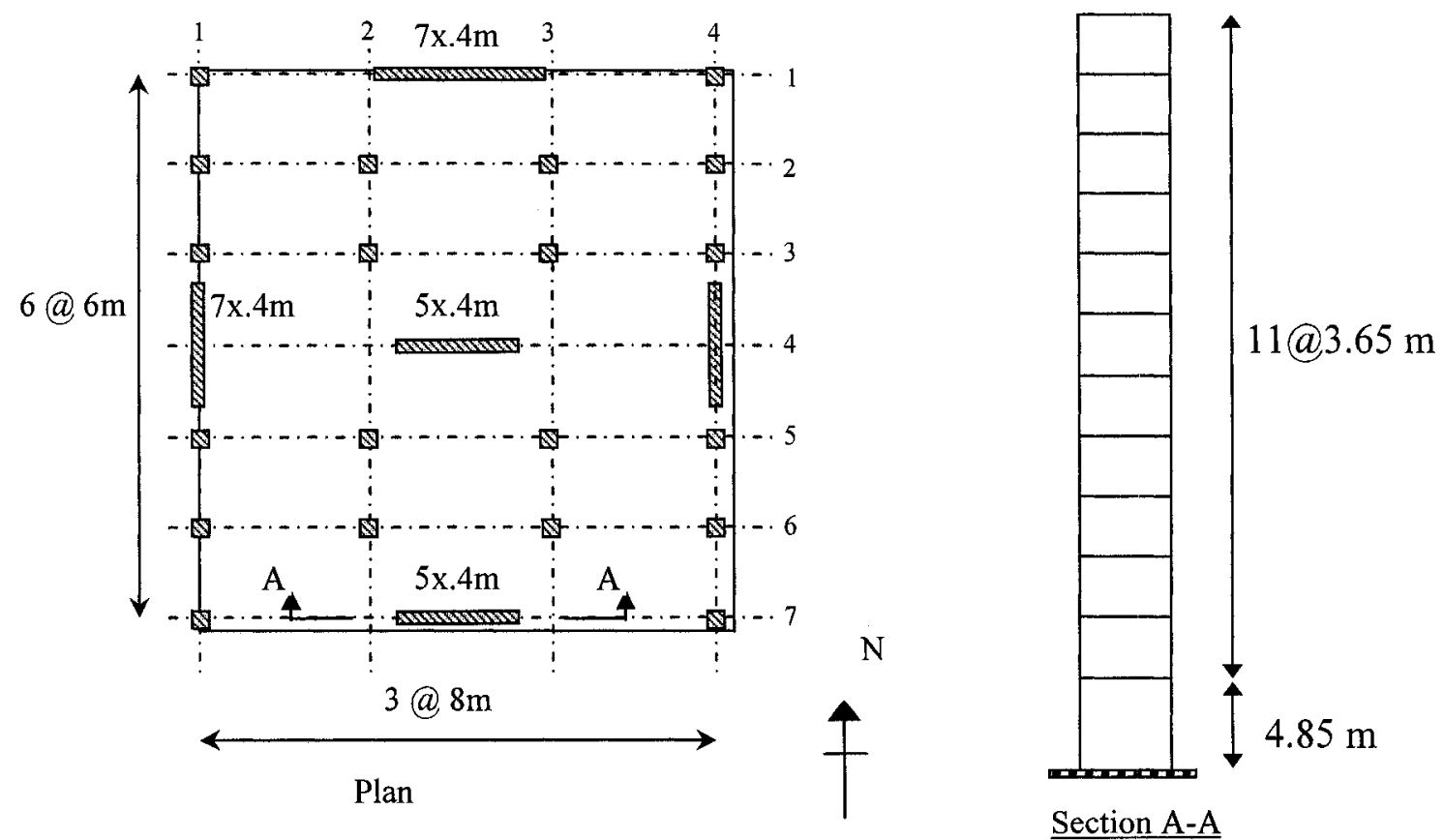

Figure 3.7: Plan view of unsymmetric 12-storey shear wall building
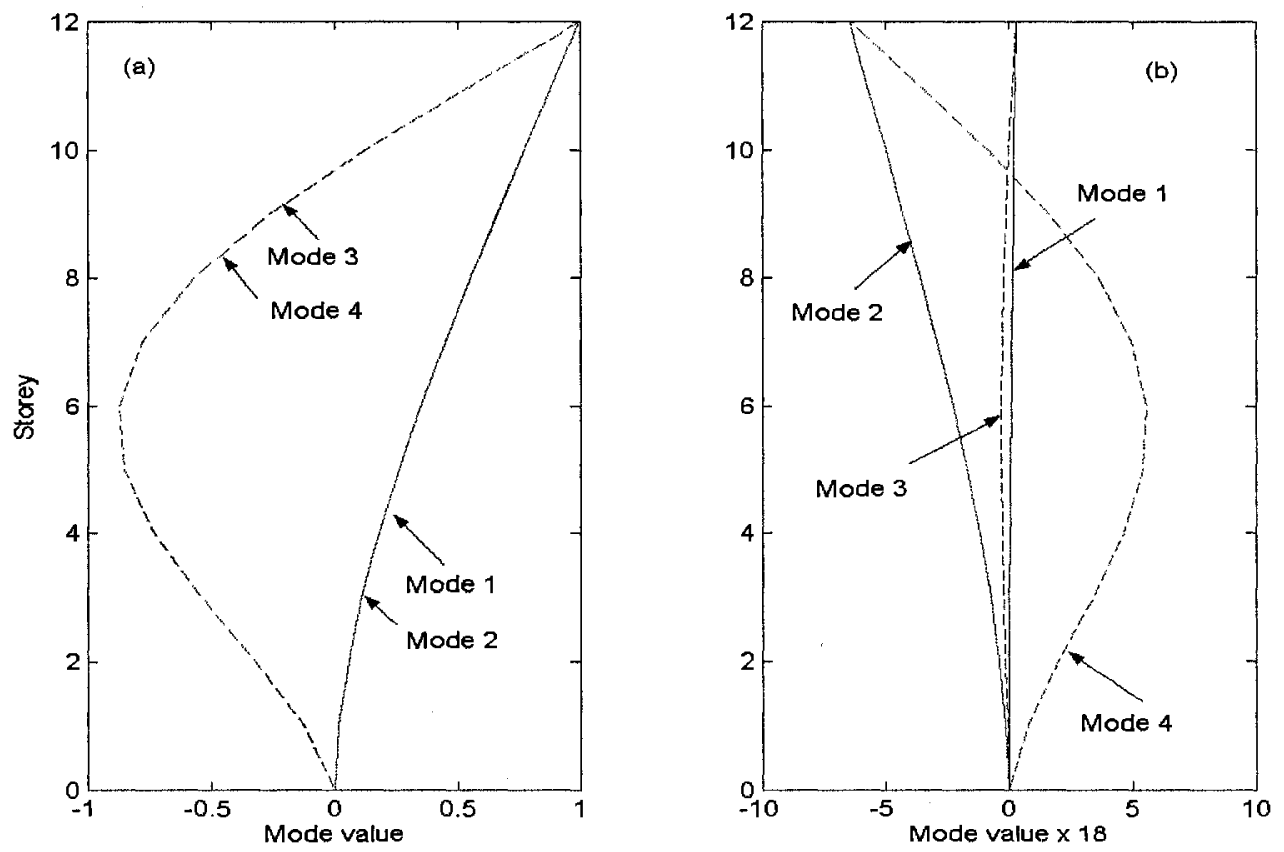

Figure 3.8: Mode shapes of 12-storey unsymmetric building: (a) lateral displacement component, (b) rotation angle $\mathrm{x} b / 2$ 


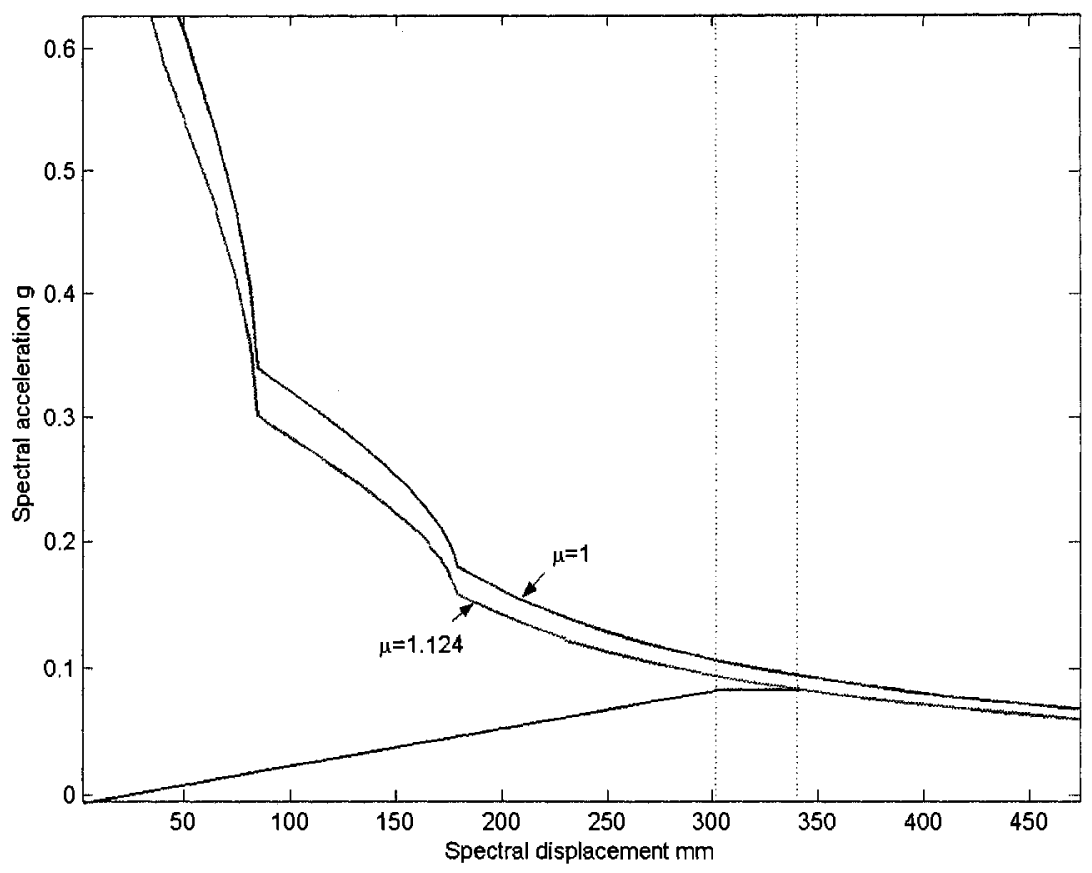

Figure 3.9: Preliminarily design; demand and capacity diagrams for 12-storey unsymmetric building

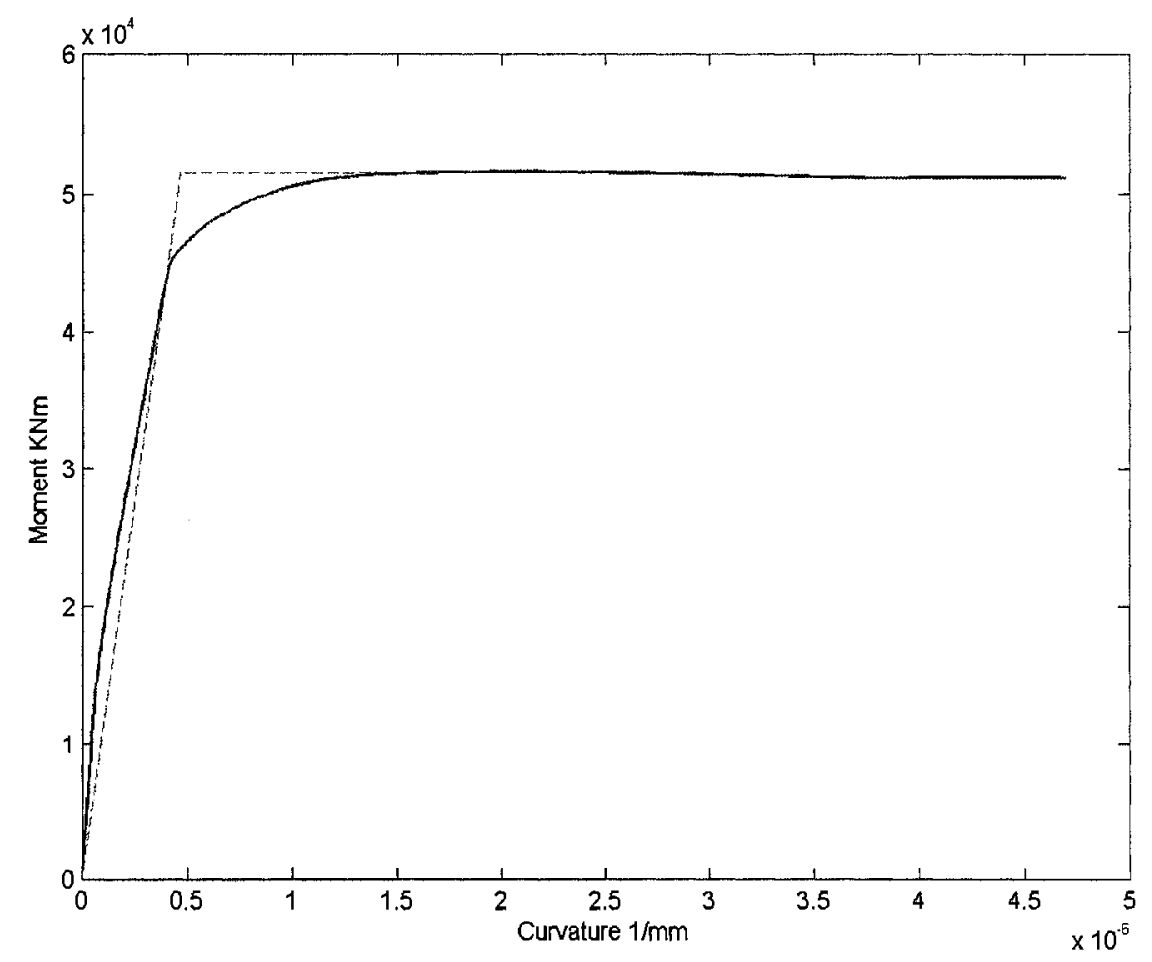

Figure 3.10: Preliminarily design; moment-curvature relationship for the 7-meter stiff edge wall of the 12-storey unsymmetric building 


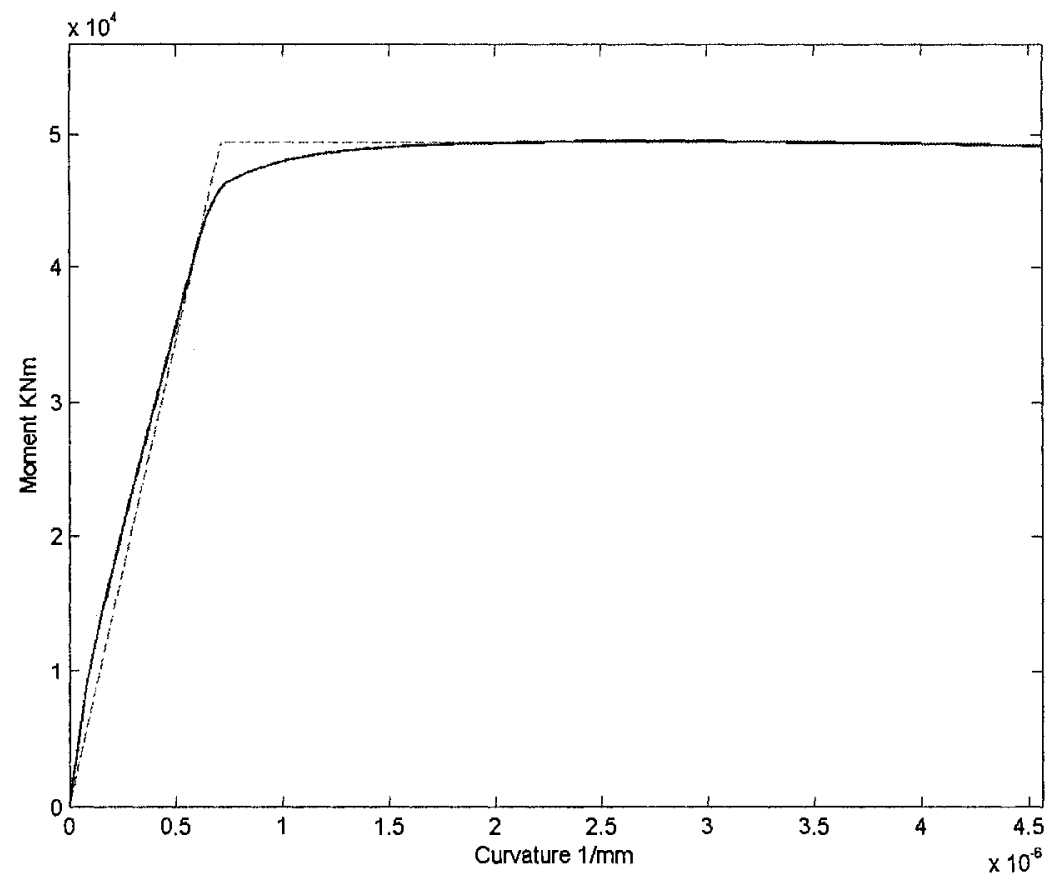

Figure 3.11: Preliminarily design; moment-curvature relationship for the 5-meter flexible edge wall of the 12-storey unsymmetric building

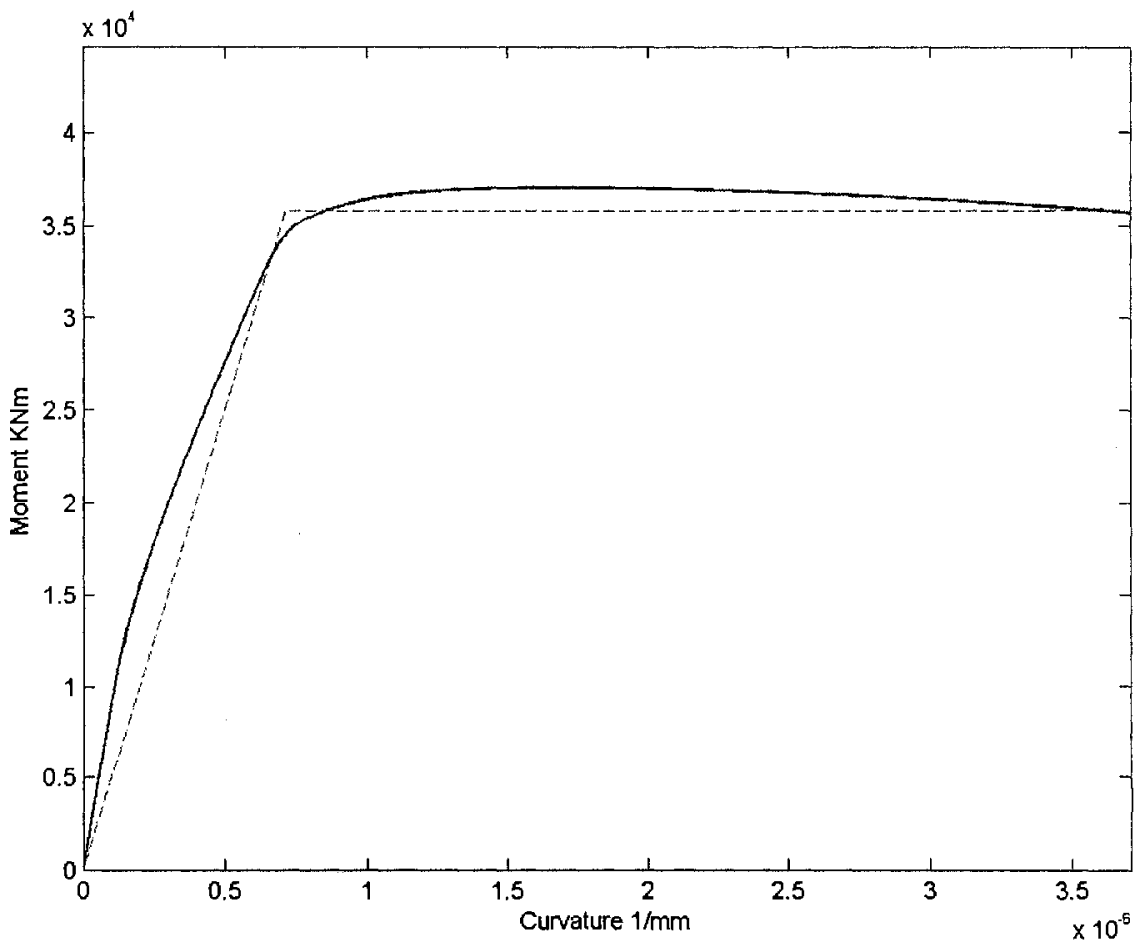

Figure 3.12: Preliminarily design; moment curvature diagram for the central 5-meter wall of the 12-storey unsymmetric building 


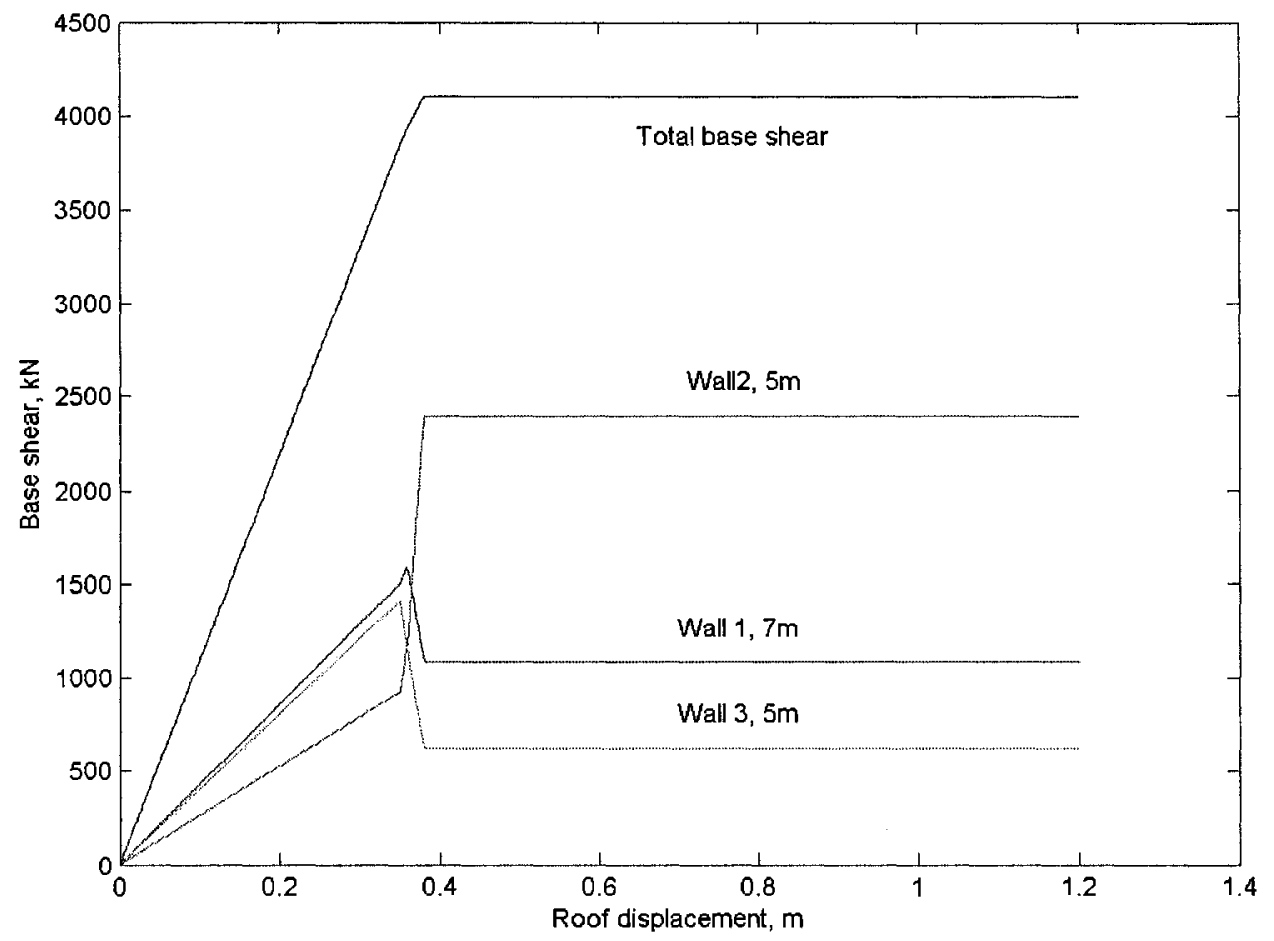

Figure 3.13: Push over curve in the first iteration for 12-storey unsymmetric building

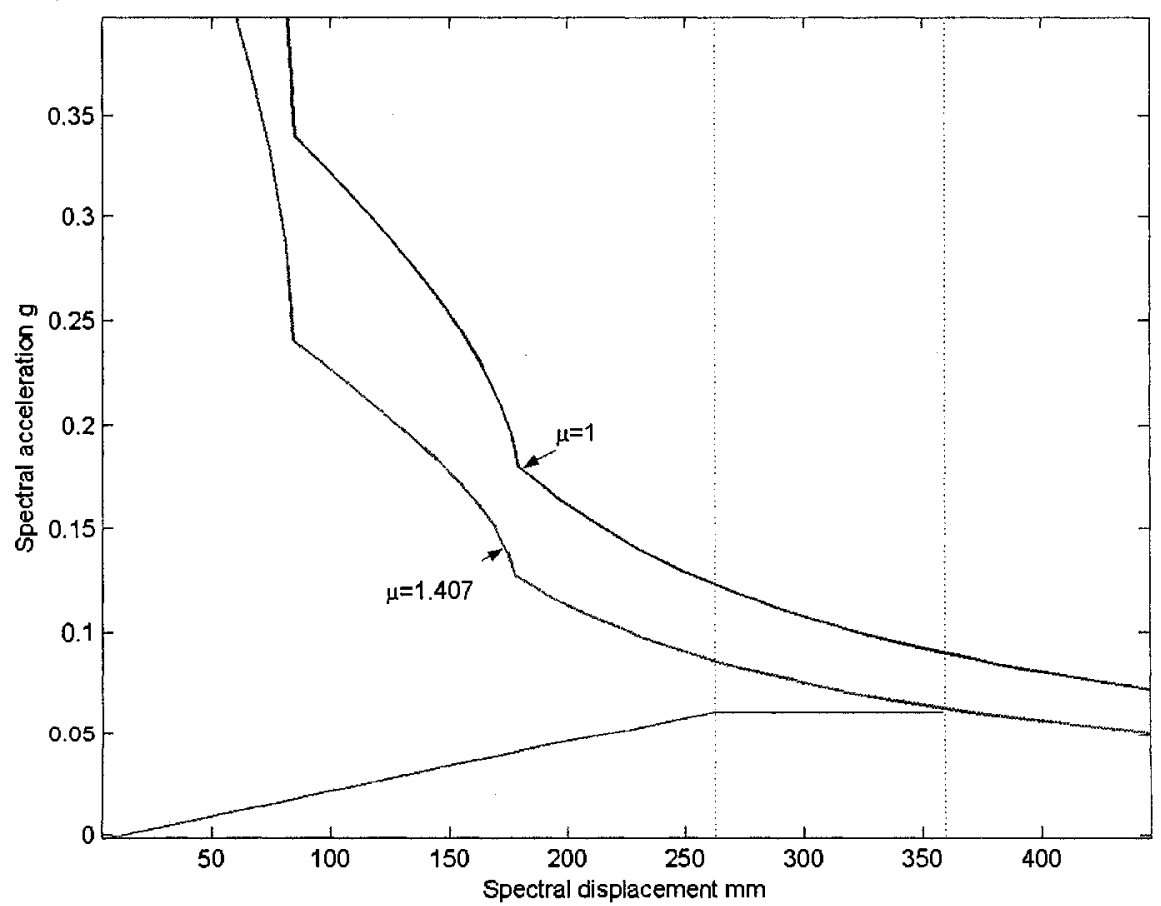

Figure 3.14: Revised demand capacity diagram for 12-storey unsymmetric shear wall building 


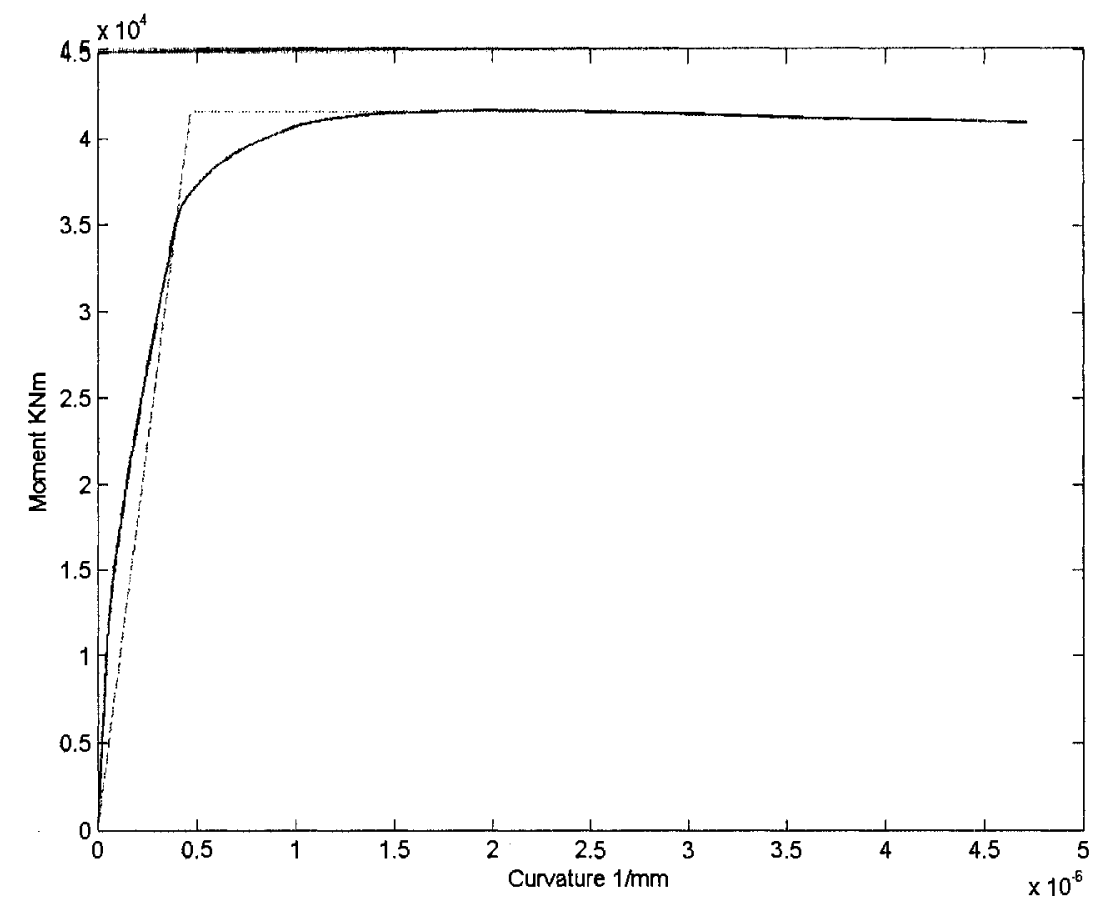

Figure 3.15: Second iteration; moment-curvature relationship for the 7-meter stiff edge wall of the 12-storey unsymmetric building

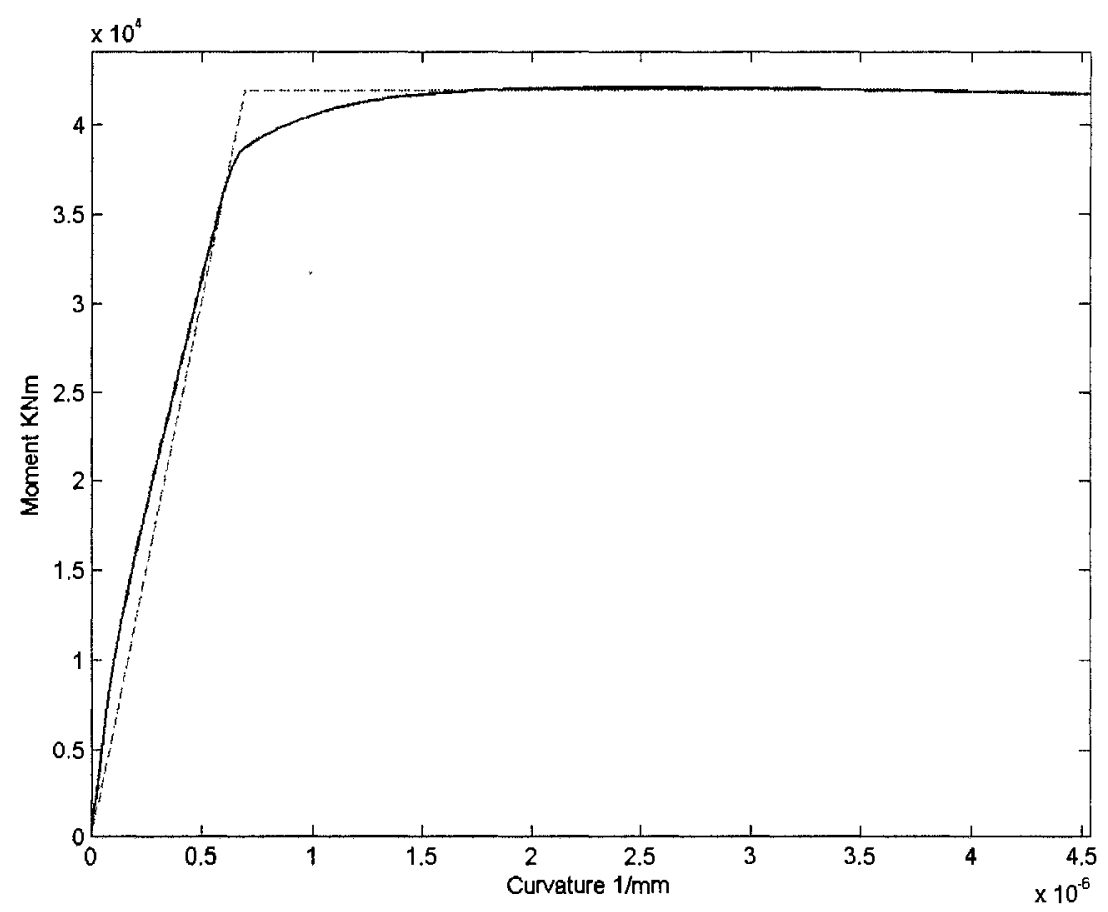

Figure 3.16: Second iteration; moment-curvature relationship for the 5-meter flexible edge wall of the 12-storey unsymmetric building 


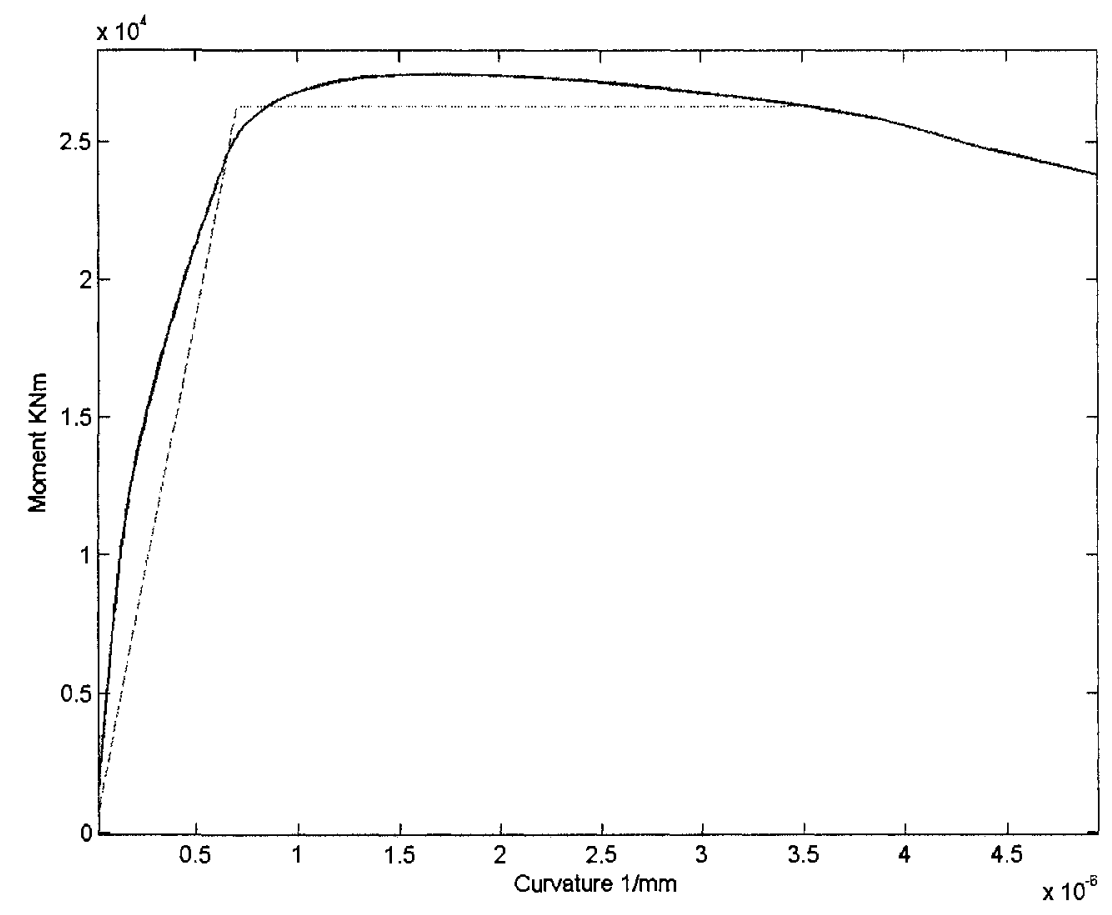

Figure 3.17: Second iteration; moment curvature diagram for the central 5-meter wall of the 12-storey unsymmetric building

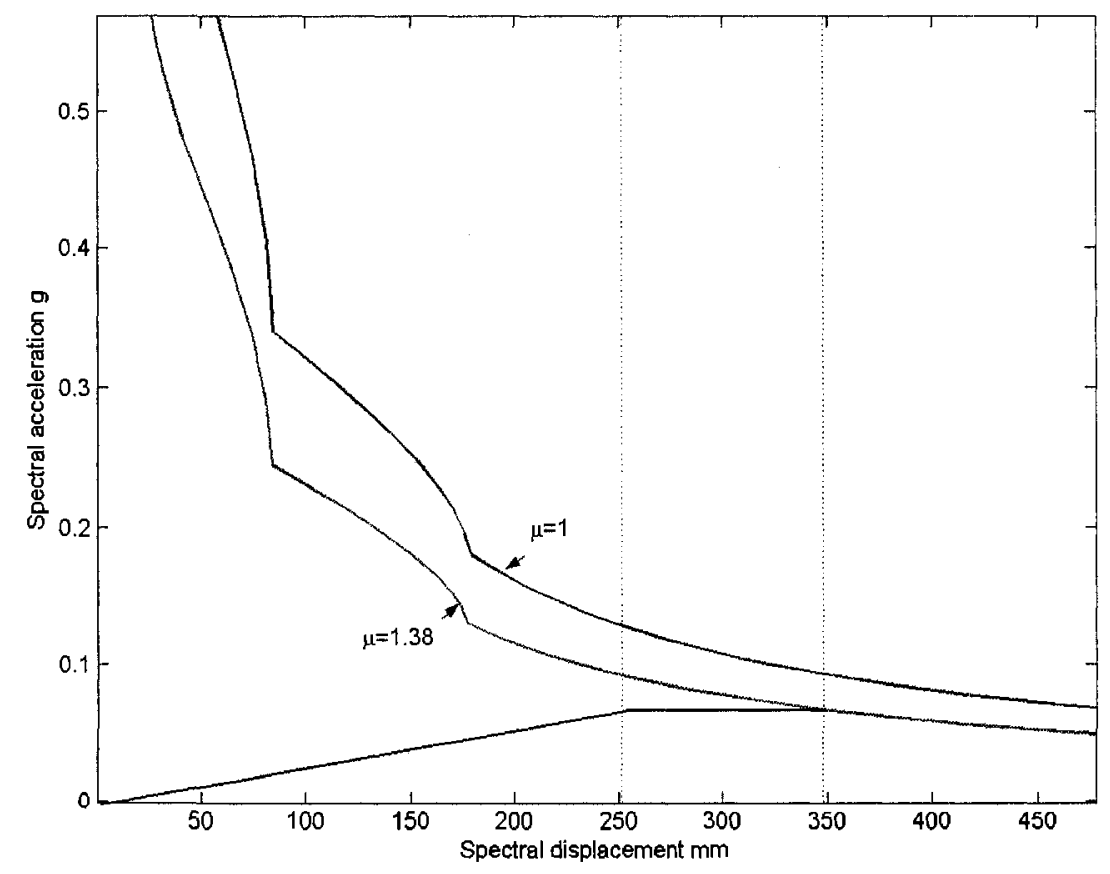

Figure 3.18: Revised demand capacity diagram for 12-storey unsymmetric shear wall building 


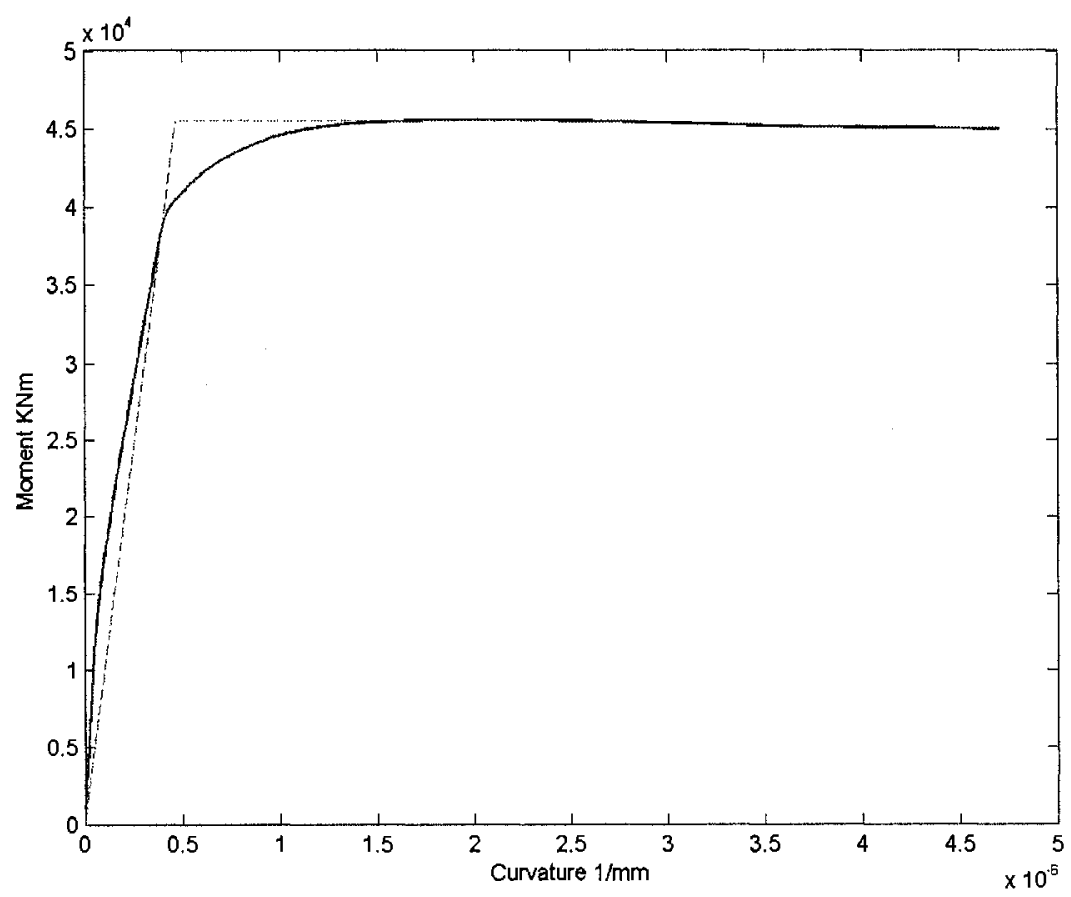

Figure 3.19: Third iteration; moment-curvature relationship for the 7-meter stiff edge wall of the 12-storey unsymmetric building

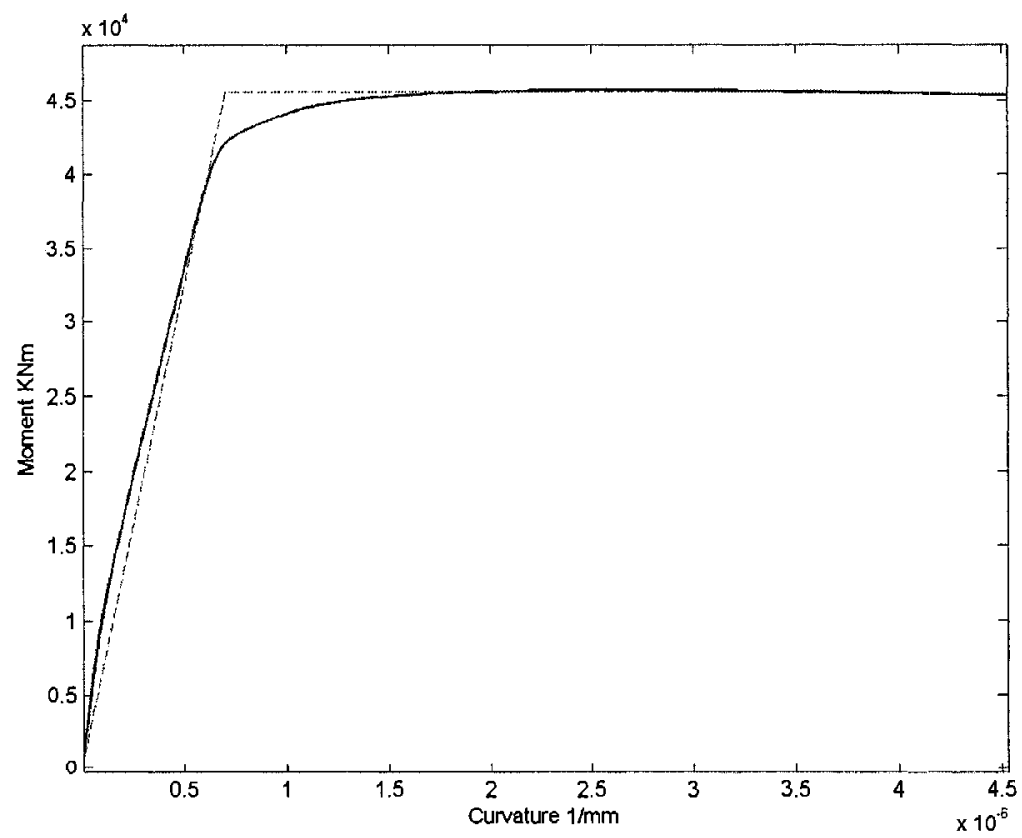

Figure 3.20: Third iteration; moment-curvature relationship for the 5-meter flexible edge wall of the 12 -storey unsymmetric building 


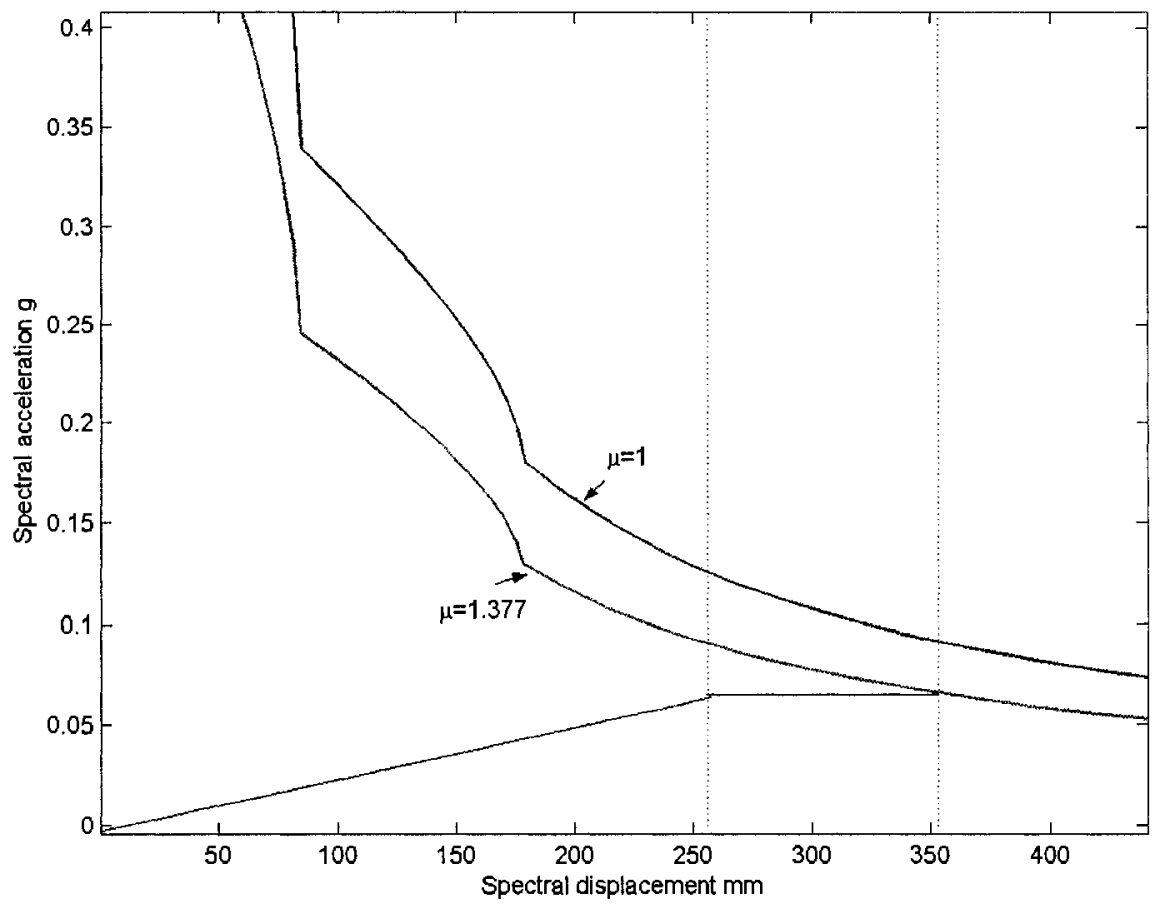

Figure 3.21: Revised demand capacity diagram for 12-storey unsymmetric shear wall building 


\section{Chapter 4}

\section{Evaluation of displacement based seismic design methods}

\subsection{Introduction}

In this chapter an evaluation of the two displacement based seismic design methods developed in this thesis for symmetric building with multiple shear walls and unsymmetric torionaly stiff building is presented. The approximate estimate of the response obtained from the modal push-over analysis that was used in the displacement based design is compared with the exact response obtained from the rigorous non-linear time history analysis. The main response parameters that will be evaluated are maximum roof displacement, maximum inter-storey drift ratio and maximum base shear in order to ensure that (1) the roof displacement obtained from the nonlinear RHA will not exceed the roof displacement which these two buildings were designed to experience in the DBSD, (2) the maximum inter storey drift ratio obtained from the nonlinear RHA will not exceed $2.5 \%$ to satisfy the near collapse performance level, and (3) the base shear obtained from the nonlinear RHA will not exceed the base shear which the shear walls in the two buildings were designed to carry.

Humar and Freddy (2006) collected, filtered and scaled 26 pairs of ground motion acceleration records for matching the seismic demand represented by the UHS of the city 
of Vancouver. Ten of those 26 pairs of ground motions are used for running the nonlinear RHA whose results are presented in this chapter.

The peak values of the three response parameters that will be evaluated is obtained from the output files of the nonlinear RHA for the 20 ground motion records. Each response parameter is statistically processed to obtain the geometric mean, the dispersion and the $84^{\text {th }}$ percentile value. Data for individual ground motions are also of interest. For this purpose, histograms of the 20 values of the peak response are plotted at the end of this chapter.

In order to make a comparison between the 20 values of the peak response and the response obtained from the modal push-over analysis of the DBSD the bias values of the response parameters are computed. A bias value is the ratio between the response obtained from the modal push-over analysis of the DBSD and the peak response for each

ground motion. The geometric mean, the dispersion and the $84^{\text {th }}$ percentile value are obtained for the bias values and histograms of the bias are plotted. Such plots are presented at the end of this chapter.

\subsection{Finite element model used in the Nonlinear RHA}

The nonlinear analyses were carried out using the computer program Opensees developed at the University of California at Berkley. A beam with hinges element developed by Michael H. Scott (2006) is used to model the shear walls. This element is based on the 
non-iterative (or iterative) flexibility formulation, and considers plasticity to be concentrated over specified hinge lengths at the element ends. This type of element divides the element in three parts: two hinges at the ends, and a linear-elastic region in the middle (Figure 4.1). The hinges are defined by assigning to each hinge a previouslydefined section property. That section property models the moment curvature relationship of the shear walls as determined during the DBSD. The length of all the plastic hinges is selected to be very small so that plasticity is concentrated at point hinges. Failure occurs at the plastic hinges due to flexure only. Shear and sliding failures are not considered. All the beams with hinge elements that model the shear walls are assumed as being fixed at the foundation level; an elasto-plastic hinge will be formed at that level. A rigidDiaphragm object is used to construct a constraint for all the nodes at the same storey level. This object constrains certain degrees-of-freedom at all the slave nodes in the same storey level so that the floor moves as a rigid plane with the master node lying at the center of mass. The nonlinear RHA is carried out using a unidirectional ground motion in the east-west direction. The results of the nonlinear RHA for three dimensional model of a symmetric building are compared with the results of the nonlinear RHA for a two dimensional model of the same symmetric building developed using computer program DRAIN_2DX and identical results are obtained.

A mass and stiffness proportional Rayleigh (Chapter 11, Chopra 2007) damping is assigned to the modes that make significant contribution to the response assuming damping ratio $\xi$ to be $5 \%$. For example $5 \%$ damping ratio is assigned to the first and 
fifth modes for the 12-storey unsymmetric torsionaly stiff building because only the first five modes make significant contribution to the response. For the same reason $5 \%$ damping ratio is assigned to the first and third modes for the 12 storey symmetric building as shown in Table 4.1. The other higher modes in the two buildings therefore have a very large damping ratio and consequently make smaller contribution to the various response parameters. The mass and stiffness proportional damping coefficients $a_{o}$ and $a_{1}$ are expressed in terms of the natural frequencies of the mode shapes to which the $5 \%$ damping ratio is assigned.

$a_{o}=\xi \frac{2 \omega_{i} \omega_{j}}{\omega_{i}+\omega_{j}} \quad a_{1}=\xi \frac{2}{\omega_{i}+\omega_{j}}$

where $\xi$ is equal to $5 \%$, and modes $i$ and $j$ are assigned the selected damping.

\subsection{Ground motion for the city of Vancouver}

Humar and Freddy (2006) collected, filtered and scaled 26 pairs of ground motion acceleration records for matching the seismic demand represented by the UHS of the city of Vancouver. Ten of those 26 pairs of ground motions shown in Table 4.2 have been used for running the nonlinear RHA whose results are presented in this chapter. The ground motions were scaled using a scaling method developed by (Somerville et al., 1997) in which the scaling factor was selected to minimize the squared error between the spectral response of the average of two pairs ( $\mathrm{A}$ and $\mathrm{B}$ ) and the target spectral acceleration values for 4 different periods namely $0.3,1,2$ and 4 seconds. Thus this factor ensures that higher modes are considered in the matching process. 


\subsection{Methodology of the statistical evaluation of the response}

The nonlinear response of multi-storey shear wall buildings is complicated and varies significantly from record to record, especially for unsymmetric buildings. Consequently the best distribution for analyzing the results of the nonlinear RHA is the lognormal distribution adopted by Chopra and Geol (2004). The most logical parameters for the evaluation of any lognormal distribution are the geometric mean $\bar{X}$, the $84^{\text {th }}$ percentile and the dispersion measure $\delta_{\mathrm{X}}$ given by

$$
\begin{aligned}
& \bar{X}=\exp \left[\frac{\sum_{i=1}^{n} \ln x_{i}}{n}\right] \\
& P_{84}=\bar{X} \exp \left(\delta_{x}\right) \\
& \delta_{X}=\left[\frac{\sum_{i=1}^{n}\left(\ln x_{i}-\ln \bar{X}\right)^{2}}{n-1}\right]^{1 / 2}
\end{aligned}
$$

The peak response is evaluated for three different response parameters: base shear, roof displacement and storey drift ratio. A histogram for each one of those response parameters is plotted. In order to evaluate the lognormal distribution of the peak response 
for each response parameter the geometric mean $\bar{X}$, the $84^{\text {th }}$ percentile and the dispersion measure $\delta_{\mathrm{X}}$ are obtained.

It will be of interest to compare the peak response for each response parameter being evaluated as obtained from the nonlinear RHA with the response obtained from the modal pushover analysis of the DBSD. For that purpose the bias (the ratio between the response obtained from the modal push-over analysis of the DBSD and the peak response obtained from the RHA for each ground motion) is obtained. The geometric mean $\bar{X}$, the 84th percentile and the dispersion measure $\delta_{X}$ are obtained for those biases. The calculated biases in each response parameter indicate that the DBSD underestimates the response if the geometric mean of the biases is smaller than one and overestimates it if the bias is larger than one. Thus the design method provides a conservative approach for estimating any of the response parameters when the geometric mean is larger than one and an unconservative approach for estimating any of the response parameters when the geometric mean is smaller than one. Histogram of those biases are plotted in order to evaluate the response for individual ground motions.

Histograms for the three different response parameters (roof displacement, base shear and maximum inter-storey drift ratio) for the 12-storey symmetric building are shown in Figure 4.2 with the median response and the range of each response parameter indicated on each histogram. Histograms for the bias of all those response parameters are shown in Figure 4.3 with the median bias and the range of the bias of each response parameter indicated on each histogram. 
Each edge in any unsymmetric building will experience a different roof displacement and maximum inter-storey drift. Consequently there should be a separate evaluation for these two response parameters at each edge of the 12-storey unsymmetric torsionaly stiff building whose design is presented in this thesis. Histograms for the roof displacement and maximum inter-storey drift ratio at each edge of the 12-storey unsymmeric building are plotted in Figure 4.4 and Figure 4.6 with the median response and the range of each response parameter shown on those figures. Bias of those two response parameters are also plotted in Figure 4.5 and Figure 4.7 in separate histograms for each edge of the 12storey unsymmetric building. Histogram for the base shear and the bias of the base shear are also plotted in Figure 4.8 and Figure 4.9 with the median and the range shown in each figure.

\subsection{Evaluation of the results of the 12-storey symmetric building}

An analysis of the results is presented in the following paragraphs.

\subsubsection{Roof displacement}

The roof displacement has a median value of $0.334 \mathrm{~m}$ and $84^{\text {th }}$ percentile value of $0.484 \mathrm{~m}$. It is of interest to note that even though all the records have been selected to match the magnitude distance scenario and the foundation soil characteristics and scaled to match the design spectrum, the response values show a large range. This range for the roof displacement is from $0.15 \mathrm{~m}$ to $0.587 \mathrm{~m}$. The large range of values is a reflection of the 
complicated nature of nonlinear response. The roof displacement obtained from the DBSD by the SRSS combination rule is larger than both the median and $84^{\text {th }}$ percentile value. All bias values for the roof displacement are larger than 1 which indicates that the roof displacement obtained from the nonlinear RHA for all of the 20 ground motion records is smaller than the roof displacement which the symmetric building was designed to experience in the DBSD. The dispersion of the roof displacement is 0.3692 . Since the bias is calculated by a single DBSD value and a range of RHA values, the bias values will have a range that is directly related to the range of RHA values and a similar dispersion.

\subsubsection{Maximum inter-storey drift ratio}

The maximum inter-storey drift ratio has a median value of 0.0129 and $84^{\text {th }}$ percentile value of 0.0161 . Again, the drifts cover a wide range from 0.00778 to 0.0184 . The maximum inter-storey drift ratio obtained from the DBSD using the SRSS combination rule is larger than both the median and $84^{\text {th }}$ percentile value. All bias values for the maximum inter-storey drift ratio are larger than 1 except for one ground motion. The maximum inter-storey drift ratios under all of the 20 ground motion records are smaller than 0.025 which indicates that the near collapse performance level which the 12-storey symmetric building was deigned to experience has been achieved. The dispersion of the maximum inter-storey drift ratio is 0.223 .

\subsubsection{Base shear}


The base shear has a median value of $10561.1 \mathrm{kN}$ and $84^{\text {th }}$ percentile value of 12797.4 $\mathrm{kN}$. The base shears range from $7019 \mathrm{kN}$ to $14603 \mathrm{kN}$. In a majority of the cases the base shear obtained from the DBSD by the SRSS combination rule is smaller than the median. In fact 16 of the bias values for the base shear are smaller than 1 which indicates that the base shear is underestimated by the DBSD when the SRSS combination rule is used. The median value of the bias is 0.883 . Such underestimation of the shear is quite common when SRSS rule is used and has been observed even in linear response spectrum analysis Chopra (2004). When the ABSSUM combination rule is used the base shear obtained from the DBSD is larger than the base shear obtained from the nonlinear RHA for 20 ground motions. The dispersion of the base shear is 0.191 .

\subsection{Evaluation of the results of the 12-storey unsymmetric building}

An analysis of the results is presented in the following paragraph

\subsubsection{Roof displacement}

\subsubsection{Stiff edge roof displacement}

The roof displacement at the stiff edge has a median value of $0.298 \mathrm{~m}$ and $84^{\text {th }}$ percentile value of $0.462 \mathrm{~m}$. As compared to the symmetric building, the range of values in this case is even larger, from $0.155 \mathrm{~m}$ to $0.735 \mathrm{~m}$. This shows that the nonlinear response of unsymmetric buildings is even more complicated and subject to considerable variation 
depending on the details of the ground motion and the characteristics of the building. The roof displacement at the stiff edge obtained from the DBSD by the SRSS combination rule is larger than the median but smaller than the $84^{\text {th }}$ percentile value. The bias values for the roof displacement at the stiff edge are larger than 1 except for 4 ground motion records which indicates that the roof displacement at the stiff edge obtained from the nonlinear RHA is in general smaller than the roof displacement which the stiff edge was designed to experience in the DBSD. The dispersion of the roof displacement at the stiff edge is 0.438 .

\subsubsection{Middle wall roof displacement.}

The roof displacement at the middle wall has a median value of $0.322 \mathrm{~m}$ and $84^{\text {th }}$ percentile value of $0.499 \mathrm{~m}$. The values range from $0.162 \mathrm{~m}$ to $0.766 \mathrm{~m}$. The roof displacement at the middle wall obtained from the DBSD by the SRSS combination rule

is larger than both the median and $84^{\text {th }}$ percentile value. The bias results for the roof displacement at the middle wall are larger than 1 except for 3 ground motions records. This indicates that the roof displacement at the middle wall obtained from the nonlinear RHA is in general smaller than the roof displacement which the middle wall was designed to experience in the DBSD. The dispersion of the roof displacement at the middle wall is 0.437 .

\subsubsection{Flexible edge roof displacement}


The roof displacement at the flexible edge has a median value of $0.352 \mathrm{~m}$ and $84^{\text {th }}$ percentile value of $0.549 \mathrm{~m}$. The values range from $0.170 \mathrm{~m}$ to $0.846 \mathrm{~m}$. The roof displacement at the flexible edge obtained from the DBSD by the SRSS combination rule is larger than both the median and $84^{\text {th }}$ percentile value. The bias values for the roof displacement at the flexible edge are larger than 1 except for 3 ground motions records. This indicates that the roof displacement at the middle wall obtained from the nonlinear RHA is in general smaller than the roof displacement which the flexible edge was designed to experience in the DBSD. The dispersion of the roof displacement at the flexible edge is 0.437 .

\subsubsection{Maximum inter-storey drift ratio}

\subsubsection{Stiff edge maximum inter-storey drift ratio}

The maximum inter-storey drift ratio at the stiff edge has a median value of 0.011 and $84^{\text {th }}$ percentile value of 0.0142 . Again, the values cover a wide range from 0.0078 to 0.0203. The maximum inter-storey drift ratio at the stiff edge obtained from the DBSD by the SRSS combination rule is larger than the median and smaller than the $84^{\text {th }}$ percentile value. All the bias values for the maximum inter-storey drift ratio at the stiff edge are larger than 1 except for 5 ground motion records, which indicates that the maximum inter-storey drift ratio at the stiff edge obtained from the nonlinear RHA is smaller than the maximum inter-storey drift ratio at the stiff edge obtained from the DBSD by the 
SRSS combination rule except for 5 out of the 20 ground motion records used in running the nonlinear RHA. All the maximum inter-storey drift ratios at the stiff edge for the 20 ground motion records were smaller than 0.025 which indicates that the near collapse performance level which the stiff edge was designed to experience was achieved. The dispersion of the maximum inter-storey drift ratio at the stiff edge is 0.253 .

\subsubsection{Middle wall maximum inter-storey drift ratio}

The maximum inter-storey drift ratio at the middle wall has a median value of 0.0123 and $84^{\text {th }}$ percentile value of 0.0157 . The values range from 0.0083 to 0.0215 . The maximum inter-storey drift ratio at the middle wall obtained from the DBSD by the SRSS

combination rule is larger than the median and smaller than the $84^{\text {th }}$ percentile value. All the bias values for the maximum inter-storey drift ratio at the middle wall are larger than 1 except for 4 ground motion records, which indicates that the maximum inter-storey drift ratio at the middle wall obtained from the nonlinear RHA was smaller than the maximum inter-storey drift ratio at the middle wall obtained from the DBSD by the SRSS combination rule except for 4 out of the 20 ground motion records used in running the nonlinear RHA. The maximum inter-storey drift ratios at the middle wall for all of the 20 ground motion records are smaller than 0.025 , which indicates that the near collapse performance level which the middle wall was deigned to experience was achieved. The dispersion of the maximum inter-storey drift ratio at the middle wall is 0.24 .

\subsubsection{Flexible edge maximum inter-storey drift ratio}


The maximum inter-storey drift ratio at the flexible edge has a median value of 0.0138 and $84^{\text {th }}$ percentile value of 0.0176 . The values range from 0.009 to 0.0236 . The maximum inter-storey drift ratio at the flexible edge obtained from the DBSD by the SRSS combination rule is larger than the median and the $84^{\text {th }}$ percentile value. All the bias values for the maximum inter-storey drift ratio at the flexible edge are larger than 1 except for 3 ground motion records which indicates that the maximum inter-storey drift ratio at the flexible edge obtained from the nonlinear RHA is smaller than the maximum inter-storey drift ratio at the flexible edge obtained from the DBSD by the SRSS combination rule except for 3 out of the 20 ground motion records used in running the nonlinear RHA. The maximum inter-storey drift ratios at the flexible edge for all of the 20 ground motion records are smaller than .025 which indicates that the near collapse performance level which the flexible edge was designed to experience was achieved. The dispersion of the maximum inter-storey drift ratio at the flexible edge is 0.239 .

\subsubsection{Base shear}

The base shear has a median value of $13043.4 \mathrm{kN}$ and $84^{\text {th }}$ percentile value of 16080.9 $\mathrm{kN}$. The values range from $8631 \mathrm{kN}$ to $18258 \mathrm{kN}$. The base shear obtained from the DBSD by the SRSS combination rule is smaller than both the median and $84^{\text {th }}$ percentile values. Also 15 of the bias values for the base shear are smaller than 1, which indicates that the base shear is underestimated by the DBSD when the SRSS combination rule is used. The median value of the bias is 0.83 . As stated earlier, the underestimation can be 
partly attributed to the nature of the SRSS estimation. When the ABSSUM combination rule is used the base shear obtained from the DBSD is larger than the base shear obtained from the nonlinear RHA for all the 20 ground motion records. The dispersion of the base shear is 0.209 .

\subsection{Summary and conclusion}

The median and $84^{\text {th }}$ percentile values for the roof displacement are smaller than the roof displacement obtained from the modal pushover analysis of the DBSD when using the SRSS combination rule for the 12-storey symmetric building and for each edge of the 12storey unsymmetric building. The median bias value of the roof displacement is larger than one for each of the two buildings. All the bias values of the roof displacement are larger than one for the 12-storey symmetric building. The bias values are smaller than one only for a few records for each edge of the 12-storey unsymmetric building. It can therefore be concluded that the DBSD overestimated the roof displacement for the two buildings and provided a conservative design for both of them.

The median and $84^{\text {th }}$ percentile values for the maximum inter-storey drift ratio are smaller than the maximum inter-storey drift ratio obtained from the modal pushover analysis of the DBSD when using the SRSS combination rule for the 12-storey symmetric building. The median values for the maximum inter-storey drift ratio are smaller than the maximum inter-storey drift ratio obtained from the modal pushover analysis of the DBSD when using the SRSS combination rule for each edge of the 12-storey unsymmetric 
building; however the $84^{\text {th }}$ percentile values for the maximum inter-storey drift ratio of the stiff edge and the middle wall are larger than the maximum inter-storey drift ratio obtained from the DBSD when using the SRSS combination role. The bias values are smaller than one for only a few records for the 12-storey symmetric building and for each edge of the 12-storey unsymmetric building. All of the maximum inter-storey drift ratios for the 12-storey symmetric building and for each edge of the 12-storey unsymmetric building are smaller than 0.025 for all 20 ground motion records, which indicates that the near collapse performance level was achieved for the two buildings. Thus the DBSD overestimated the maximum inter-storey drift ratio, achieved the required performance objective and provided a conservative design for the two buildings.

The median and $84^{\text {th }}$ percentile values for the base shear are larger than the base shear obtained from the modal pushover analysis of the DBSD when using the SRSS combination rule for the two buildings. When the ABSSUM combination rule is used the base shear obtained from the DBSD is larger than the base shear obtained from the nonlinear RHA for all 20 ground motion records for the two buildings. The ABSSUM combination rule thus provides a conservative value for the base shear which the shear walls of the two buildings are designed to carry. 
Table 4.1: Rayleigh damping coefficient for 12-storey symmetric and 12-storey usymmetric buildings

\begin{tabular}{|c|c|c|c|c|}
\hline Building & $\begin{array}{c}\text { Mode no i } \\
\text { natural } \\
\text { frequency } \\
\omega_{\mathrm{i}}(\mathbf{r a d} / \mathbf{s e c})\end{array}$ & $\begin{array}{c}\text { Mode no } \mathbf{j} \\
\text { natural } \\
\text { frequency } \\
\omega_{\mathrm{i}}(\mathbf{r a d} / \mathbf{s e c})\end{array}$ & $\begin{array}{c}\text { Mass } \\
\text { proportional } \\
\text { coefficient } \\
\mathbf{a}_{\mathbf{0}}\end{array}$ & $\begin{array}{c}\text { Stiffness } \\
\text { proportional } \\
\text { coefficient } \\
\mathbf{a}_{\mathbf{1}}\end{array}$ \\
\hline $\begin{array}{c}\text { 12-storey } \\
\text { symmetric }\end{array}$ & $\omega_{1}=1.459$ & $\omega_{3}=25.75$ & 0.138 & 0.0036 \\
\hline $\begin{array}{c}\mathbf{1 2} \text { storey } \\
\text { unsymmetric }\end{array}$ & $\omega_{1}=1.634$ & $\omega_{5}=28.79$ & 0.1546 & 0.00328 \\
\hline
\end{tabular}

Table 4.2: Final selections for 20 ground motions for the city of Vancouver

\begin{tabular}{|c|c|c|c|c|c|c|c|}
\hline GM & Earthquake & Record & $\begin{array}{c}\text { Number } \\
\text { of }\end{array}$ & $\Delta \mathbf{t}$ & $\begin{array}{l}\text { Scaling } \\
\text { Factor }\end{array}$ & Factor & Final \\
\hline$\#$ & name & name & Points & (s) & $\alpha_{\mathrm{sm}}$ & $\begin{array}{c}\text { from record } \\
\text { (g) }\end{array}$ & $\begin{array}{l}\text { Factor } \\
\left(\mathrm{m} / \mathrm{s}^{2}\right)\end{array}$ \\
\hline 1 & Nisqually (2001) & Nis1_NS & 17000 & 0.010 & 2.83 & 0.00079872 & 0.0221752 \\
\hline 2 & Nisqually (2001) & Nis1 EW & 17000 & 0.010 & 2.83 & 0.00079936 & 0.0221929 \\
\hline 3 & Nisqually (2001) & Nis2 NS & 48001 & 0.010 & 3.16 & 0.10193680 & 3.1594753 \\
\hline 4 & Nisqually (2001) & Nis2 EW & 48001 & 0.010 & 3.16 & 0.10193680 & 3.1594753 \\
\hline 5 & Nisqually (2001) & Nis3 NS & 17900 & 0.010 & 3.32 & 0.00080000 & 0.0260607 \\
\hline 6 & Nisqually (2001) & Nis3_EW & 17900 & 0.010 & 3.32 & 0.00080000 & 0.0260607 \\
\hline 7 & Nisqually (2001) & Nis4 NS & 20500 & 0.010 & 4.19 & 0.00080000 & 0.0328647 \\
\hline 8 & Nisqually (2001) & Nis4 EW & 20500 & 0.010 & 4.19 & 0.00080000 & 0.0328647 \\
\hline 9 & Nisqually (2001) & Nis6 NS & 48001 & 0.010 & 4.74 & 0.10193680 & 4.7382612 \\
\hline 10 & Nisqually (2001) & Nis6_EW & 48001 & 0.010 & 4.74 & 0.10193680 & 4.7382612 \\
\hline 11 & Nisqually (2001) & Nis8 NS & 104900 & 0.010 & 3.85 & 0.00079872 & 0.0030759 \\
\hline 12 & Nisqually (2001) & Nis8_EW & 104900 & 0.010 & 3.85 & 0.00079872 & 0.0030759 \\
\hline 13 & Nisqually (2001) & Nis9 NS & 48001 & 0.010 & 4.63 & 0.10193680 & 0.4723844 \\
\hline 14 & Nisqually (2001) & Nis9_EW & 48001 & 0.010 & 4.63 & 0.10193680 & 0.4723844 \\
\hline 15 & Tokachi (2003) & Tok1 NS & 29981 & 0.010 & 0.79 & 0.00000024 & 0.0000019 \\
\hline 16 & Tokachi (2003) & Tok1 EW & 29981 & 0.010 & 0.91 & 0.00000024 & 0.0000022 \\
\hline 17 & Tokachi (2003) & Tok2 NS & 19499 & 0.010 & 1.98 & 0.00000024 & 0.0000047 \\
\hline 18 & Tokachi (2003) & Tok2 EW & 19499 & 0.010 & 1.50 & 0.00000024 & 0.0000036 \\
\hline 19 & Tokachi (2003) & Tok3 NS & 24209 & 0.010 & 1.95 & & 0.0000046 \\
\hline 20 & Tokachi (2003) & Tok3 EW & 24209 & 0.010 & 1.50 & 0.00000024 & 0.0000036 \\
\hline
\end{tabular}




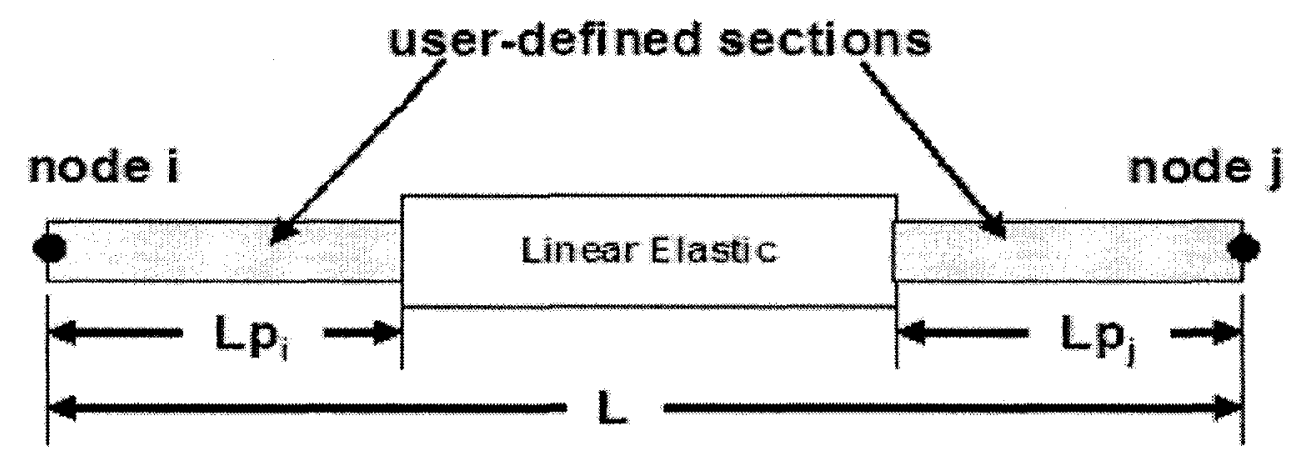

Figure 4.1: Beam with hinges element developed by Michael H. Scott (2006) 

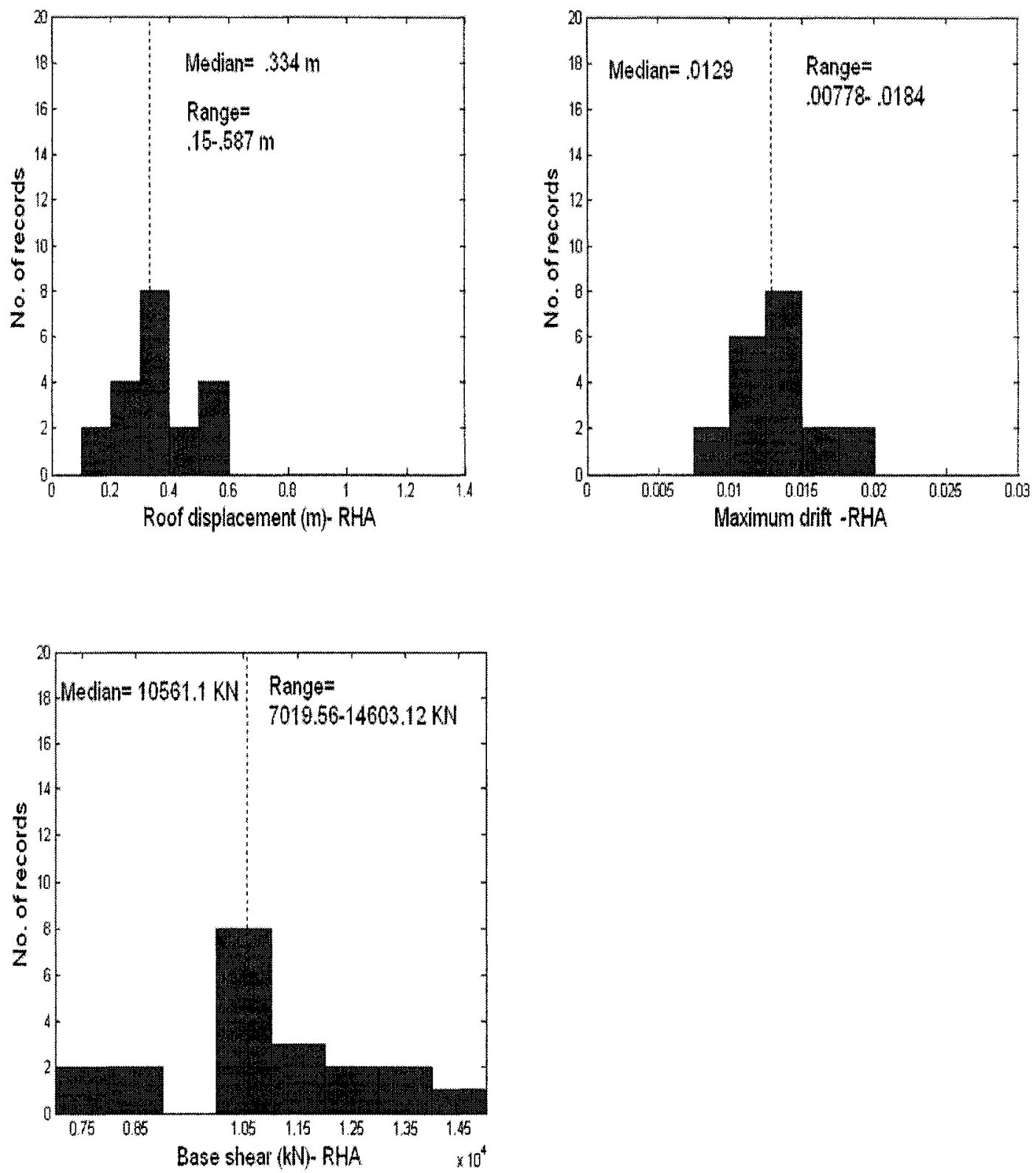

Figure 4.2: Histograms of the roof displacement, maximum inter-storey drift ratio and base shear obtained from the nonlinear RHA for the 12- storey symmetric building 

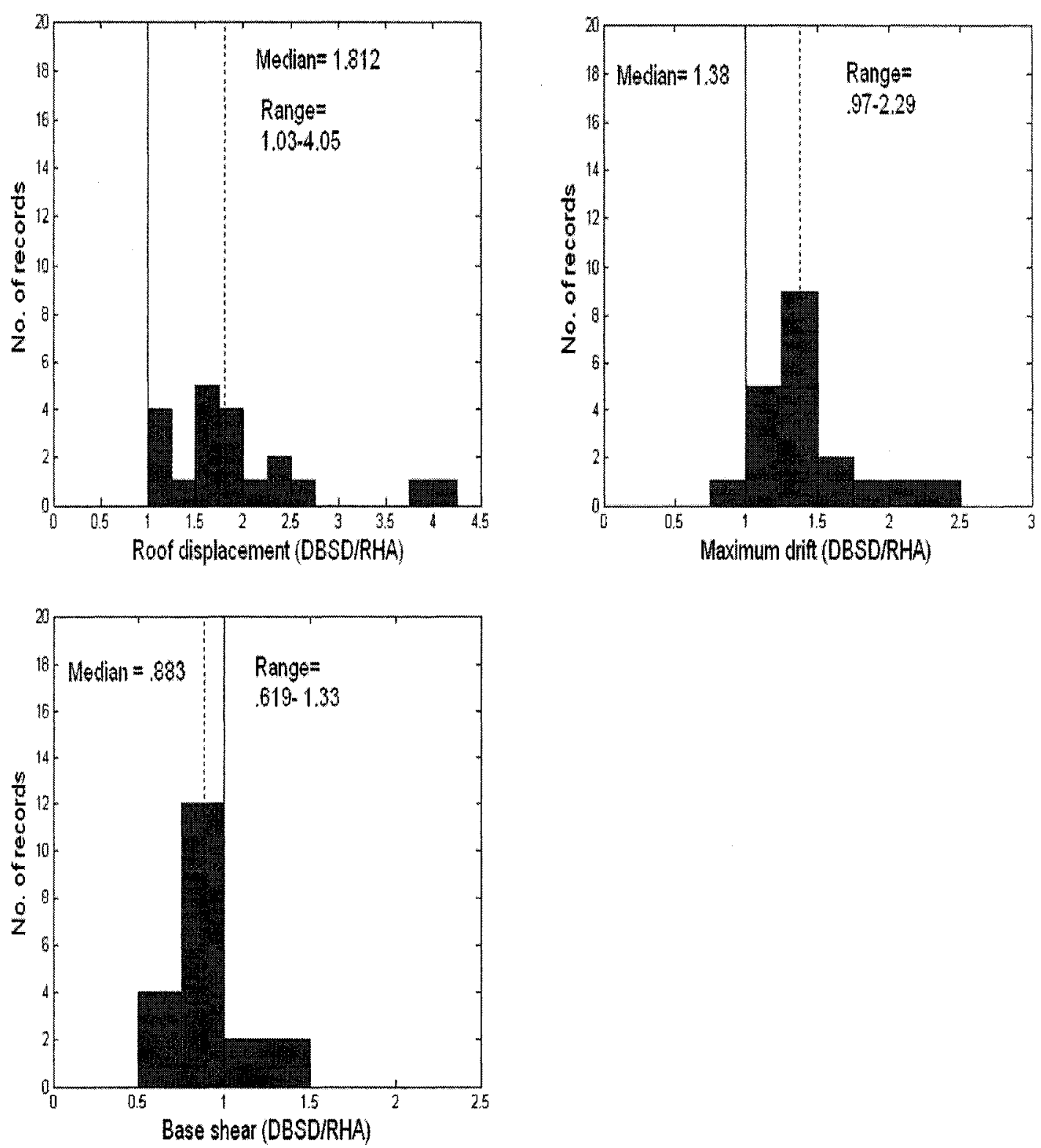

Figure 4.3: Histogram of the ratio between the roof displacement, maximum drift and base shear obtained from DBSD and nonlinear RHA for the 12- storey symmetric building 

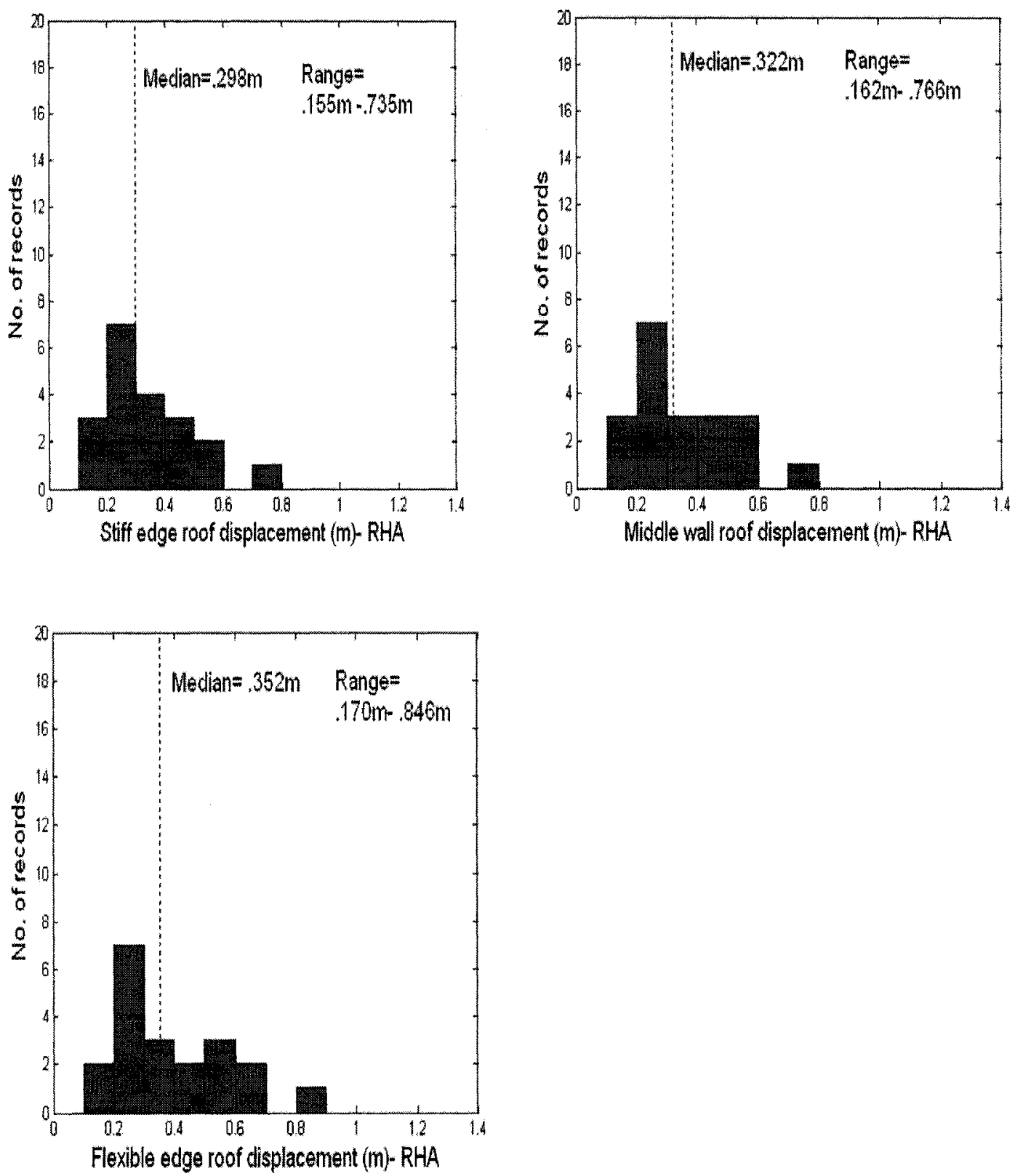

Figure 4.4: Histograms of the roof displacements at each edge of the 12-storey unsymmetric torsionaly stiff building obtained from nonlinear RHA 

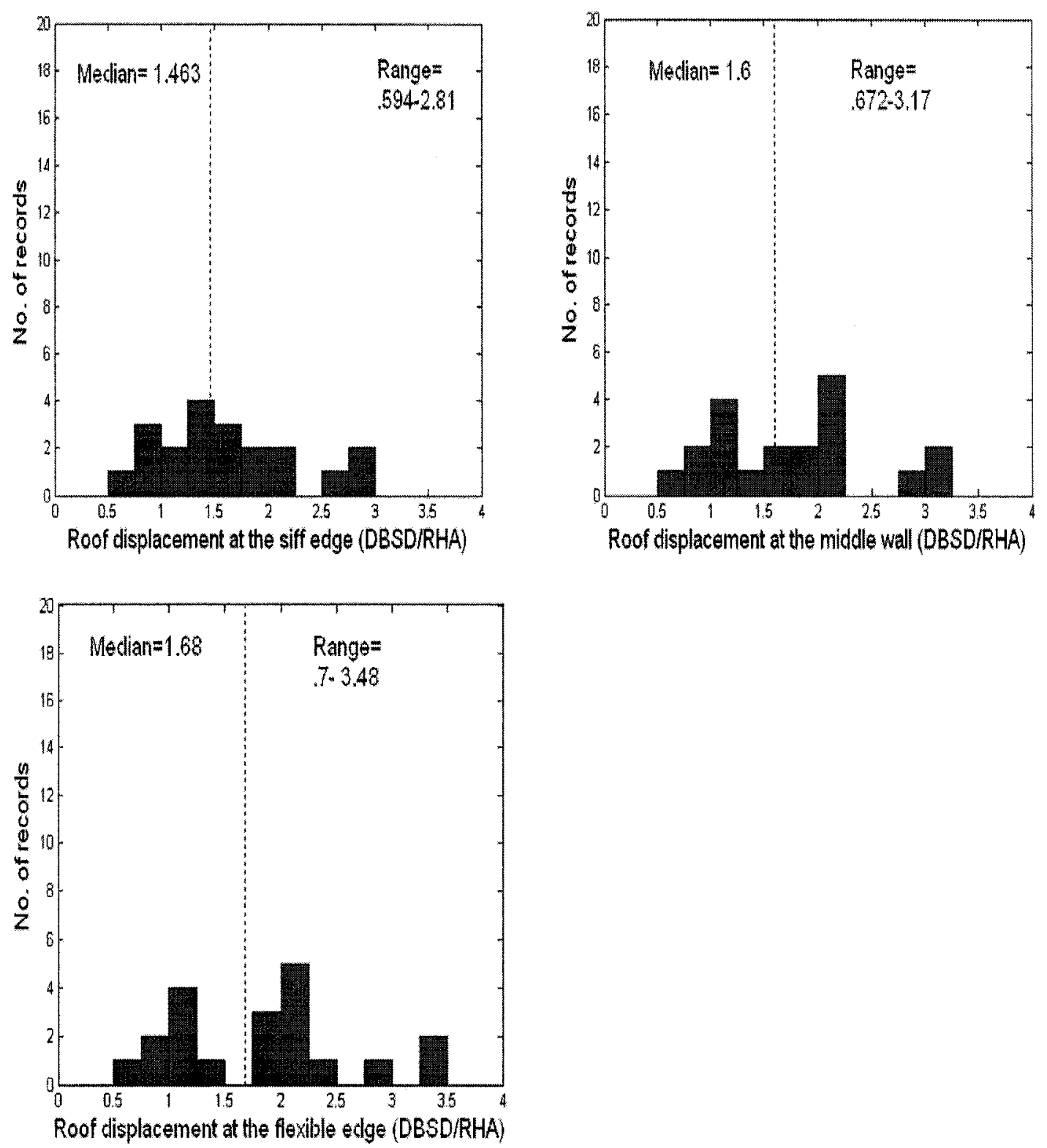

Figure 4.5: Histograms of the ratio between the roof displacements obtained from DBSD and nonlinear RHA at each edge of the 12- storey unsymmetric torsionaly stiff building 

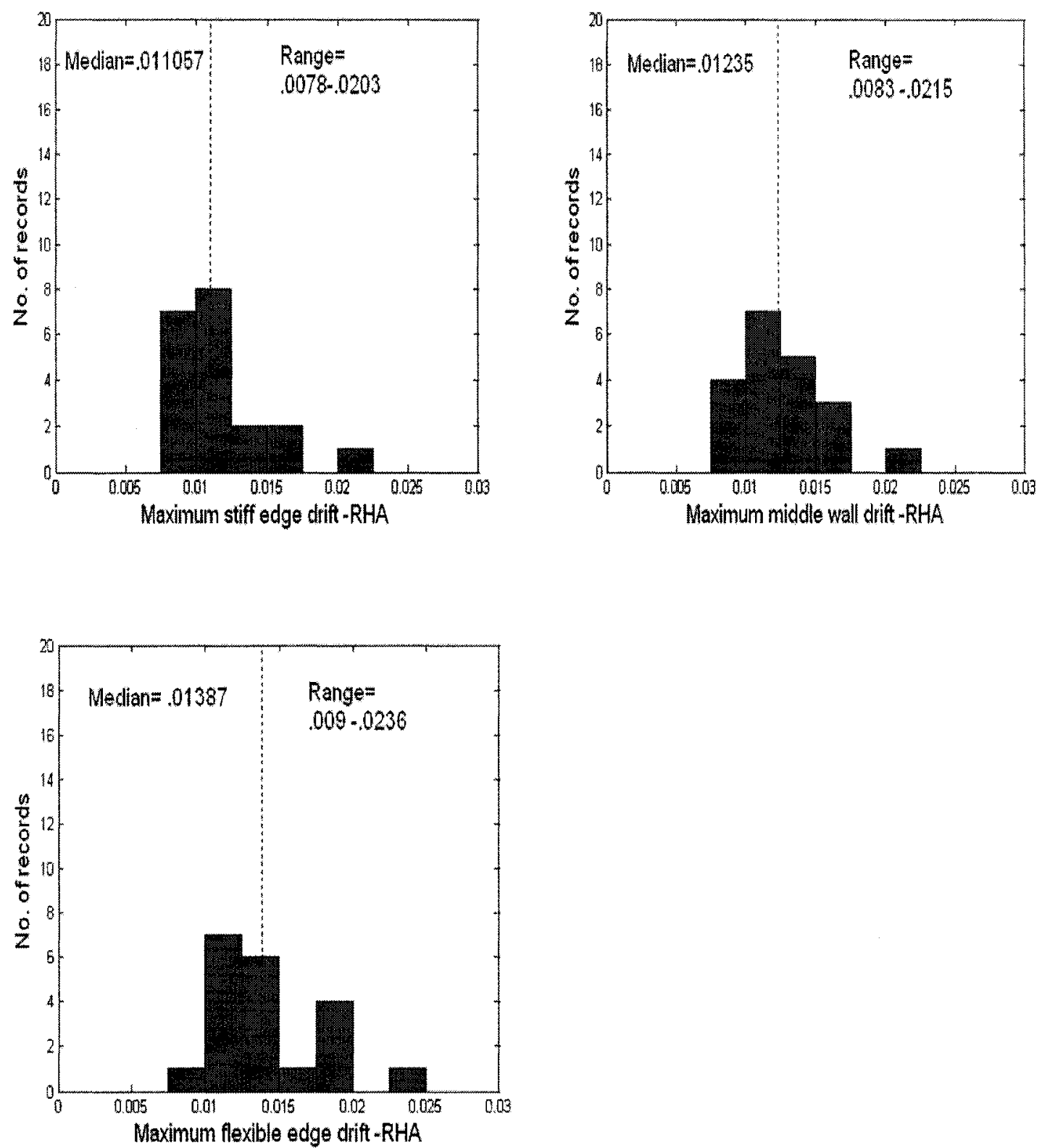

Figure 4.6: Histograms of the maximum inter-storey drift ratios obtained from nonlinear RHA at each edge of unsymmetric torsionaly stiff building 

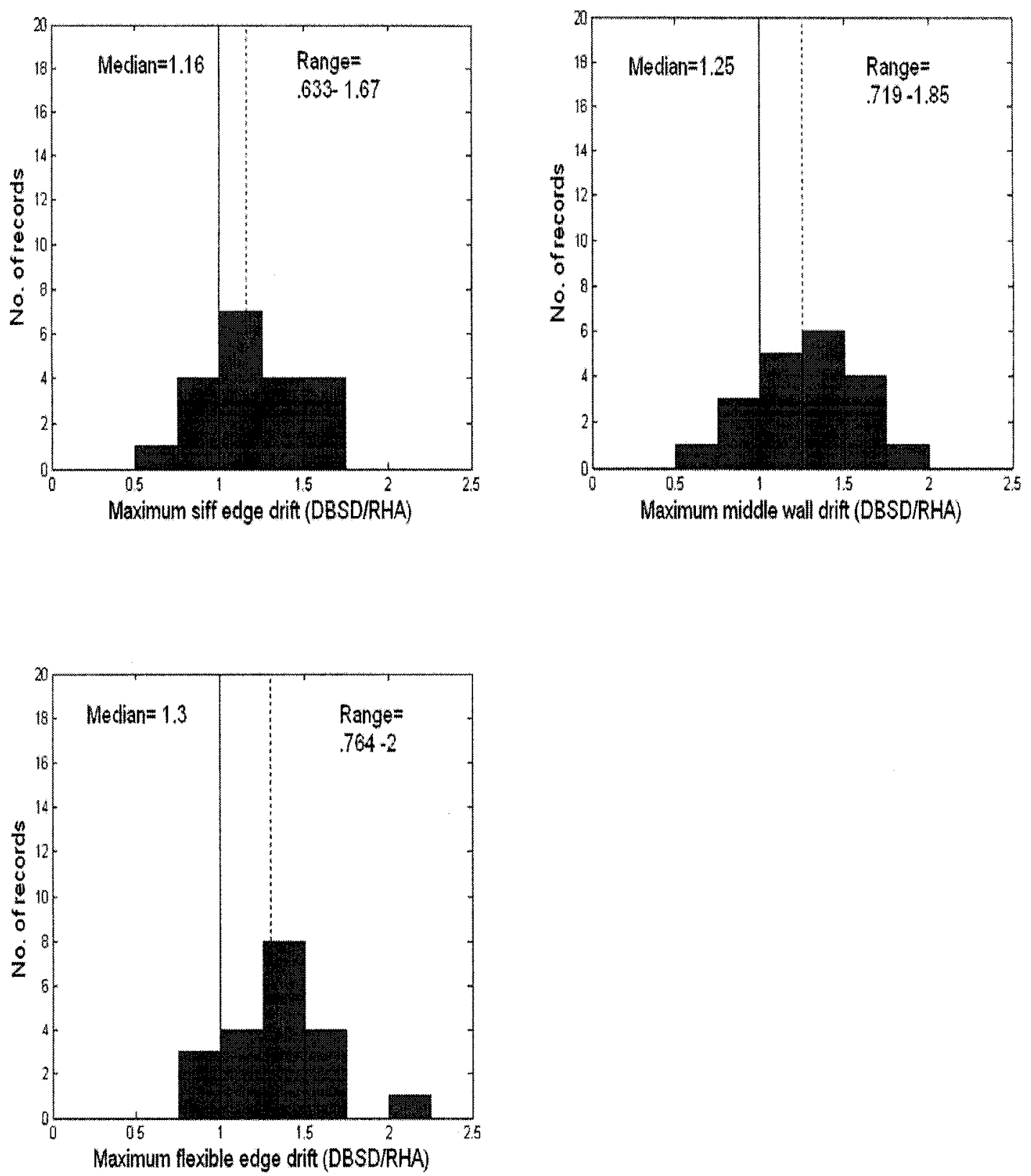

Figure 4.7: Histograms of the ratio between the drift obtained from DBSD and nonlinear RHA at each edge of the 12- storey unsymmetric torsionaly stiff building 


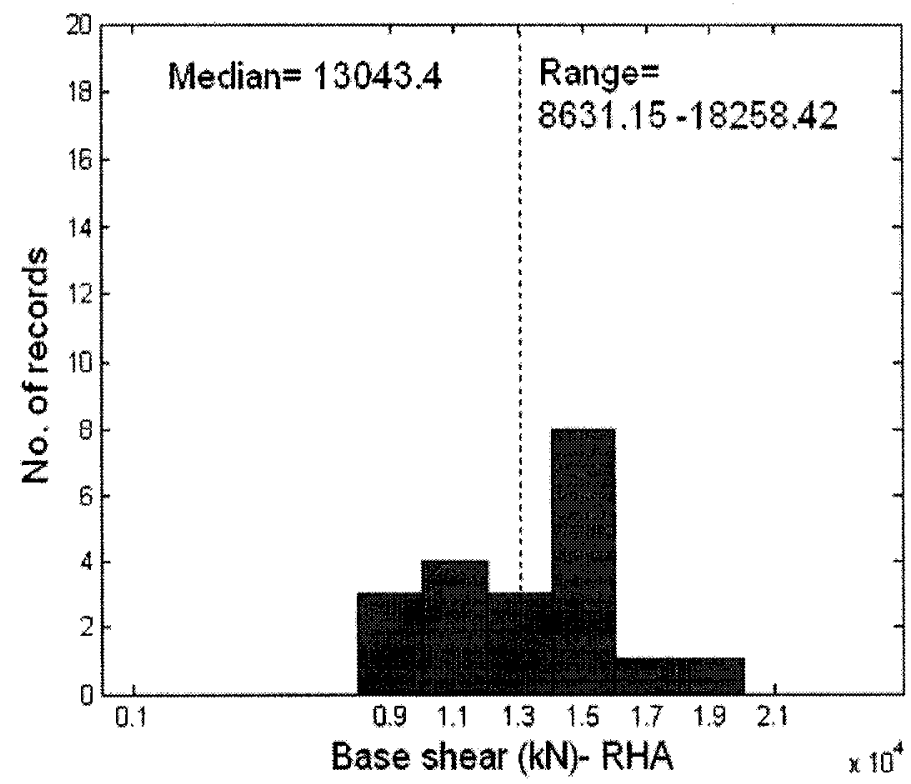

Figure 4.8: Histograms of the base shear of 12-storey unsymmetric torsionaly stiff building obtained from nonlinear RHA

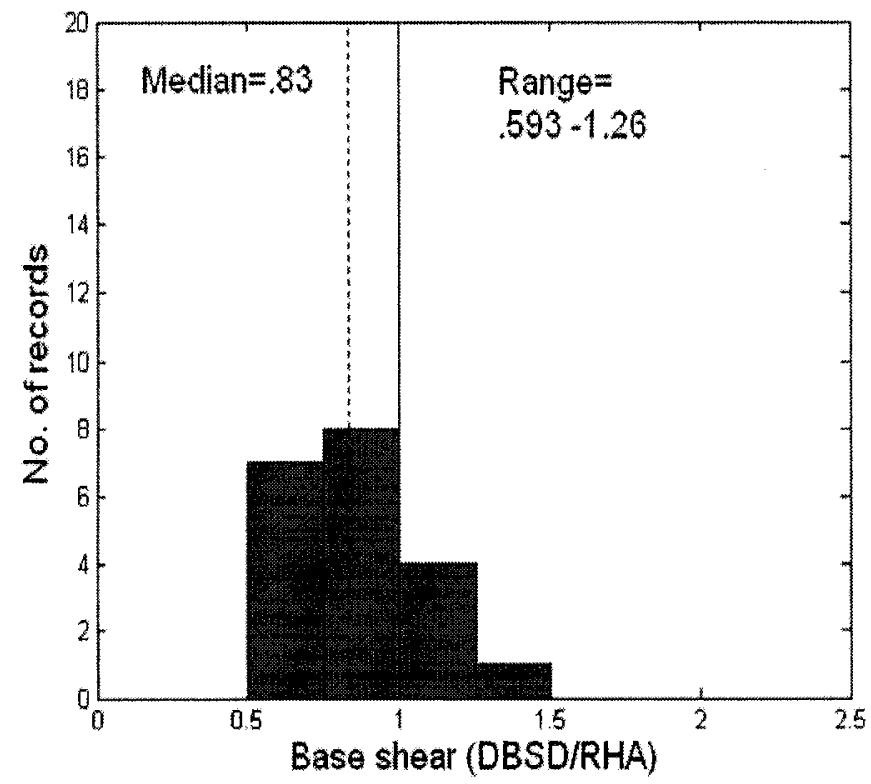

Figure 4.9: Histogram of the ratio between the base shear obtained from DBSD and nonlinear RHA for 12- storey unsymmetric torsionaly stiff building 


\section{Chapter 5}

\section{Summary, Conclusions and recommendations}

\subsection{Summary}

In this thesis a displacement based seismic design method for symmetric buildings with multiple shear walls and unsymmetric torsionally stiff buildings with multiple shear walls is presented. This design method will enable the design professionals to use the performance based design in the seismic design of such buildings. The performance levels are achieved by controlling the roof displacements under specified hazards. The target roof displacement is determined on the basis of code specified storey drift limits, element ductility capacity, and stability under P-Delta effects.

The design method for symmetric shear walls is an extension of the displacement based design method for symmetric buildings with similar size shear walls developed by Humar and Ghorbanie (2004). It will allow the seismic design of symmetric buildings with different wall sizes that might be needed when certain architectural conditions should be satisfied.

Applications of the two design methods are presented in Chapter 3. Two buildings, one symmetric and one unsymmetric, are designed to achieve the near collapse performance 
level, which according to the NBCC 2005 will be achieved by limiting the maximum inter-storey drift ratio to $2.5 \%$ under a seismic hazard with a $2 \%$ probability of exceedance in 50 years or a return period of 2500 years. The two buildings are designed also to keep the ductility demand within ductility capacity associated with a limit of 0.004 on the strain in concrete at the plastic hinge that will be formed at the foundation level which is the limiting value of compressive strain in concrete as appropriate for unconfined concrete. Also stability under P-Delta effects is ensured for the symmetric building.

The two design methods starts by obtaining preliminary estimates for the roof yield and ultimate displacements for each wall from simple empirical formulas developed in Chapter 2. The MDOF system for the two buildings is next transformed to an equivalent SDOF system based on the first mode shape using a preliminary assumption for that mode shape. The formulas that do that transformation are different for symmetric and unsymmetric buildings; they are presented in Chapter 2 for both types of buildings. The base shear demand is obtained from the UHS for the city of Vancouver for the corresponding ductility. The base shear is distributed over the height and an elastic analysis is carried out in order to find the design moment for each wall. The walls are designed for these moments. Moment curvature analyses are performed in order to find the moment capacity of the shear wall sections and more refined estimates for the yield and ultimate curvatures. A modal pushover analysis is carried out next to find the base shear capacity and the yield displacement of the designed buildings. The modal pushover analysis is performed using lateral forces and torques for the unsymmetric building and 
lateral forces only for the symmetric building. Next, iterations in the design process are carried out until convergence is achieved when the base shear and yield displacement become very close in two consecutive iterations.

An evaluation of the two design methods is presented in Chapter 4. The design response obtained from the DBSD for the two buildings is compared with the exact response obtained from the nonlinear RHA for a series of spectrum compatible ground motions.

The nonlinear RHA are carried out using 20 ground motion records scaled to match the UHS of the city of Vancouver. An evaluation for the effectiveness of the two design methods is carried out using a statistical analysis presented in Chapter 4. The statistical evaluation is performed for each edge of the unsymmetric building. The two edges of the unsymmetric building experience different roof displacements unlike the symmetric building in which each edge experiences the same roof displacement.

\subsection{Conclusions}

The following conclusion can be drawn from the work presented here

1-The two design methods presented in this thesis for symmetric buildings with multiple shear walls and unsymmetric torsionally stiff systems are simple, easy to apply, do not require sophisticated computational work and are therefore suitable for design office use. 
2- Displacement based seismic design of buildings is an effective approach to implement performance based design that will enable the design professionals to obtain a specified performance for buildings under different levels of seismic hazards.

3- The displacement based design method for unsymmetric torsionally buildings represents an original and significant research contribution to the new performance based seismic design philosophy which is the recommended design philosophy for the future buildings codes.

4- The local ductility capacity limit based on a concrete strain of .004 governed the design in all the buildings studied and the limit on the ultimate roof displacement to achieve the near collapse performance level did not govern.

5- The larger the torsional stiffness of the unsymmetric buildings the smaller is the effective modal mass of the rotational torsion dominant modes. Consequently, the rotational torsion dominant modes do not make much contribution to any of the response parameters for torsionally stiff systems as shown in Chapter 3.

6- The maximum inter-storey drift ratio did not exceed $2.5 \%$ in the 12 -storey symmetric building and at each edge of the 12-storey unsymmetric building for all the 20 ground motion records. Consequently, the near collapse performance level was achieved by the two buildings. 
7- The median and $84^{\text {th }}$ percentile roof displacements were smaller than the roof displacements obtained from the multi-modal pushover analysis for the 12-storey symmetric building. Thus the displacement based design was successful in achieving roof displacement control for the 12-sorey symmetric building.

8- The median and $84^{\text {th }}$ percentile roof displacements were smaller than the roof displacements obtained from the multi-modal pushover analysis for each edge of the 12storey unsymmetric building. Thus the displacement based design was successful in achieving roof displacement control for each edge of the 12-sorey unsymmetric building.

9- The SRSS combination rule underestimated the base shear for the two buildings, the median value of the bias being $83 \%$ for the unsymmetric building and $88 \%$ for the symmetric building. The ABSSUM gave conservative estimate of the base shear experienced by the shear walls on the two buildings.

10- The two design methods were successful in limiting the maximum inter-storey drift ratio and the roof displacement for the symmetric building and for each edge of the unsymmetric building. Those two response parameters are considered to be important measures of damage potential in the buildings. Thus damage control was achieved for the two buildings and the design method achieved the targeted performance level. 


\subsection{Recommendation for future work}

1- A new displacement based seismic design method should be developed for unsymmetric torsionaly flexible systems.

2- A new displacement based seismic design method should be developed for unsymmetric torsionaly similarly stiff systems.

3- The design methods should be modified to achieve multiple performance levels rather than only one performance level.

4- P- $\Delta$ effect should be included in the design and evaluation of the unsymmetric buildings.

5- A comprehensive study for the evaluation of the accuracy of the combination rules as well as the selection of the convenient combination rule for different response parameters should be conducted for a variety of ground motion records. 


\section{List of References}

1. Canadian Commission on Building and Fire Codes, 2005. National Building Codes of Canada 2005, National Research Council of Canada, Ottawa, ON.

2. Chopra A.K. and Goel K.G., 1999. Capacity-Demand-Diagram Methods based on Inelastic Design Spectrum. Earthquake Spectra,15(4), 637-656.

3. Chopra, A.K. 2004. Estimating sesismic demands for performance-based engineering of buildings, 13th World Conference on Earthquake Engineering.Vancouver, B.C., Canada, Paper No. 5007

4. Chopra A.K. and Goel K.G., 2001. Direct displacement-based design: use of inelastic vs. elastic design spectra. Earthquake Spectra, 17(1), 47-65.

5. Chopra A.K. and Goel K.G., 2002. A modal pushover analysis procedure for estimating seismic demands for buildings, Earthquake Engineering and Structural Dynamics. 31(3), 561-582.

6. Chopra A.K. and Goel K.G., 2002. A modal pushover analysis procedure to estimate seismic demands for unsymmetric-plan buildings, Earthquake Engineering and Structural Dynamics. 33(3), 903-927. 
7. Chopra A.K. and Goel R.K., 2004a. Evaluation of Modal FEMA pushover analysis: SAC buildings Earthquake Spectra. 20(1), 225-254.

8. Chopra A.K., 2007. Dynamics of Structures: Theory and Application to Earthquake Engineering, $2^{\text {nd }}$ Edition, Prentice Hall, India.

9. CSA, 1984. Design of concrete structures. Standard CAN A23.3-M84. Canadian Standards Association, Rexdale, ON.

10. CSA, 1994. Design of concrete structures. Standard CSA A23.394. Canadian Standards Association, Rexdale, ON.

11. Federal Emergency Management Agency, 1997. NEHPR guidelines for the seismic rehabilitation of buildings, FEMA 273, and NEHRP Commentary on the guidelines for seismic rehabilitation of buildings, FEMA 274, Federal Emergency Management Agency, Washington, D.C.

12. Edgar, F. 2000. Seismic design and evaluation of multistory building using yield point spectra. Doctoral dissertation, University of Illinois, Illinois, US.

13. Federal Emergency Management Agency, 2000. Prestandard and Commentary for the Seismic Rehabilitation of Buildings, FEMA 356, Federal Emergency Management Agency, Washington, D.C. 
14. Freddy Pina, 2006. Displacement based seismic design of shear wall buildings. Master of Applied Science thesis, Department of Civil and Environmental Engineering, Carleton University, Ottawa, ON.

15. Freeman S.A., 1998. Development and use of capacity spectrum method. Proceedings of the $6^{\text {th }}$ U.S. National Conference on Earthquake Engineering, Seattle, WA.

16. Ghorbanie M, 2007. Performance based seismic design of building structures. Doctoral thesis, Department of Civil and Environmental Engineering, Carleton University, Ottawa, ON.

17. Hamburger, R., O., 1997, Defining Performance Objectives, Seismic Design Methodologies for the Next Generation of Codes, Fajfar \& Krawinkler eds., Balkema, Rotterdam.

18. Humar J. and Ghorbanie M., 2005. A new displacement-based design method for buildings. Proceeding of the $33^{\text {rd }}$ Annual General Conference of the Canadian Society for Civil Engineering, ON, GC-136, 1-10.

19. Humar J. and Elrodesly A. , (2007). "Displacement Based Design of a Building with Multiple Reinforced Concrete Shear Walls.' CSCE 2007 Annual General Meeting \& Conference, Yellowknife, 2007. 
20. Krawinkler H. and Nassar A.A., 1992. Seismic design based on ductility and cumulative damage demands and capacities. In Nonlinear Analysis and Design of Reinforced Concrete Buildings (Editors: H. Krawinkler and P. Fajfar).Elsevier Applied Science, UK, 95-104.

21. Powell, G.H., Prakash, V., and Campbell, S., 1993, DRAIN-2DX Base Program Description and User Guide - Element Description and User Guide for Elements TYPE01,TYPE02, TYPE04, TYPE06, TYPE09, TYPE15 - Version 1.10, Report No.UCB/SEMM-93/18, Structural Engineering Mechanics and Materials, University of California at Berkeley, December.

22. Priestly M.J.N. and Kowaslsky M.J.,2000. Direct displacement-based seismic design of concrete buildings. Bulletin of the New Zealand Society for Earthquake Engineering, 33(4), 421-444.

23. Priestly M.J.N. and Kowaslsky M.J., 1998. Direct displacement-based seismic design of concrete buildings. Bulletin of the New Zealand Society for Earthquake Engineering, 31(6) 73-85.

24. Priestly M.J.N, 2000. Performance based seismic design. Bulletin of the New Zealand Society for Earthquake Engineering, 33(3), 325-346. 
25. Scott, M.H. and G.L. Fenves. "Plastic Hinge Integration Methods" journal of Structural Engineering, ASCE, 132(2):244-252, February 2006.

26. SEAOC Blue Book, 1999. Recommended Lateral Force Requirements and Commentary. Structural Engineers Association of California, Sacramento, CA.

27. SEAOC Vision 2000 Committee, 1995. Performance-based seismic engineering. Report prepared by Structural Engineers Association of California, Sacramento, CA.

28. Yavari S., 2001. Design of Concrete Shear Wall Buildings for Earthquake Induced Torsion. Master of Applied Science thesis, Department of Civil and Environmental Engineering, Carleton University, Ottawa, ON. 